US Army Corps

of Engineers ${ }_{\circledast}$

Engineer Research and

Development Center

Navigation Systems Research Program

\title{
Determining Miter Gate Plate Corrosion and Thickness of Anti-Corrosion Coatings; and Development of a Mobile Sensor Inspection Platform
}

James A. Evans, James R. Tallent, Richard D. Brown,

April 2019

Anton Netchaev, and Clayton R. Thurmer

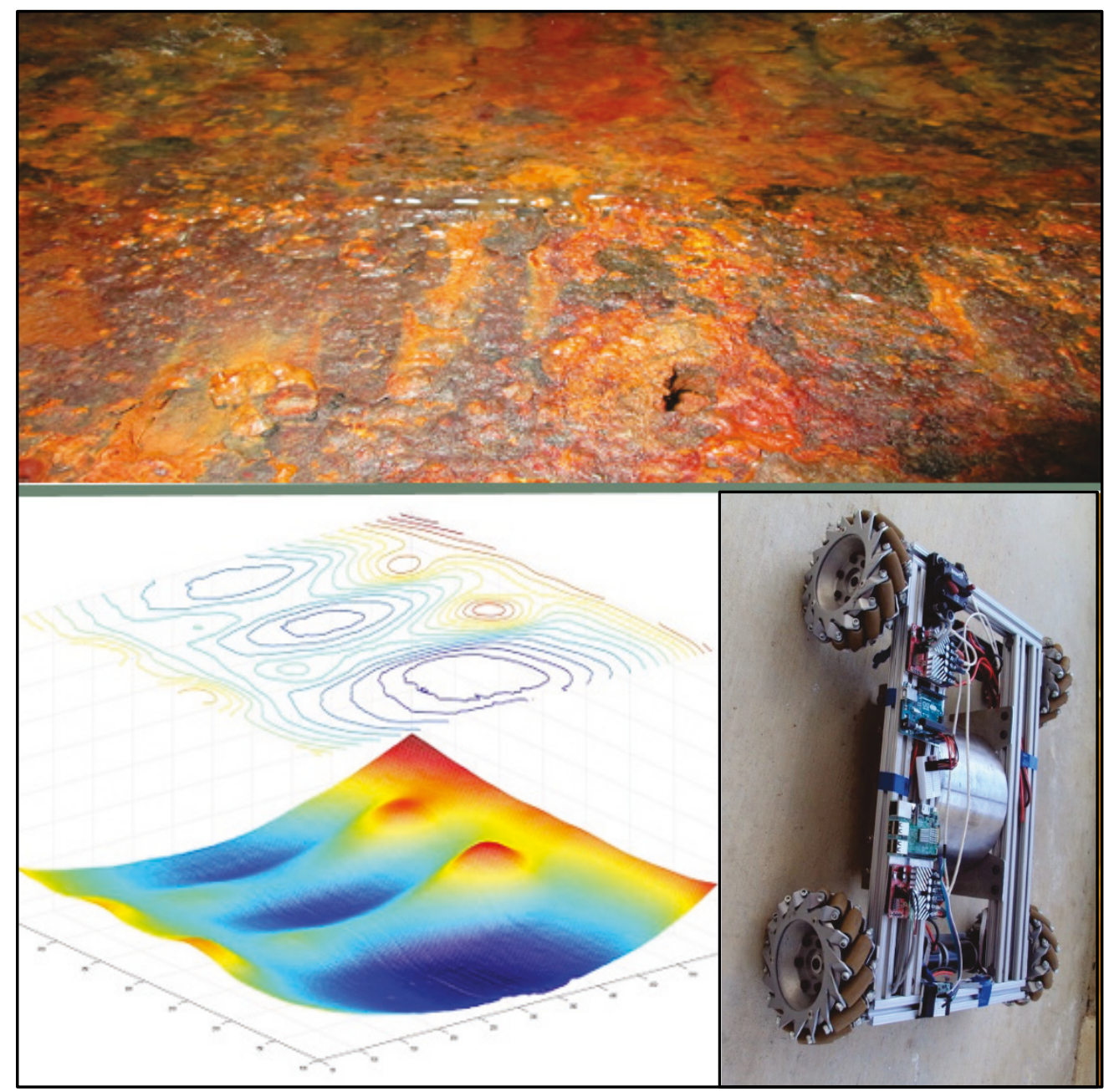


The U.S. Army Engineer Research and Development Center (ERDC) solves the nation's toughest engineering and environmental challenges. ERDC develops innovative solutions in civil and military engineering, geospatial sciences, water resources, and environmental sciences for the Army, the Department of Defense, civilian agencies, and our nation's public good. Find out more at www.erdc.usace.army.mil.

To search for other technical reports published by ERDC, visit the ERDC online library at http://acwc.sdp.sirsi.net/client/default. 


\section{Determining Miter Gate Plate Corrosion and Thickness of Anti-Corrosion Coatings; and Development of a Mobile Sensor Inspection Platform}

James A. Evans, James R. Tallent, Richard D. Brown, Anton Netchaev, and Clayton R. Thurmer

Information Technology Laboratory

U.S. Army Engineer Research and Development Center 3909 Halls Ferry Road

Vicksburg, Mississippi 39180-6199

Final report

Approved for public release; distribution is unlimited.

Prepared for U.S. Army Corps of Engineers

Washington, DC 20314-1000

Under Work Unit H1HF62, "Corrosion Detection and Coating Thickness System" 


\section{Abstract}

Navigation structures such as miter gates and sluice gates are primarily made out of steel, which makes them highly susceptible to corrosion, pitting, and fatigue cracks after many years in service. To mitigate the corrosion issue, protective anti-corrosion epoxy coatings are applied to the steel surface before the structure goes into operation and following scheduled inspections if coating loss is detected. The inspection process is typically a costly and potentially dangerous endeavor due to the need to inspect submerged areas of the structure where structural and environmental conditions may be at their worst. Divers are often used when dewatering is too costly or not possible.

This study was generated by the need to find a better solution to the navigational structure corrosion/coatings inspection process. Primary objectives of this endeavor are to improve inspection area coverage, reduce inspection subjectiveness, reduce time, reduce cost, and reduce risk to human life. To achieve these objectives, a sensor system was developed to collect corrosion data and anti-corrosion coating thickness data; the system was then integrated onto a semi-automated platform capable of traversing targeted inspection areas above and below the water surface. This platform is referred to as the Mobile Sensor Inspection Platform.

DISCLAIMER: The contents of this report are not to be used for advertising, publication, or promotional purposes. Citation of trade names does not constitute an official endorsement or approval of the use of such commercial products. All product names and trademarks cited are the property of their respective owners. The findings of this report are not to be construed as an official Department of the Army position unless so designated by other authorized documents. 


\section{Contents}

Figures and Tables....

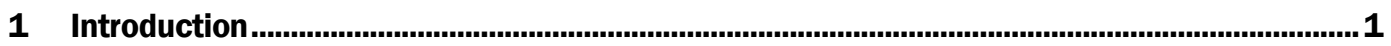

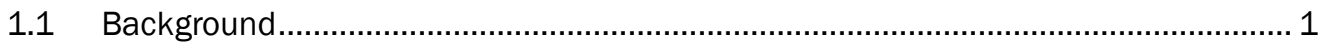

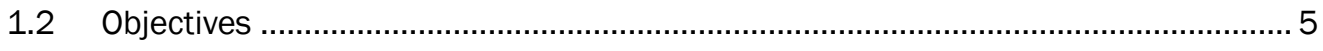

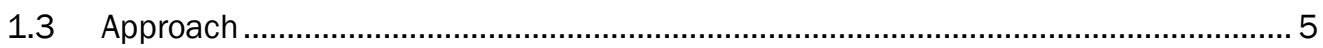

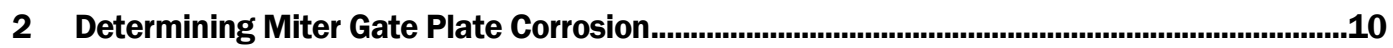

2.1 Existing technologies for miter gate plate corrosion assessment ............................ 10

2.1.1 Visual inspection ....................................................................................... 10

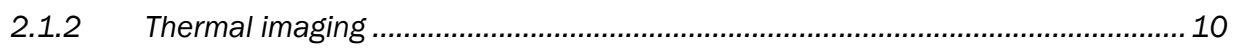

2.1.3 Ultrasonic Pulse-Echo technique ............................................................... 11

2.1.4 Eddy Current technique ............................................................................ 12

2.1.5 Magnetic Flux Leakage (MFL) technique...................................................... 13

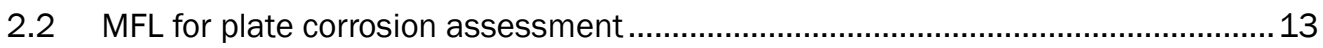

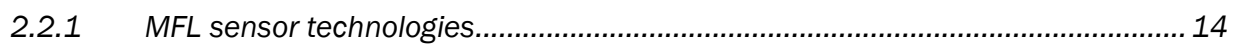

2.2.2 MFL sensor circuit selection....................................................................... 16

2.2.3 MFL corrosion sensor test setup................................................................ 18

2.2.4 MFL corrosion sensor test procedure ......................................................... 21

2.2.5 MFL corrosion sensor data analysis ................................................................... 22

2.2.6 MFL corrosion sensor data comparison and anomalies ......................................26

2.2.7 MFL corrosion sensor package design .............................................................29

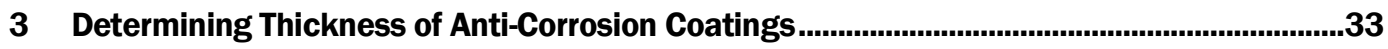

3.1 Existing technologies for miter gate anti-corrosion thickness assessment of

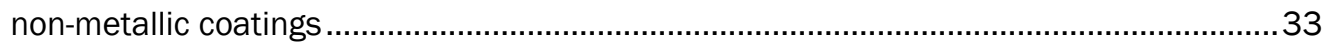

3.1.1 Electromagnetic Induction sensor ………………………………….......... 33

3.1.2 Ultrasonic Pulse-Echo sensor .................................................................... 34

3.1.3 Low-Coherence Interferometry sensor......................................................... 34

3.1.4 Magnetic Pull-Off gage.............................................................................. 35

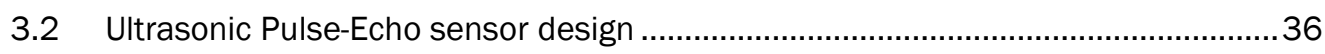

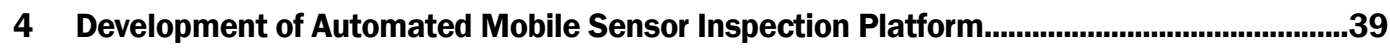

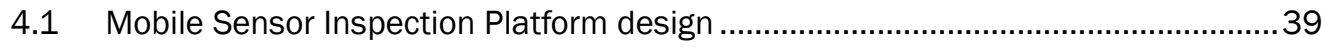

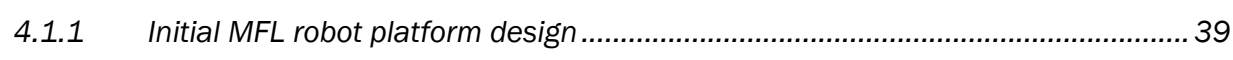

4.1.2 Second MFL robot platform design ........................................................... 40

4.1.3 MFL robot platform design ........................................................................ 42

4.2 Mobile platform wheel design ................................................................... 44

4.2.1 Initial magnetic wheel design ......................................................................... 44 
4.2.2 Present magnetic wheel design ........................................................................ 45

4.3 Lateral motion of the Mobile Sensor Inspection Platform ...................................46

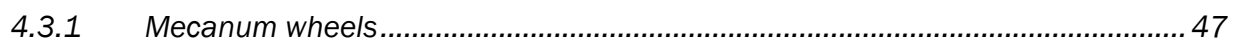

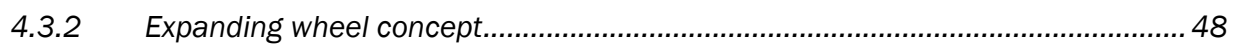

4.3.3 Mobile Sensor Inspection Platform water sealing.................................................. 48

4.4 Mobile Sensor Inspection Platform control and navigation ..................................49

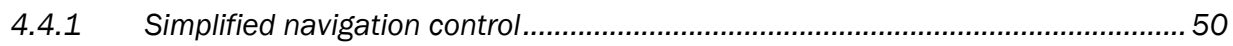

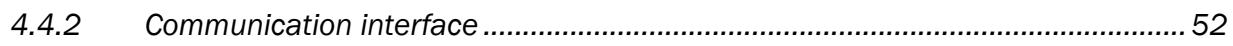

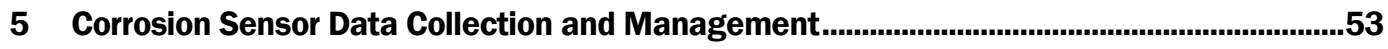

6 Underwater Imaging System for Corrosion Assessment....................................................54

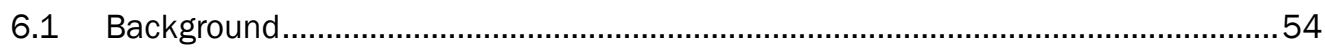

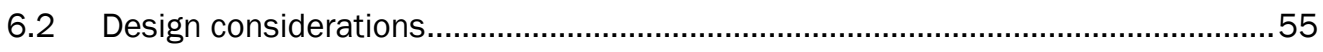

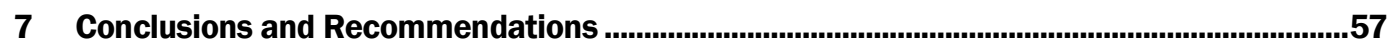

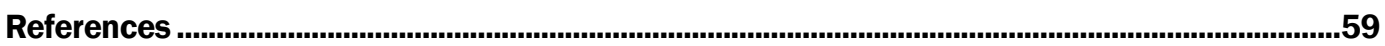

Appendix: Safe Underwater Corrosion Condition Assessment of Structures..................................61

\section{Report Documentation Page}




\section{Figures and Tables}

\section{Figures}

Figure 1. Typical navigation lock on the Mississippi River, near Bellevue, IA......................................

Figure 2. Typical hydraulic steel structure miter gate, opening upstream........................................... 2

Figure 3. Wooden miter gate, Lock 16, Hennepin Canal, near Geneseo, IL.......................................

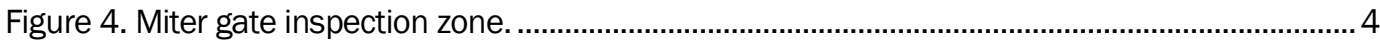

Figure 5. USACE diver inspection of Pickwick Lock, near Counce, TN................................................ 4

Figure 6. Downstream miter gate leaf installed at Markland Locks and Dam, Ohio River.................. 6

Figure 7. Upstream view of a closed miter gate. ……………………………………………….... 6

Figure 8. Diver visual inspection for corrosion. ...........................................................................

Figure 9. Thermal imaging used to detect material loss due to corrosion (image courtesy

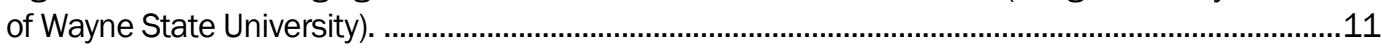

Figure 10. Ultrasonic Pulse-Echo testing. ………………….............................................................11

Figure 11. Physical principle of EC testing (Merrick Group 2015)...................................................12

Figure 12. Physical principle of MFL...........................................................................................13

Figure 13. Concept drawing of Linear Magnetic Flux Sensor array..................................................15

Figure 14. Test plate design......................................................................................................18

Figure 15. Numerical simulation of MFSD. …………………...............................................19

Figure 16. MFSD with sensor attached......................................................................................

Figure 17. Three-axis XYZ Table for magnetic flux sensor test. ........................................................20

Figure 18. Steel plate test standard. .........................................................................................21

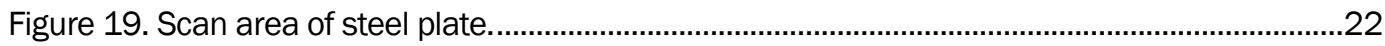

Figure 20. Data interpolation (source: Matlab)..........................................................................2

Figure 21. Gabor complex function (Hjelmas and Wroldsen 1999; Murthy 2014). .........................23

Figure 22. Gabor response to various wavelengths and angles. ...................................................2

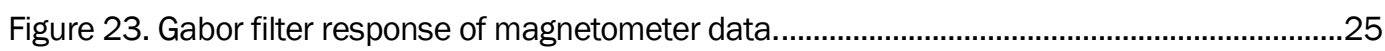

Figure 24. Example sensor test response. .............................................................................25

Figure 25. Three components of magnetic flux sensitivity (Shi et al. 2015). ....................................26

Figure 26. Example plot of 3D raw magnetometer sensor data for individual axial components of the test plate..............................................................................................................2

Figure 27. Example plot of vector data showing magnetic induction due to anomalies. ...................27

Figure 28. Freescale Mag3110 magnetometer plate scan................................................................28

Figure 29. NVE Corp AA002-02E magnetometer plate scan. ...........................................................28

Figure 30. Melexis MLX90393 Triaxis plate scan.........................................................................29

Figure 31. Original flat flux bridge design. ...................................................................................30

Figure 32. FEMM simulations with arched magnetic flux leakage device.........................................31

Figure 33. Melexis MLX90393 Triaxis flux sensors mounted beneath the arched flux

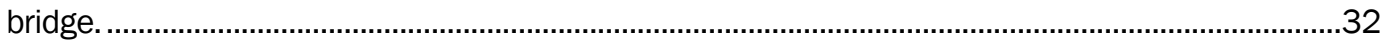

Figure 34. Final flux bridge and permanent magnet design............................................................32 


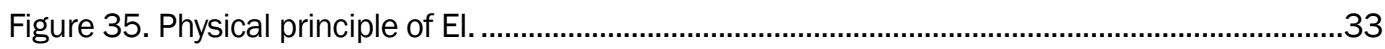

Figure 36. Ultrasonic Pulse-Echo for coating thickness measurement..............................................34

Figure 37. Physical principle of Low-Coherence Interferometry (Novacam Technologies Inc.

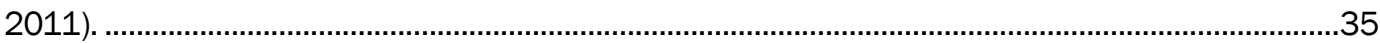

Figure 38. Magnetic Pull-Off type gage................................................................................................36

Figure 39. Overview of the coating thickness measurement system...............................................3

Figure 40. Received voltage from piezo-film versus time shows echo response...............................38

Figure 41. Initial MFL robotic crawler test platform (dimensions: 9 in. wide, 11 in. long,

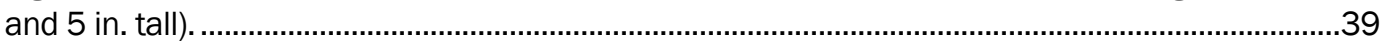

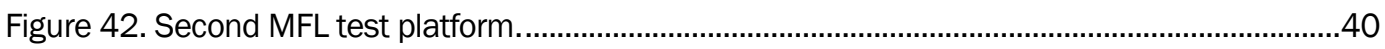

Figure 43. Electrical component layout for inspection platform....................................................... 41

Figure 44. Concept drawing of inspection crawler in action. ...............................................................4 41

Figure 45. Magnetic crawler test steel wall platform. .......................................................................42

Figure 46. Prototype of present MFL magnetic crawler large test platform used to collect data from the laboratory test bed above water. This version is not waterproofed and is not

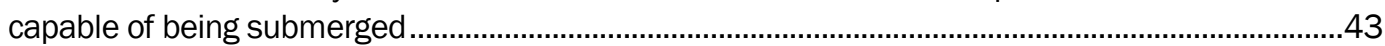

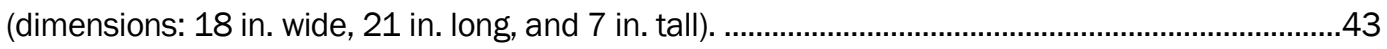

Figure 47. Present MFL magnetic crawler test platform capable of being submerged, showing the waterproof housing around the motors (dimensions: 14 in. wide, 22 in. long, and 8 in. tall).

Figure 48. Prototype of present design climbing vertical wall. ..........................................................44

Figure 49. Magnetic crawler drive wheel with a flux plate removed. ...................................................45

Figure 50. Present magnetic wheel design. ...........................................................................................46

Figure 51. Prototype of present MFL test platform with present magnetic wheel design..................46

Figure 52. Prototype of present MFL test platform with non-magnetic Mecanum-type wheels to investigate horizontal moves.

Figure 53. Computer-aided drawing of an expanding wheel shown compressed

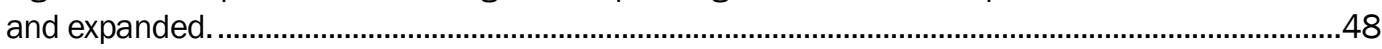

Figure 54. Simplified 2D path of mobile platform on miter gate.........................................................50

Figure 55. Raw magnetic flux data from X-axis of sensor array (left) with 3D rendering of

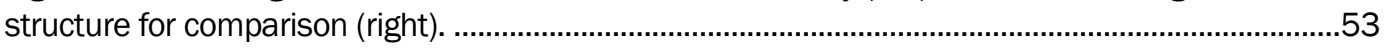

Figure 56. Prototype Mobile Sensor Inspection Platform inspecting steel plate................................53

Figure 57. Imaging system's lateral and vertical move control. .........................................................54

Figure 58. Imaging system's three axes of motion control. ................................................................55

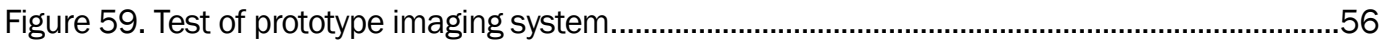

Figure 60. Polymer ultrasonic sensor array. ......................................................................................57

\section{Tables}

Table 1. Corrosion sensor package operation criteria. ..................................................................... 7

Table 2. Mobile inspection platform operation criteria. .........................................................................8

Table 3. Existing NDT corrosion inspection technologies. ................................................................... 8

Table 4. Existing NDT coating thickness measurement technologies. ................................................ 8 
Table 5. Selected sensors for MFL test. .......................................................................................

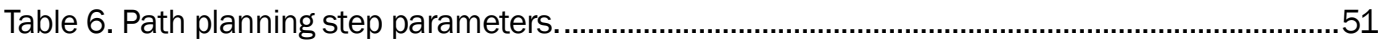

Table 7. Inspection camera specifications..................................................................................56 


\section{Preface}

The investigation reported herein was authorized by Headquarters, USACE (HQUSACE), and was performed during Fiscal Years 16-17 under the Navigation Systems Research Program, Work Unit H1HF62, "Corrosion Detection and Coating Thickness System." Mr. James A. Evans, U.S. Army Engineer Research and Development Center (ERDC), Information Technology Laboratory (ITL), primary author of this technical report and Principal Investigator for Work Unit H1HF62, is also the Principal Investigator for other similar investigations being conducted by ITL. Mr. Jeffrey A. McKee was Chief of the HQUSACE Navigation Branch and Navigation Business Line Manager.

The Program Manager for the Navigation Systems Research Program was Mr. Charles E. Wiggins, ERDC Coastal and Hydraulics Laboratory (CHL). Mr. W. Jeff Lillycrop, CHL, was the ERDC Technical Director for Civil Works and Navigation, Research, Development, and Technology Transfer portfolio.

At the time this research was conducted, Dr. Reed L. Mosher was Director, ERDC Information Technology Laboratory (ITL); Ms. Patti Duett was Deputy Director, ITL; and Dr. Jerry Ballard was Chief, Computational Science and Engineering Division, ITL. Mr. José E. Sánchez was Director, CHL; Mr. Jeffrey R. Eckstein was Deputy Director, CHL; and Dr. Jacqueline S. Pettway was Chief, Navigation Division, CHL.

At the time of publication of this report, COL Ivan P. Beckman was Commander of ERDC, and Dr. David W. Pittman was Director of ERDC. 


\section{Unit Conversion Factors}

\begin{tabular}{|l|c|l|}
\hline Multiply & By & To Obtain \\
\hline tesla & $10^{4}$ & gauss \\
\hline feet & 0.3048 & meters \\
\hline inches & 0.0254 & meters \\
\hline
\end{tabular}




\section{Introduction}

\subsection{Background}

The U.S. Army Corps of Engineers (USACE) manages and maintains a portfolio of degrading navigational infrastructure with many locks and dams (Figure 1) being at least 80 years old or older, thus exceeding their design life. Tight budgetary constraints over many years, and insufficient funding for maintenance and inspection, have the potential to lead to various failure mechanisms such as corrosion.

Figure 1. Typical navigation lock on the Mississippi River, near Bellevue, IA.

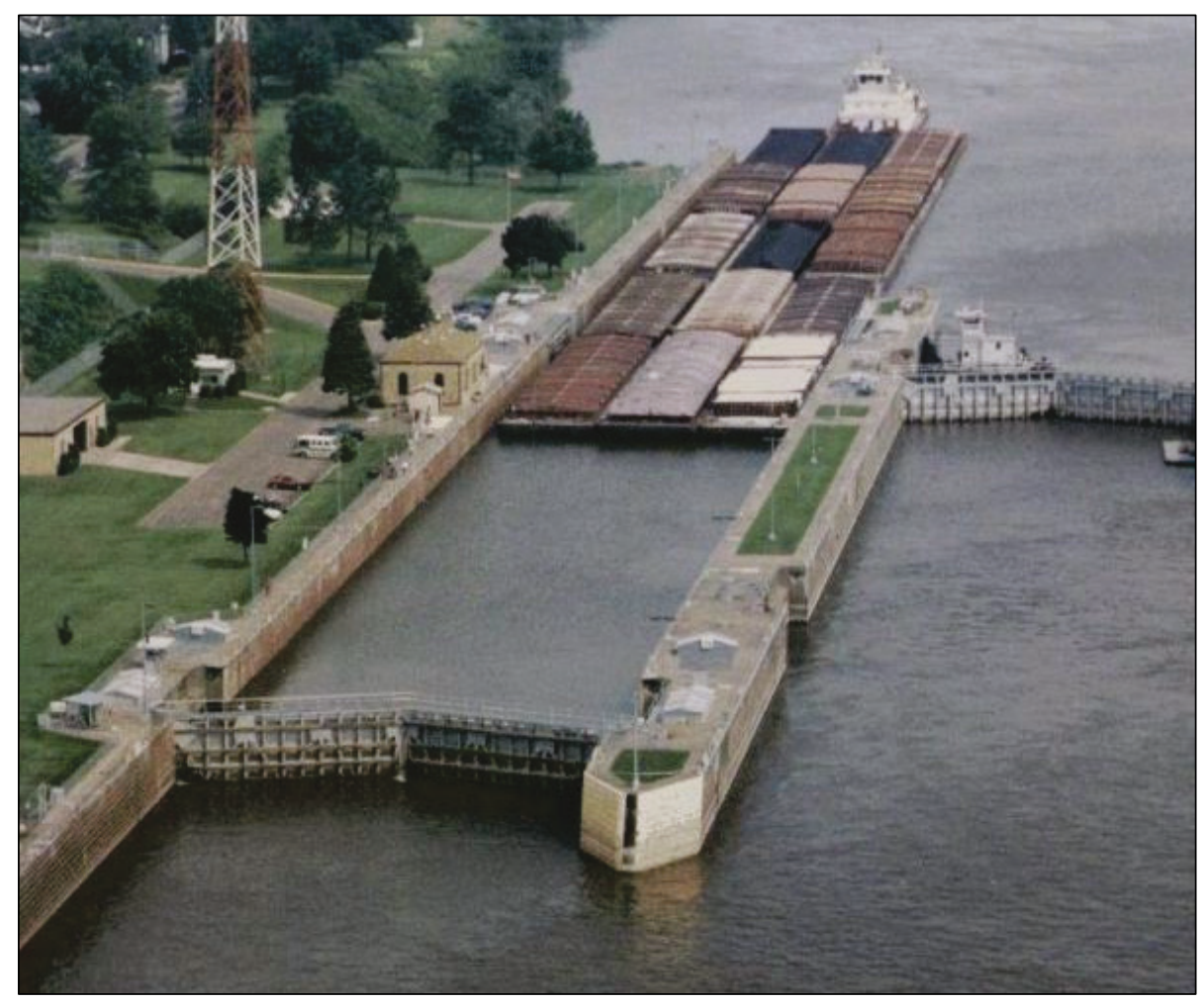

The inspections of these structures for corrosion, and the condition of anti-corrosion coatings above and below the waterline (particularly below the waterline), are extremely costly since it often requires dewatering of lock chambers and disruption of navigation. In many cases, the inspections are simply not being done, and the conditions are left unknown. Without sufficient condition information, these valuable assets cannot be adequately managed, and progressing deterioration can result in failures that severely impact navigation capability, user safety, and the 
surrounding communities. Identifying problem areas early will allow for maintenance prioritization and for the programming of repair funds in a timely manner.

There are numerous types of river structures where steel is the primary construction component. These steel components are of primary concern in this research investigation, one such important component being the miter gate of a navigational lock (Figure 2). Miter gates are the watertight leaves that seal off the chamber from the upper and lower reaches of the lock and control the water level in the lock chamber, thus allowing ship traffic to navigate between stretches of water of different elevations on river and canal waterways. The USACE presently maintains 238 lock chambers at 198 lock sites throughout the United States (Estes et al. 2004).

Figure 2. Typical hydraulic steel structure miter gate, opening upstream.

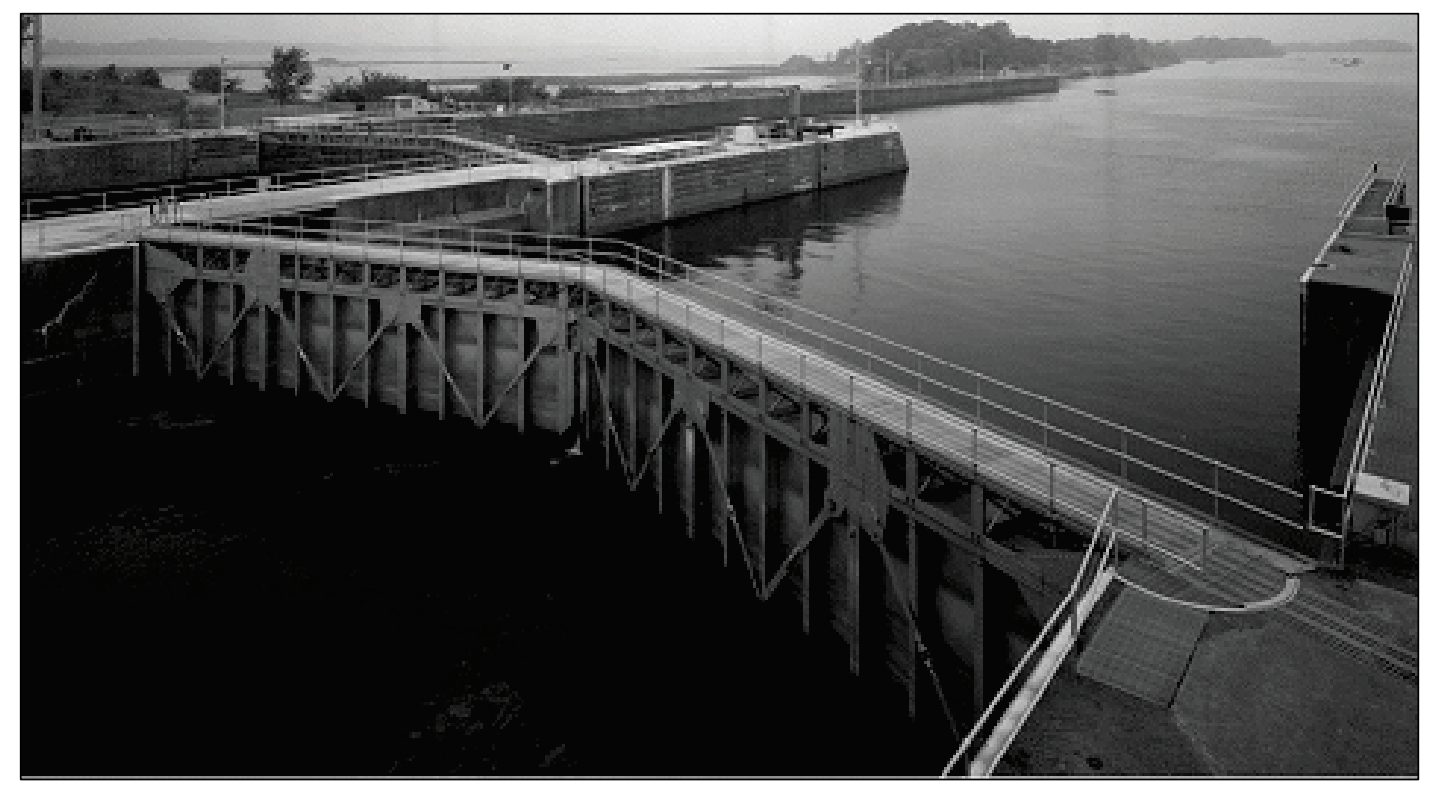

The miter gate was invented by Leonardo da Vinci in 1480 and was originally constructed of wood, leather, and coal-tar (Canal and Lock 2017). Historical navigational structures still exist but are relegated to parks and other scenic areas (Figure 3). By the mid- to late-180os, steel became the primary component of the miter gate. In recent years, materials such as aluminum, fiberglass, and advanced composites are being tested as a substitute materials for the miter gate (Daniel 2011). The primary reason for replacing steel with another material is simply due to the adverse effects of corrosion on a hydraulic steel structure and thus the high cost of maintaining the steel structure. 
Figure 3. Wooden miter gate, Lock 16, Hennepin Canal, near Geneseo, IL.

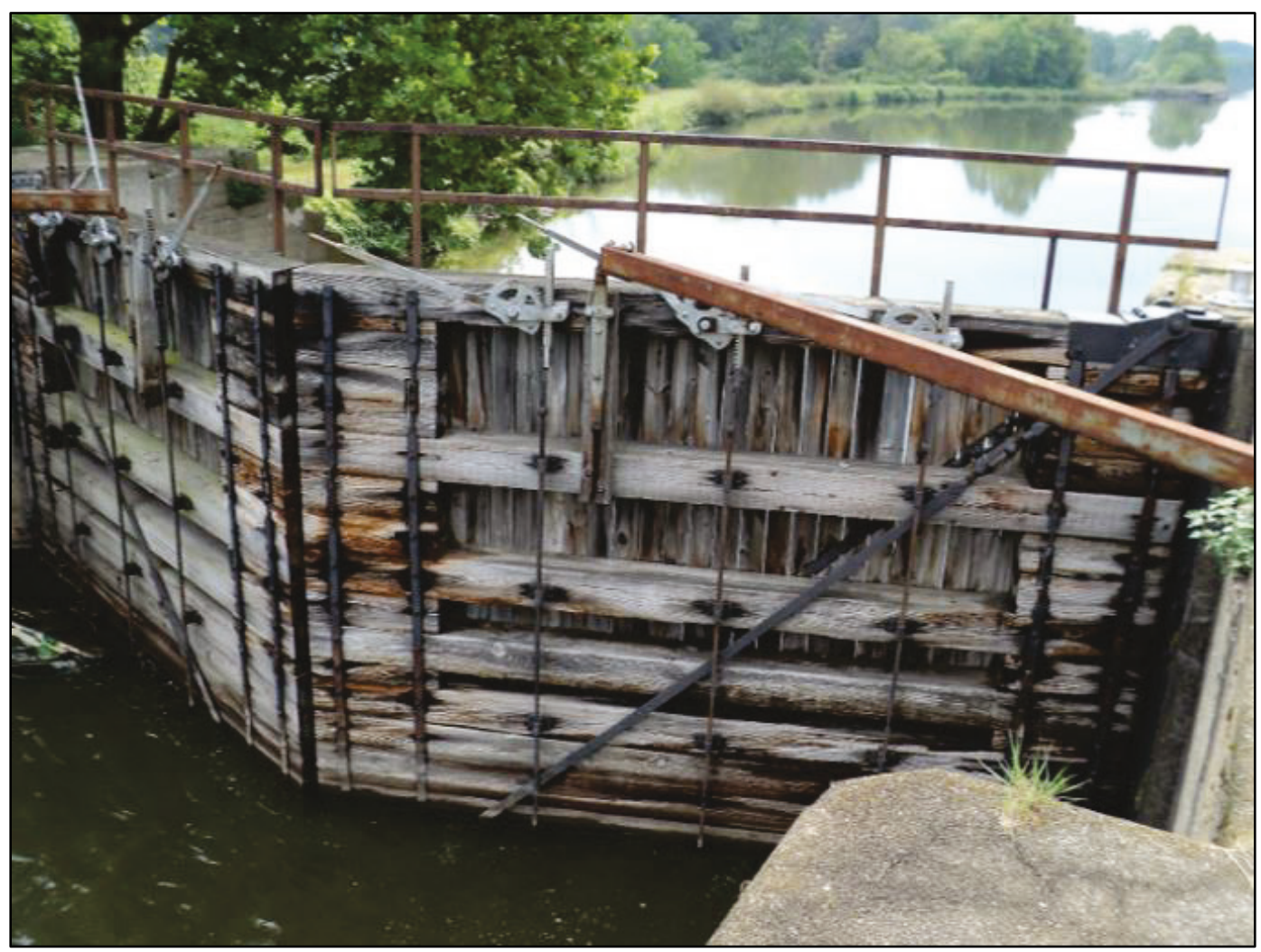

The present miter gate inspection methodology is primarily based on visual observations and then choosing the most appropriate rating described in the standardized inspection guide Inspection and Rating of Miter Lock Gates (Greimann et al. 1990). Using this inspection method, the miter gate is divided into three zones defined by the lower and upper pool elevations, namely (1) the atmospheric zone, (2) the splash zone, and (3) the submerged zone, as shown in Figure 4. The atmospheric zone is where the gate is only exposed to air, the splash zone is where the gate is exposed to both water and air as the water in the chamber is raised and lowered, and the submerged zone is where the gate remains constantly underwater (Estes et al. 2004). Studies indicate that material loss due to corrosion is normally greatest in the splash zone but that the submerged zone cannot be ignored since that is the zone where structural stresses on the gates are often greatest (Estes et al. 2004). Inspecting the submerged zone presents a challenge due to fiscal constraints and disruption of river navigation associated with dewatering the lock chamber. When dewatering is not an option, divers are employed to inspect the submerged zone (Figure 5). However, limited visibility and limited precision of test equipment often result in inconclusive results. 
Figure 4. Miter gate inspection zone.

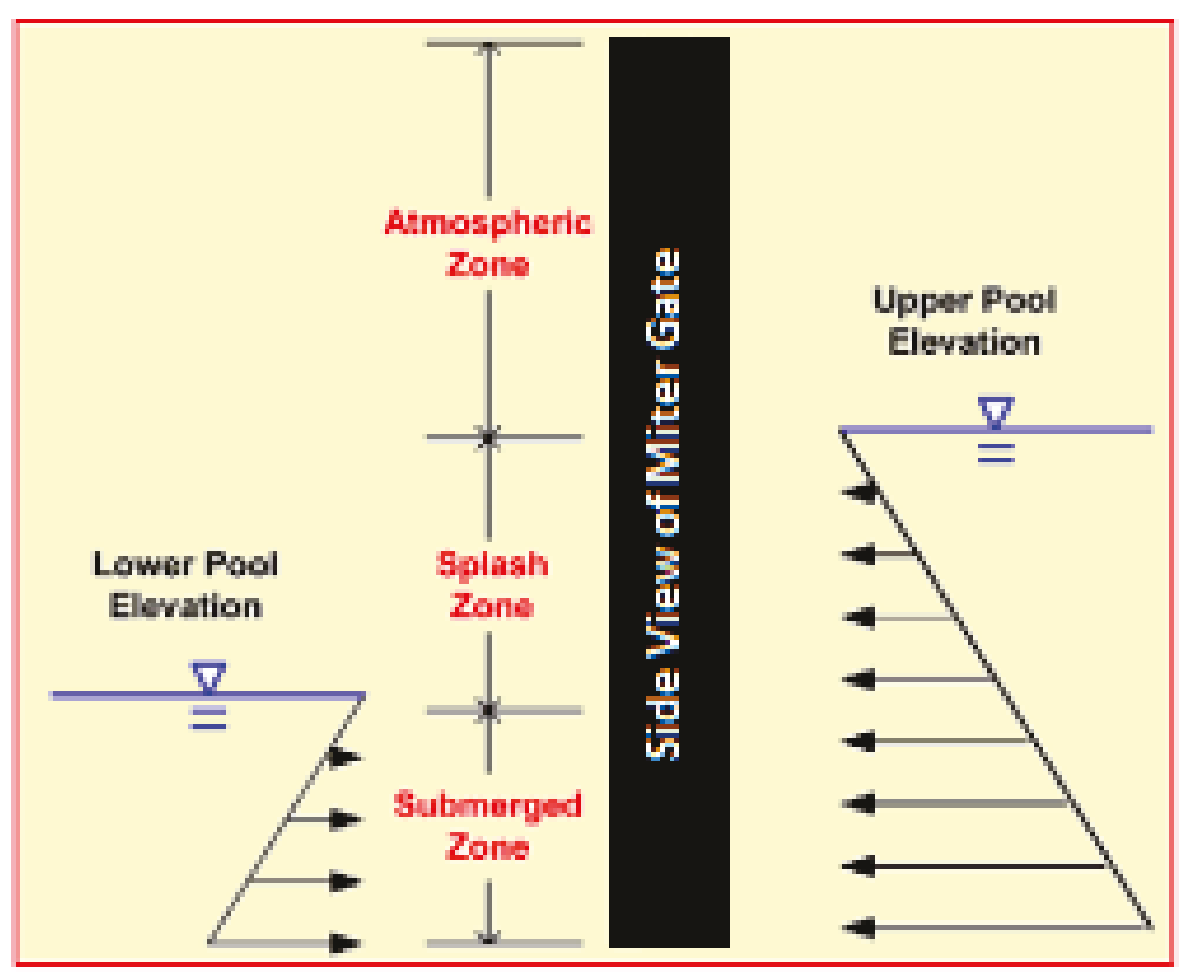

Figure 5. USACE diver inspection of Pickwick Lock, near Counce, TN.

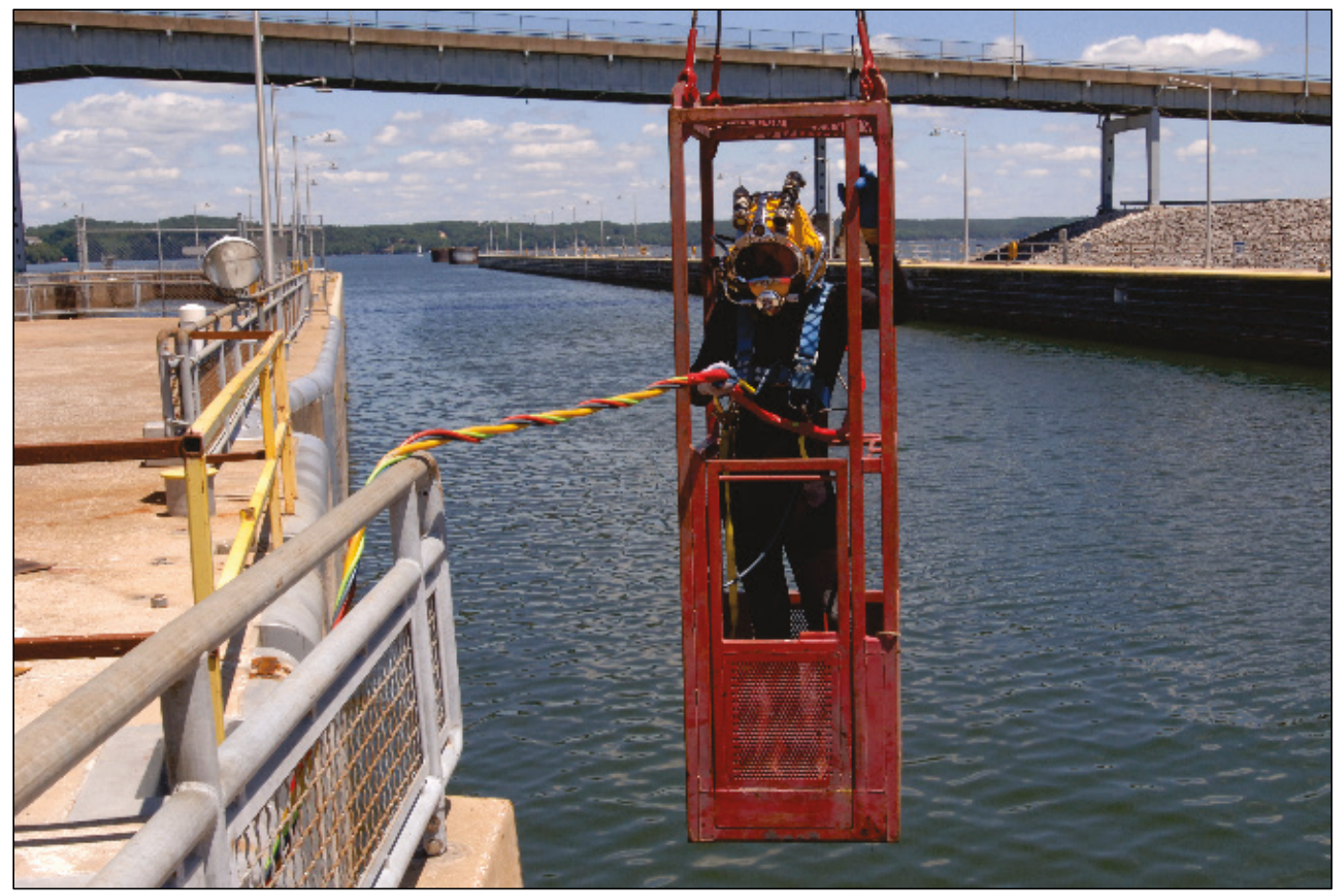




\subsection{Objectives}

The objects of this research investigation were to assess present navigational steel structure corrosion and anti-corrosion coating inspection methodology, to evaluate present state-of-the-art nondestructive testing (NDT) of corrosion and anti-corrosion coating inspection technologies, and to develop procedures and specifications necessary to modernize and automate the inspection process in both the above- and below-water regions of navigational steel structures. Since the U.S. Bureau of Reclamation (USBR) is also responsible for a significant number of marine structures, USACE has partnered with the USBR in this research effort (see Appendix).

The final objective of this investigation was to develop a semi-automated field inspection capability (robot) for the purpose of detecting and quantifying corrosion and thickness of anti-corrosion coatings on navigational structures above and below the water surface. Present-day inspection methodologies are human labor intensive, hazardous, and can be prone to error due to difficult environmental conditions and human limitations. Using present technologies, a more automated type of condition assessment of navigational structures can be developed.

\subsection{Approach}

A typical modern miter gate consists of supporting girders (framed in either the horizontal or vertical direction) and intercostals (diaphragms) that are perpendicular to the girders and are designed as fixed end beams. A skin plate covers this grid-like structure and holds back the water on the upstream side. The gates swing about their supports at the concrete chamber wall and meet at an angle of approximately 30 degrees (deg) when closed, or mitered (USACE 1994). The downstream side of a single miter gate leaf is shown in Figure 6, and in Figure 7 both upstream sides of a closed miter gate are shown. 
Figure 6. Downstream miter gate leaf installed at Markland Locks and Dam, Ohio River.

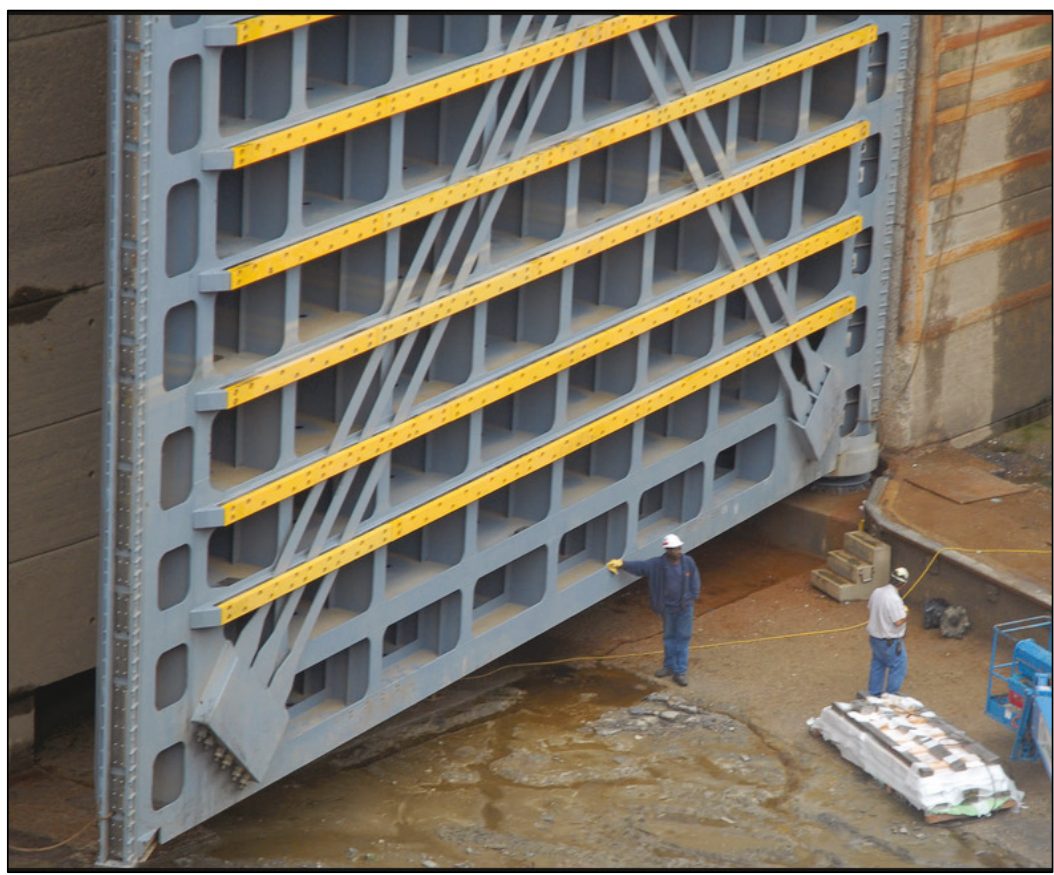

Figure 7. Upstream view of a closed miter gate.

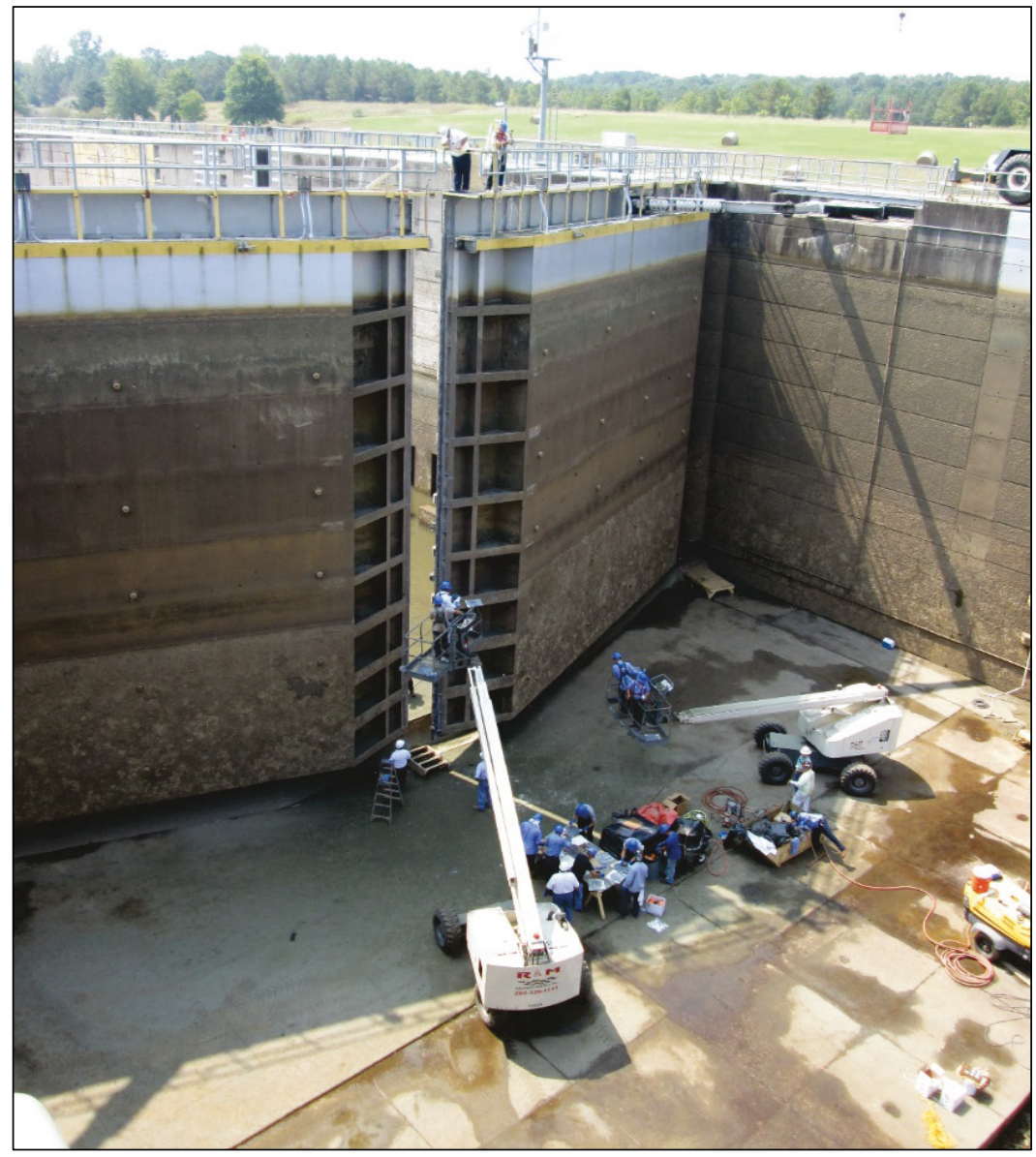


The upstream-side of a modern steel miter gate leaf is comprised of a relatively smooth steel skin plate while the downstream-side is a mesh of steel girders. This configuration leads to the conclusion that developing a semi-automated inspection system (robot) for the upstream-side (smooth plate) is significantly less complex than for the downstream-side. Therefore, two separate inspection solutions may ultimately be required: one for the upstream-side of the gate and one for the downstream-side. These two separate approaches are discussed herein.

The corrosion measurement sensor package, the anti-corrosion coating thickness sensor package, and the automated inspection platform (carrier robot) are three separate products of this investigation. All three products are designed to meet the harsh realities of miter gate field conditions. Based on customer requirements as dictated by observed field conditions, the inspection system design criteria are outlined in Tables 1 through 4 .

The miter gate corrosion inspection system discussed herein consists of three primary components: (1) the corrosion inspection sensor, (2) the protective coating thickness measurement sensor, and (3) the automated mobile inspection platform (robot). In Tables 1 and 2, a list of key operational criteria are given for the inspection sensor packages and the mobile inspection platform.

Table 1. Corrosion sensor package operation criteria.

\begin{tabular}{|c|l|}
\hline Item & Description \\
\hline 1 & Measure without making contact with steel surface \\
\hline 2 & Measure while moving over steel surface \\
\hline 3 & Measure both steel surface and internal steel structure \\
\hline 4 & Measure over wide area (not single point) \\
\hline 5 & Measure at relatively high speeds (50 hertz [Hz]) \\
\hline 6 & Relatively low-cost sensor array \\
\hline 7 & Relatively low power \\
\hline 8 & Robust \\
\hline 9 & Operable in both air and water \\
\hline 10 & Operable on dirty steel surface (organics) \\
\hline
\end{tabular}


Table 2. Mobile inspection platform operation criteria.

\begin{tabular}{|c|l|}
\hline Item & Description \\
\hline 1 & Operate above and below water surface (two bar) \\
\hline 2 & Climb steel walls (in and out of water) on dirty surface \\
\hline 3 & Make lateral moves or small radius turns (skid-steer like) \\
\hline 4 & Maneuver over small objects (0.5 inch [in.]) \\
\hline 5 & Move at a constant speeds (non-stop) \\
\hline 6 & Semi-autonomous operation \\
\hline 7 & Path planning capability \\
\hline 8 & Relatively low power \\
\hline 9 & Robust \\
\hline 10 & Capable of carrying sensor payload \\
\hline
\end{tabular}

Based on a review of existing NDT for corrosion and coating thickness assessment (Tables 3 and 4), the magnetic flux leakage technology (MFL) and the Ultrasonic Pulse-Echo technology were selected for development of the corrosion and coating thickness sensors, respectively. Both of these technologies satisfied operational criteria outlined in Table 1 above.

Table 3. Existing NDT corrosion inspection technologies.

\begin{tabular}{|c|l|}
\hline Item & Technology \\
\hline 1 & Visual Inspection \\
\hline 2 & Thermal Imaging \\
\hline 3 & Ultrasonic Pulse-Echo \\
\hline 4 & Eddy Current \\
\hline 5 & Magnetic Flux Leakage \\
\hline
\end{tabular}

Table 4. Existing NDT coating thickness measurement technologies.

\begin{tabular}{|c|l|}
\hline Item & Technology \\
\hline 1 & Electromagnetic Induction \\
\hline 2 & Ultrasonic Pulse-Echo \\
\hline 3 & Low-Coherence Interferometry \\
\hline 4 & Magnetic Pull-Off \\
\hline
\end{tabular}


The corrosion measurement sensor package, the anti-corrosion coating thickness sensor package, and the Mobile Sensor Inspection Platform were developed in parallel. Hence, in-progress modifications to the automated inspection platform were necessary to meet the final corrosion sensor and anti-corrosion coating sensor inspector packages design criteria. 


\section{Determining Miter Gate Plate Corrosion}

\subsection{Existing technologies for miter gate plate corrosion assessment}

\subsubsection{Visual inspection}

Visual inspection of steel structures under normal light spectrum remains the most common form of corrosion inspection (Figure 8). This is also the case for submerged steel structures where turbidity is minimal. Where visual inspection is possible, the process can be automated using cameras, lighting, and image processing algorithms that analyze for color, texture, and edge features. One key limitation of normal light visual inspection is the inability to detect corrosion below the surface of the steel substrate. For this reason, it has become standard practice to combine visual inspection with one of the methods discussed in Sections 2.1.2 through 2.1.5 below.

Figure 8. Diver visual inspection for corrosion.

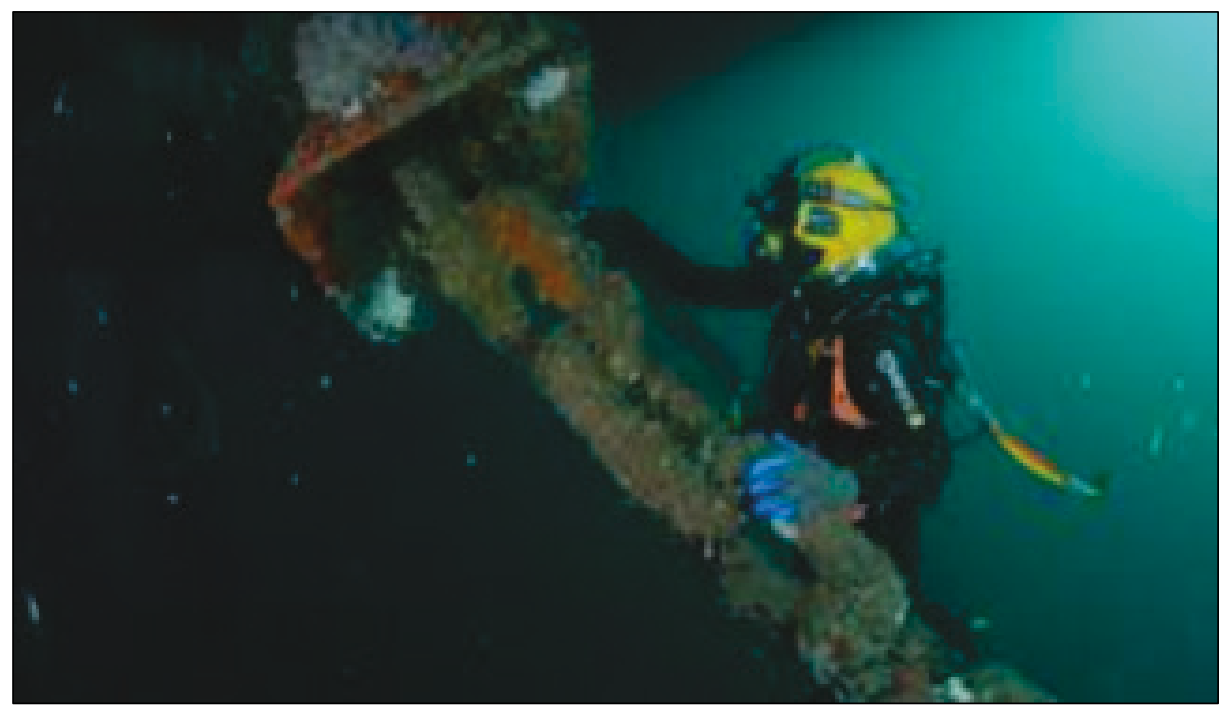

\subsubsection{Thermal imaging}

Thermal imaging techniques have been developed for corrosion detection and can be used to determine surface and subsurface properties of a sample material (Figure 9). Thermal imaging works by applying heat to an area under examination, then acquiring a thermal image of the sample surface as the heat dissipates into the surrounding structure. Material flaws such as corrosion, cracks, and water intrusion will result in a different rate of heat dissipation compared to that of a non-compromised structure. Common 
issues experienced with the thermal imaging technique include detector sensitivity, dynamic range, and signal discrimination.

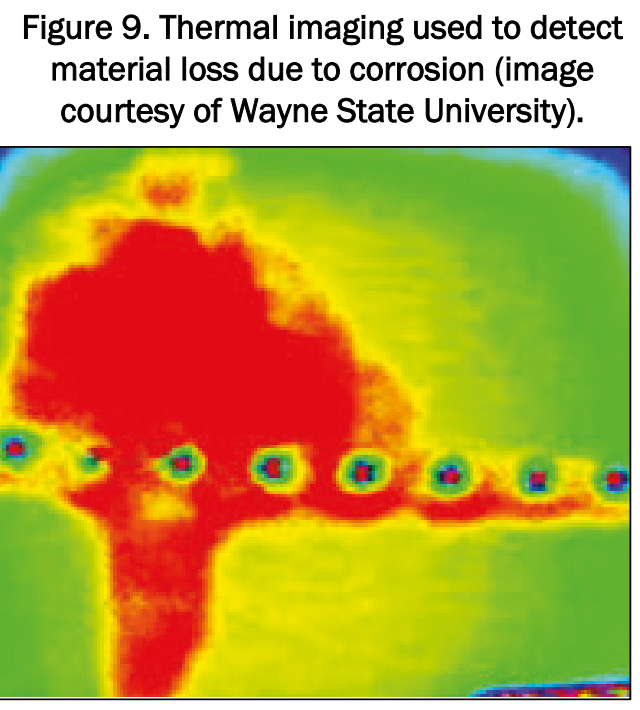

\subsubsection{Ultrasonic Pulse-Echo technique}

The Ultrasonic Pulse-Echo technique uses an ultrasonic transducer to send an acoustical pulse through a metal substrate. The pulse reflects back from the edges of the substrate to the transducer and is converted into a highfrequency electrical signal (Figure 10). The echoed waveform is digitized and analyzed to determine the substrate properties. If the return signal (echo) differs significantly from that of a healthy structure, it may conclude that the substrate is damaged. Using signal processing techniques, it is possible to determine damage type (corrosion, pitting, cracks, and material loss) and damage location. This technique typically requires the ultrasonic sensor to be in direct contact with a cleaned test surface.

Figure 10. Ultrasonic Pulse-Echo testing.

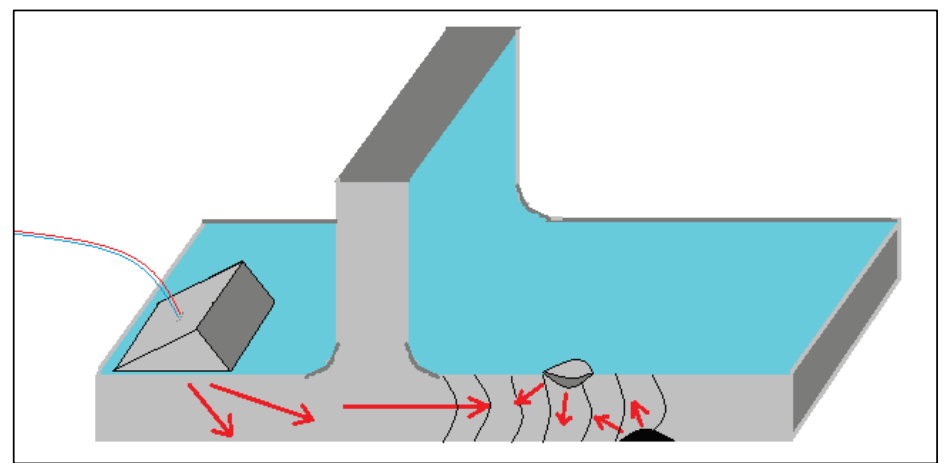




\subsubsection{Eddy Current technique}

Eddy Current (EC) and Pulsed Eddy Current (PEC) techniques have been used successfully in recent years to detect flaws or corrosion in ferrous materials (Figure 11). This technology is not new; however, application of this technology to corrosion and flaw detection is relatively new. The basic principle of EC measurement is that when a coil of conductive wire is excited with an alternating electrical current, it produces an alternating magnetic field around itself. The direction of current induced in a conductor by a changing magnetic field due to Faraday's law of induction will be such that it will create a field that opposes the change that produced it (Valchev and Bossche 2005). When this wire probe is placed in contact with a conductive material such as steel, electrical currents opposed to the ones in the coil are induced in the material. These opposing electrical currents are identified as Eddy Currents (Merrick Group 2015). Variations in the electrical conductivity and magnetic permeability of the test object, and the presence of defects, causes a change in the EC and a corresponding change in phase and amplitude that can be detected by measuring the impedance changes in the coil, resulting in a sign of the presence of defects. One of the primary advantages of the PEC technique over the conventional EC technique is that with PEC there is no need for direct contact with the substrate under test (Huang 2016).

Figure 11. Physical principle of EC testing (Merrick Group 2015).

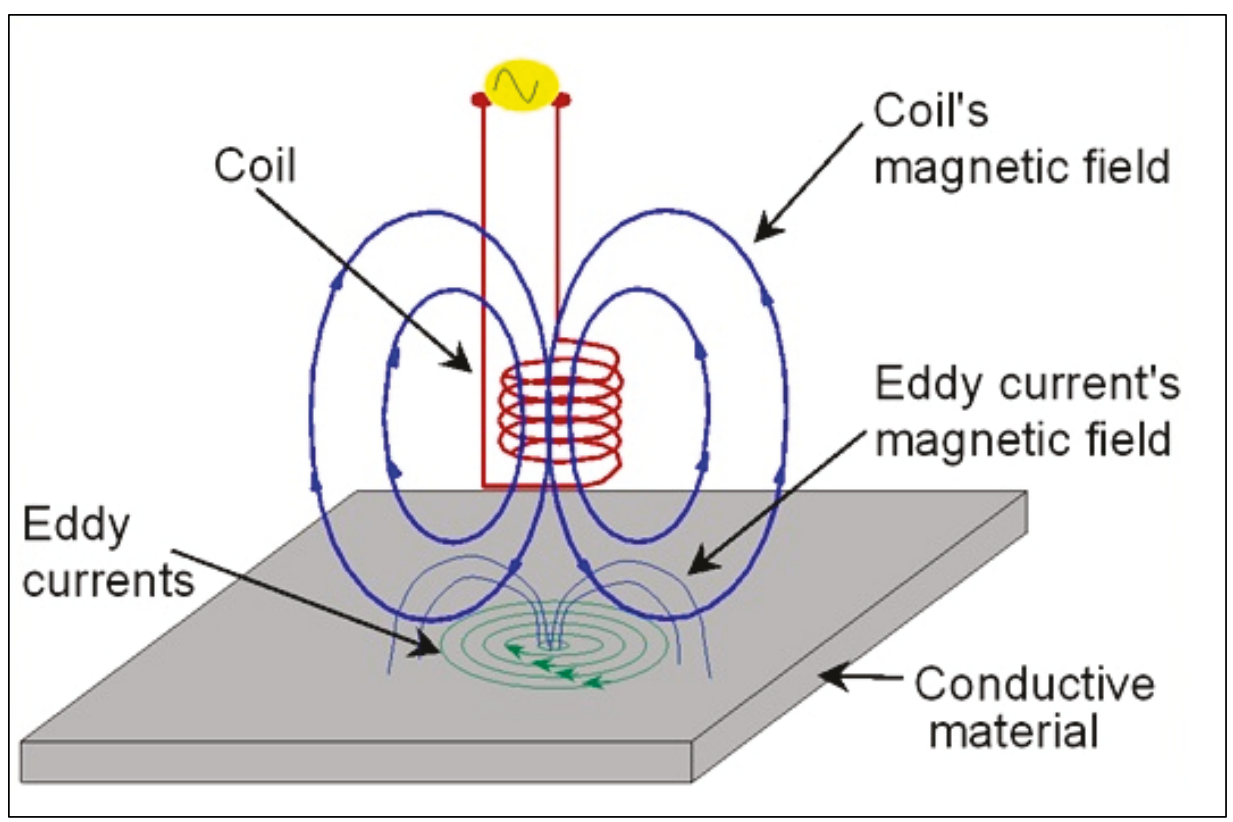




\subsubsection{Magnetic Flux Leakage (MFL) technique}

The MFL technique uses permanent magnets to temporarily magnetize a steel test substrate (Figure 12). The magnetic flux flowing through the steel substrate is uniform when there are no flaws in the substrate. If surface or internal flaws are present such as pitting, corrosion, or other forms of damage, the magnetic flux lines are distorted. This distortion or leakage can be measured by a magnetic field sensor located adjacent to the test point. MFL is presently recognized as an industry standard for metallic pipe wall assessment (Shi et al. 2015). Many commercial products are available that employ this technology in dry environments.

Figure 12. Physical principle of MFL.

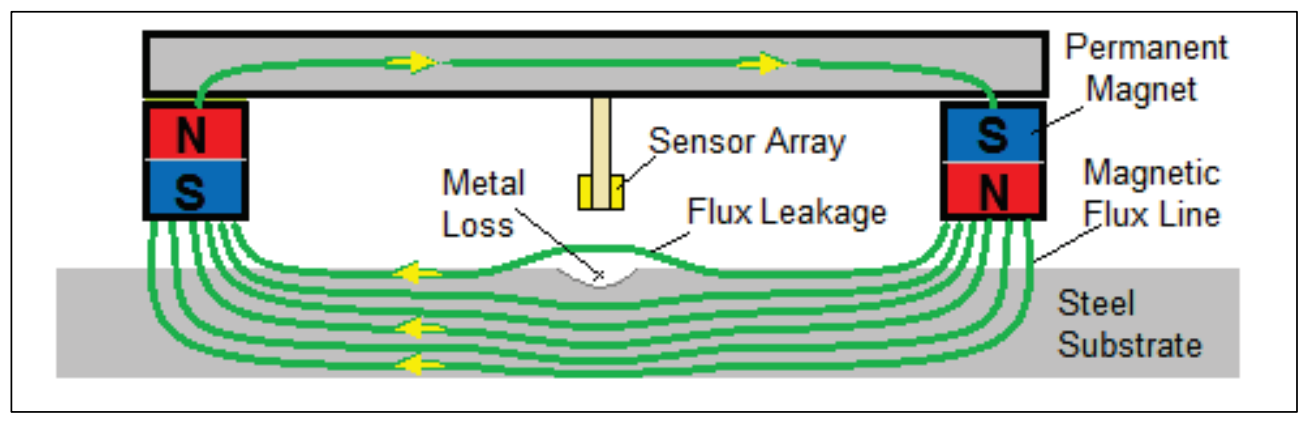

\subsection{MFL for plate corrosion assessment}

Table 1 lists features and capabilities that are used as design criteria for the corrosion sensor. Using this sensor criteria list to rank existing corrosion sensors (discussed in Section 2.1), the two technologies that best meet the requirements of this investigation include PEC and MFL. Additional considerations such as sensor cost resulted in the final selection of MFL technology as the prototype sensor development strategy.

Section 2.1.5 briefly discussed the basic principle of MFL on ferromagnetic substrate. To further elaborate the technique, the test material is magnetized close to the magnetic saturation point under a constant applied magnetic field. The magnetic saturation point is the state reached when an increase in applied external magnetic field cannot increase the magnetization of the material further. Different materials have different saturation levels; for example, high permeability iron alloys reach magnetic saturation at 1.6 - 2.2 Tesla (Laughton and Warne 2003). If the test material is free from any defects, the magnetic field will concentrate inside the ferromagnetic material; conversely, if the material has any defects, those defects will have a much different magnetic permeability and distort the 
magnetic flux lines in the substrate. Magnetic flux lines will be distorted around the defect, and a portion of the magnetic flux may be emitted and leaked from the substrate. This MFL can then be detected with a magnetic flux sensor such as a magnatometer. A 3-axis magnatometer can be used to measure both magnitude and direction of magnetic flux, thus making it possible to characterize the defect in the substrate.

\subsubsection{MFL sensor technologies}

As listed in Table 1, Item 4, the sensor must be capable of sampling over a wide area as opposed to a single point measurement. To achieve this goal, it is necessary to develop a linear array of individual 3-axis sensors where sensor spacing is designed to ensure complete coverage of test substrate. Similar to a line-scan camera, the Linear Magnetic Flux Sensor is designed to image the flux lines of the steel substrate as the sensor is moved over the surface at a fixed speed. In Figure 13 a linear sensor array is shown suspended over a steel substrate. Parallel permanent magnets are located on both sides of the sensor array. The polarization of the magnets is arranged such that the magnetic flux flows from one permanent magnet to the other through the flux bridge and substrate. The flux bridge is illustrated in the upper-right diagram. This steel bridge connects to both permanent magnets and completes the magnetic flux circuit. The sensor array, permanent magnets, and flux bridge move over the steel substrate at a constant speed. If a defect is located between the permanent magnets, such as the illustrated crack, the magnetic flux will flow over the crack allowing the sensors to capture the flux anomaly. This scenario assumes that the steel plate is at or near the magnetic saturation point. 
Figure 13. Concept drawing of Linear Magnetic Flux Sensor array.

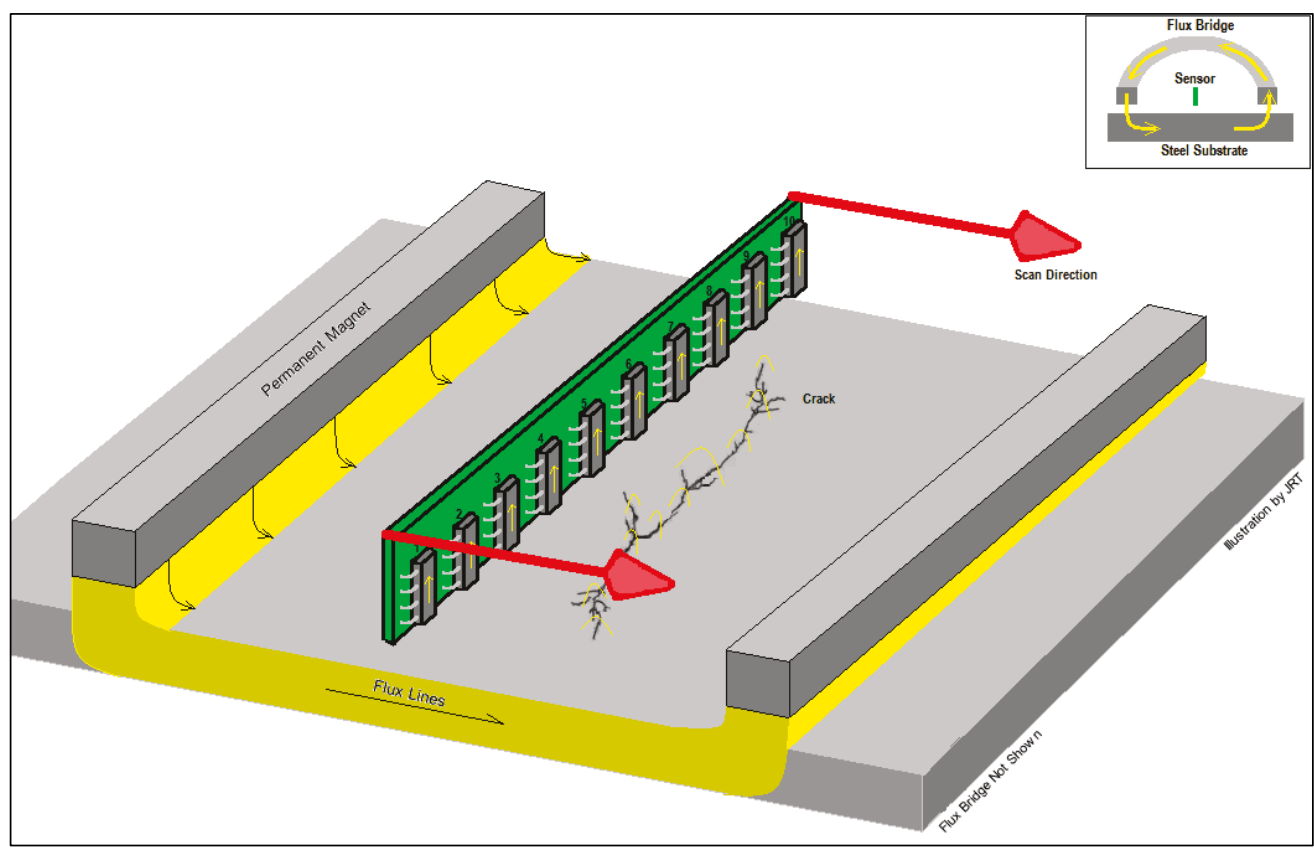

There are several types of sensor technologies that can be used to measure MFL:

- Induction Coil - can be used to measure changes in magnetic field based on Faraday's law of induction that describes the relationship of induced voltage to a changing magnetic field where the output voltage is proportional to the time derivative of the magnetic flux. Basically, the Induction Coil magnetometer consists of a wire coil with a very large number of turns of wire wrapped around a ferrous core.

- Hall Effect - is the production of a potential difference (voltage) across an electrical conductor when a magnetic field is applied in a direction perpendicular to the current flow. When the magnetic field is absent, the electrical charges (electrons, ions, holes) flow straight; however, when a magnetic field is applied, they experience a force known as the Lorentz force that alters the direction of current flow (Paun et al. 2013). This flow alteration results in a voltage that can be measured and used to approximate the magnetic field orientation.

- Anisotropic Magnetoresistive (AMR) - is a type of magnetoresistance displayed by all metallic magnetic materials, which arises because conduction electrons have more frequent collisions when they move parallel to the magnetization in the material than when they move perpendicular to it. The effect arises from the simultaneous action of magnetization and electron spin-orbit interaction (Nickel 1995). 
- Giant Magnetoresistive (GMR) - is a quantum mechanical magnetoresistance effect observed in thin-film structures composed of alternating ferromagnetic and non-magnetic conductive layers. The effect is observed as a significant change in the electrical resistance depending on whether the magnetization of adjacent ferromagnetic layers is in a parallel or an antiparallel alignment. The overall resistance is relatively low for parallel alignment and relatively high for antiparallel alignment. The magnetization direction can be controlled, for example, by applying an external magnetic field. The effect is based on the dependence of electron scattering on the spin orientation (White 1992).

- Tunnel Magnetoresistance - is a magnetoresistive effect that occurs in a magnetic tunnel junction, which is a component consisting of two magnets separated by a thin insulator. If the insulating layer is thin enough (typically a few nanometers), electrons can tunnel from one magnet into the other. Since this process is forbidden in classical physics, the tunnel magnetoresistance is a strictly quantum mechanical phenomenon (Mathon 2001).

In selecting sensors for experimental test purpose, three requirements had to be met:

1. Small size ( $<5$ millimeters $[\mathrm{mm}])$ - to maximize flux field measurement resolution, the spacing between individual sensor elements in the linear array will be on the order of millimeters.

2. Three axes of sensitivity (or can be easily assembled while retaining a relatively small footprint of $<1$ square centimeter).

3. Relatively low cost $(<\$ 50$ per sensor).

Based on the above sensor criteria, the induction coil was eliminated since a 3 -axis coil sensor is not readily available and size limitations could not be met.

\subsubsection{MFL sensor circuit selection}

Table 5 lists the integrated circuit (IC) sensors selected for evaluation. Laboratory test were conducted to evaluate each of the six sensors listed in Table 5 for sensitivity, repeatability, and stability. All but one of these sensors have three axes of magnetic flux sensitivity (Item 5). Therefore, for test comparison purposes, three single-axis NVE Corp AA002002E IC chips were combined to make a single 3 -axis sensor. 
Table 5. Selected sensors for MFL test.

\begin{tabular}{|c|c|c|c|}
\hline 1 & $\begin{array}{l}\text { Honeywell HMC5883L, } \\
\text { 3-axis magnetometer }\end{array}$ & $\begin{array}{l}\text { Based on AMR technology, with } \\
\text { 12-bit analog output proportional } \\
\text { to the magnetic flux density } \\
\text { sensed along the XYZ. The } \\
\text { HMC5883L has a magnetic field } \\
\text { range (+/- } 0.8 \text { milli-Tesla [mt]). }\end{array}$ & \\
\hline 2 & $\begin{array}{l}\text { Honeywell HMC5983, } \\
\text { 3-axis magnetometer }\end{array}$ & $\begin{array}{l}\text { Based on AMR technology, } 12 \text {-bit } \\
\text { temperature compensated ADC } \\
\text { and digital output (I2C* or SPI**) } \\
\text { proportional to the magnetic flux } \\
\text { density sensed along the XYZ. The } \\
\text { HMC5983 has a magnetic field } \\
\text { range }(+/-0.8 \mathrm{mt}) \text {. }\end{array}$ & \\
\hline 3 & $\begin{array}{l}\text { Melexis MLX90393, } \\
\text { 3-axis magnetometer }\end{array}$ & $\begin{array}{l}\text { Based on the Hall-effect, } 16-\text { bit } \\
\text { i2c proportional to the magnetic } \\
\text { flux density sensed along the XYZ } \\
\text { axes and a temperature output } \\
\text { signal. The MLX90393 has a } \\
\text { magnetic field range }(+/-5-50 \\
\text { mt). }\end{array}$ & \\
\hline 4 & $\begin{array}{l}\text { Freescale MAG3110, } \\
\text { 3-axis magnetometer }\end{array}$ & $\begin{array}{l}\text { Based on the Hall-effect, digital } \\
\text { output (I2C) proportional to the } \\
\text { magnetic flux density sensed } \\
\text { along the XYZ axes. The MAG3110 } \\
\text { has a magnetic field range }(+/- \\
1.0 \mathrm{mt}) \text {. }\end{array}$ & \\
\hline 5 & $\begin{array}{l}\text { NVE Corp AA002-02E, } \\
\text { 1-axis magnetometer }\end{array}$ & $\begin{array}{l}\text { Based on GMR technology. } \\
\text { Wheatstone Bridge Analog Output. } \\
\text { The AA002-02E has a magnetic } \\
\text { field range }(0.15-1.0 \mathrm{mt}) \text {. }\end{array}$ & \\
\hline 6 & $\begin{array}{l}\text { Memsic } \\
\text { MMC5883MA, } \\
\text { 3-axis magnetic } \\
\text { sensor }\end{array}$ & $\begin{array}{l}\text { Based on AMR technology, with } \\
\text { 16-bit analog output proportional } \\
\text { to the magnetic flux density } \\
\text { sensed along the XYZ. The } \\
\text { MMC5883MA has a magnetic } \\
\text { field range (+/- } 8 \text { Gauss). }\end{array}$ & 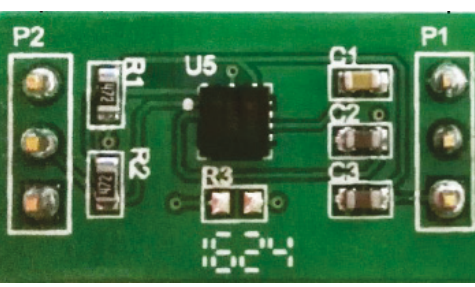 \\
\hline
\end{tabular}

*Inter-Integrated Circuit

$* *$ Serial Peripheral Interface 
This list of sensors was quickly reduced to a sample size of four due to overall performance of the sensors (resolution, consistency of results). The four sensors selected for detailed analysis included (1) Freescale MAG3110 3-axis magnetometer, (2) NVE AAoo2-2E, 1-axis magnetometer, (3) Memsic MMC5883MA 3-axis magnetic sensor, and (4) Melexis MLS90393 Triaxis magnetometer. The four selected sensors were further analyzed using a one-quarter in. thick plate with etched defects, as shown in Figure 14. This test plate was scanned using a computer numerical control machine to maximize stability as the sensor is moved across the steel surface.

Figure 14. Test plate design.

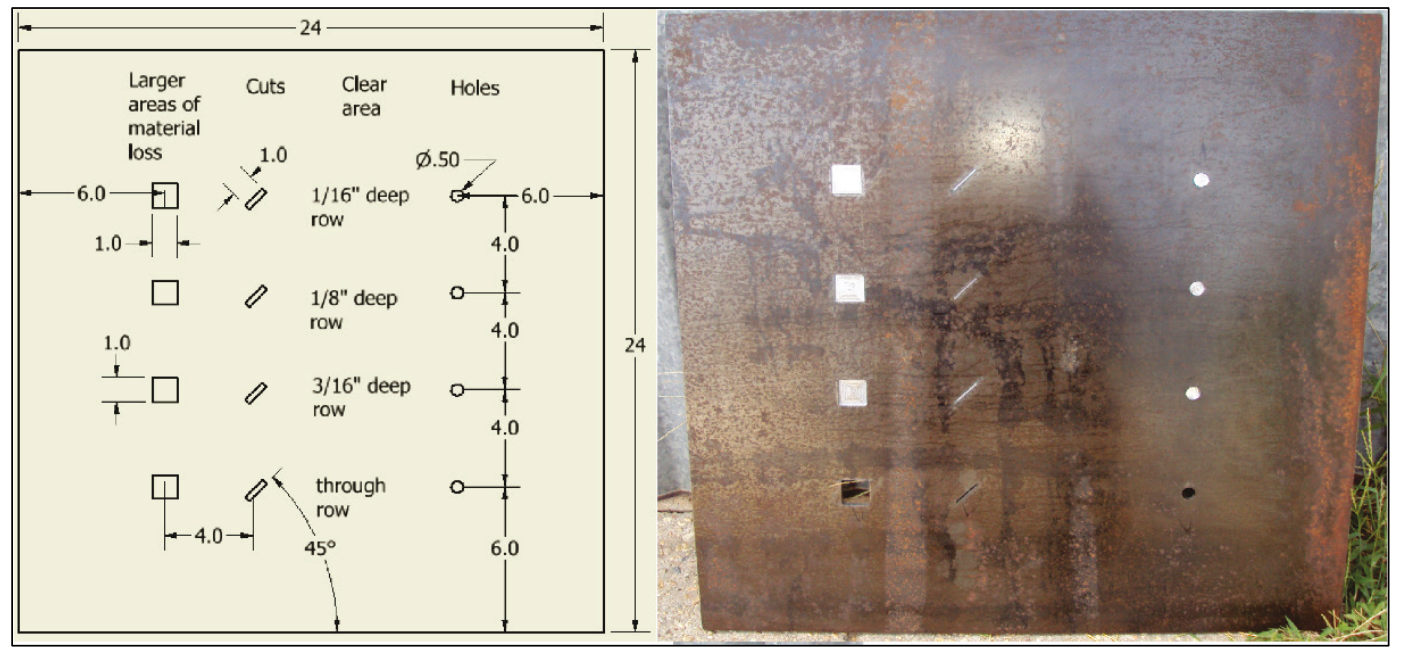

\subsubsection{MFL corrosion sensor test setup}

The laboratory test setup for the magnetic flux sensors included the following:

- Magnetic Flux Saturation Device (MFSD) - The MFSD consisted of two magnets and a steel plate. The two magnets were used to induce a magnetic field of near saturation level to a steel substrate. To measure the induced magnetic field, a magnetic flux sensor was attached to the steel plate at a location where it would not be saturated by the magnetic fields generated by the two magnets. The design of the MFSD and the optimum location of the magnetic flux sensor were performed using Finite Element Method Magnetics (FEMM) (Meeker 2014), a two-dimensional (2D) magnetic field simulation software package (Figure 15). Considering the measurement range of the magnetic flux sensors under test typically varied from +/- 1.0 mt, the MFSD was 
designed to satisfy this condition. The prototype design consists of two nickel-coated N42 grade neodymium magnets of dimension 2 in. $\times$ 0.375 in. $\times 0.375$ in. (Figure 16). The combined pull force of the magnets was 11.3 pounds $(\mathrm{lb})$. The dimensions of the steel flux bridge was 2 in. $\times 5.5$ in.

Figure 15. Numerical simulation of MFSD.

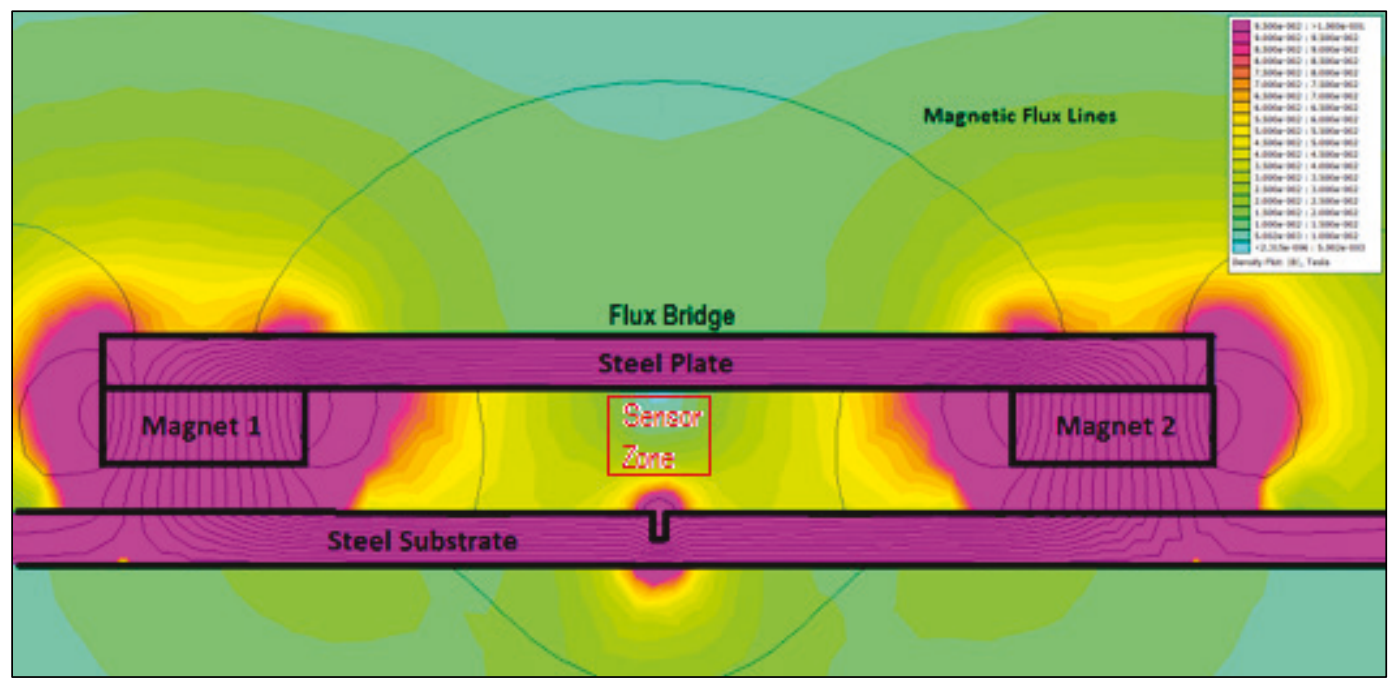

Figure 16. MFSD with sensor attached.

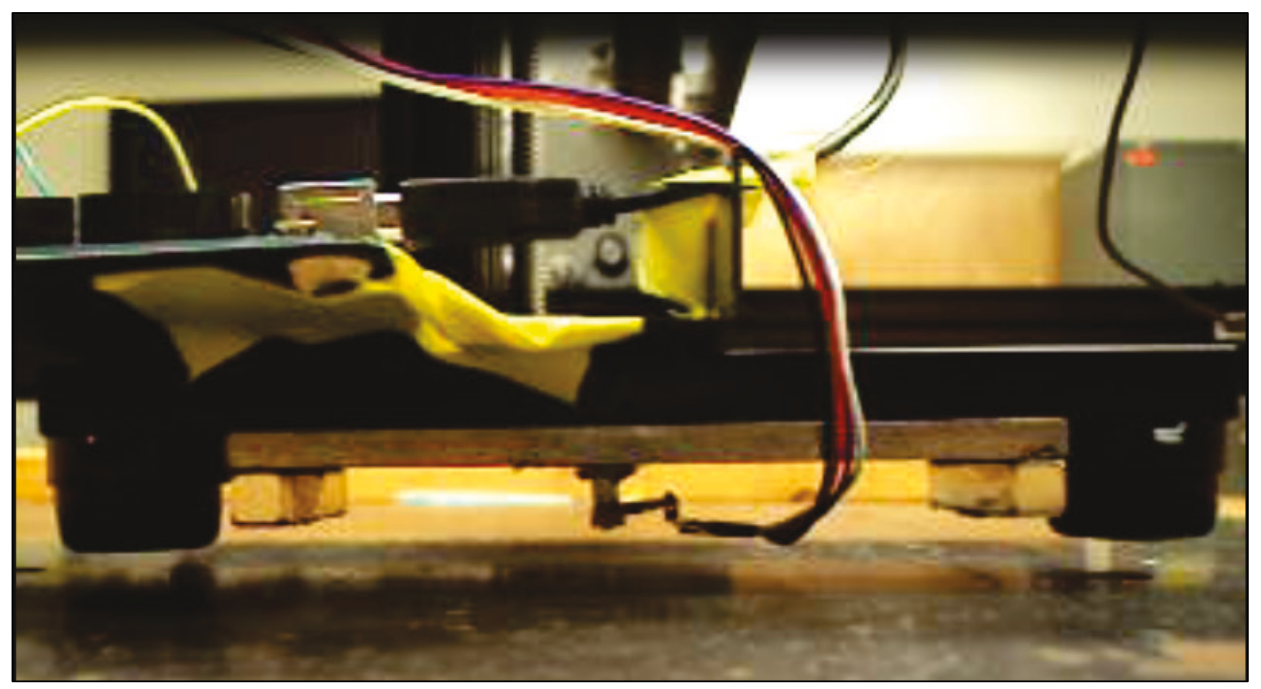

- 3-Axis (XYZ) Table - The XYZ Table was for delivering the MFSD to targeted areas on a test substrate with sub-millimeter precision. A water tank could be placed below the XYZ Table (Figure 17) to provide a wet test area. The extent of travel was approximately 0.5 meter $(\mathrm{m})$ in the $x$ - and $y$-direction, and $0.15 \mathrm{~m}$ in the $z$-direction. 
Figure 17. Three-axis XYZ Table for magnetic flux sensor test.

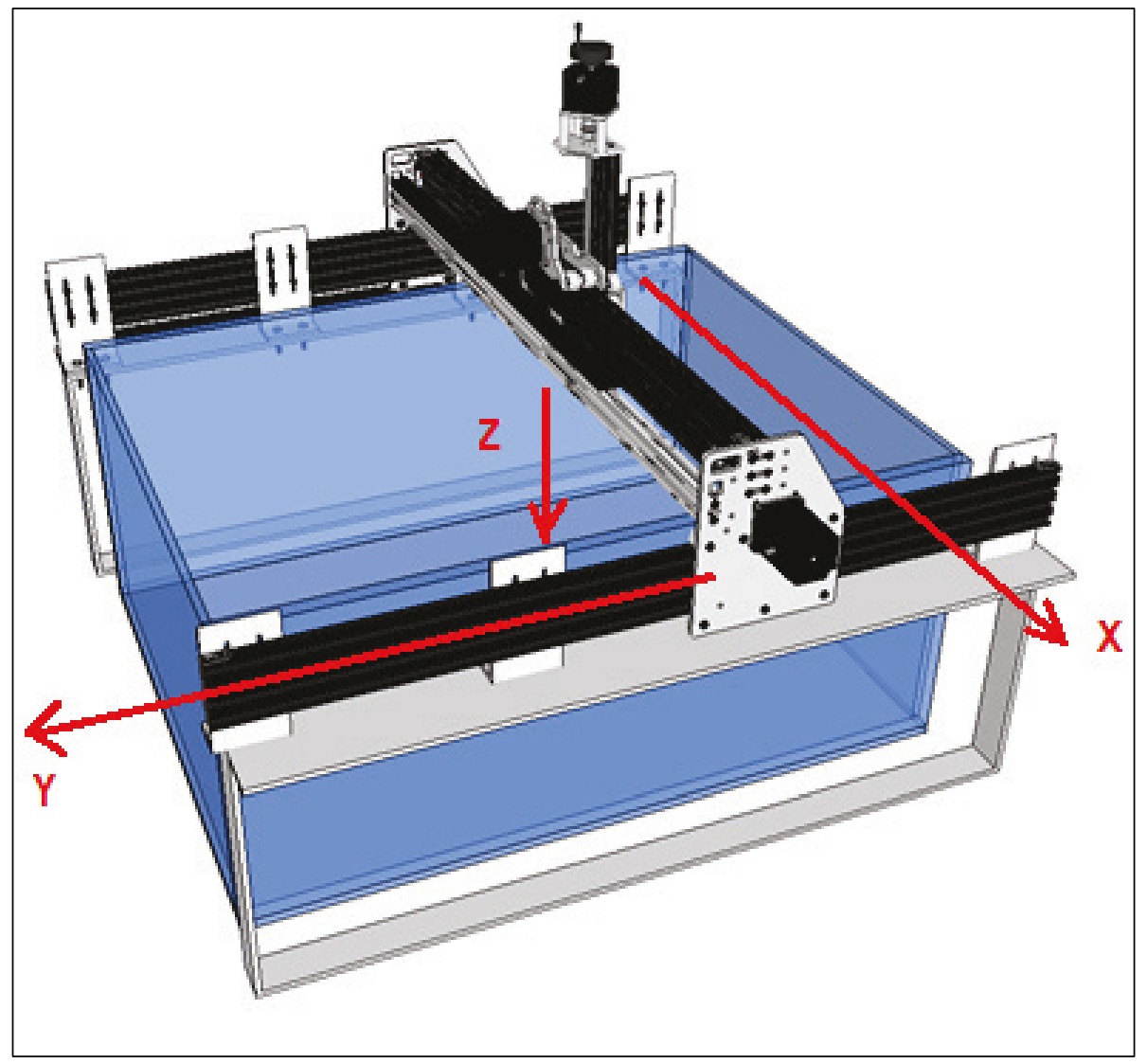

- Test Substrate - The test substrate provided a standard consisting of 12 defects of various shape and depth. The standard was made of rolled steel with thickness of $0.25 \mathrm{in}$. and dimensions of 2 feet $(\mathrm{ft}) \times 2 \mathrm{ft}$. The standard was divided into four zones (Figure 18):

- Square cut zone - four 1 in. $\times 1$ in. squares of depth varying from 0.0625 in. to 0.25 in.

○ Line cut zone - four 1 in. $\times 0.125$ in. lines of depth varying from 0.0625 in. to 0.25 in.

- Blank Zone - a zone of no defect

- Circle cut zone - four 0.5 in. diameter circles of depth varying from 0.0625 in. to $0.25 \mathrm{in}$. 
Figure 18. Steel plate test standard.

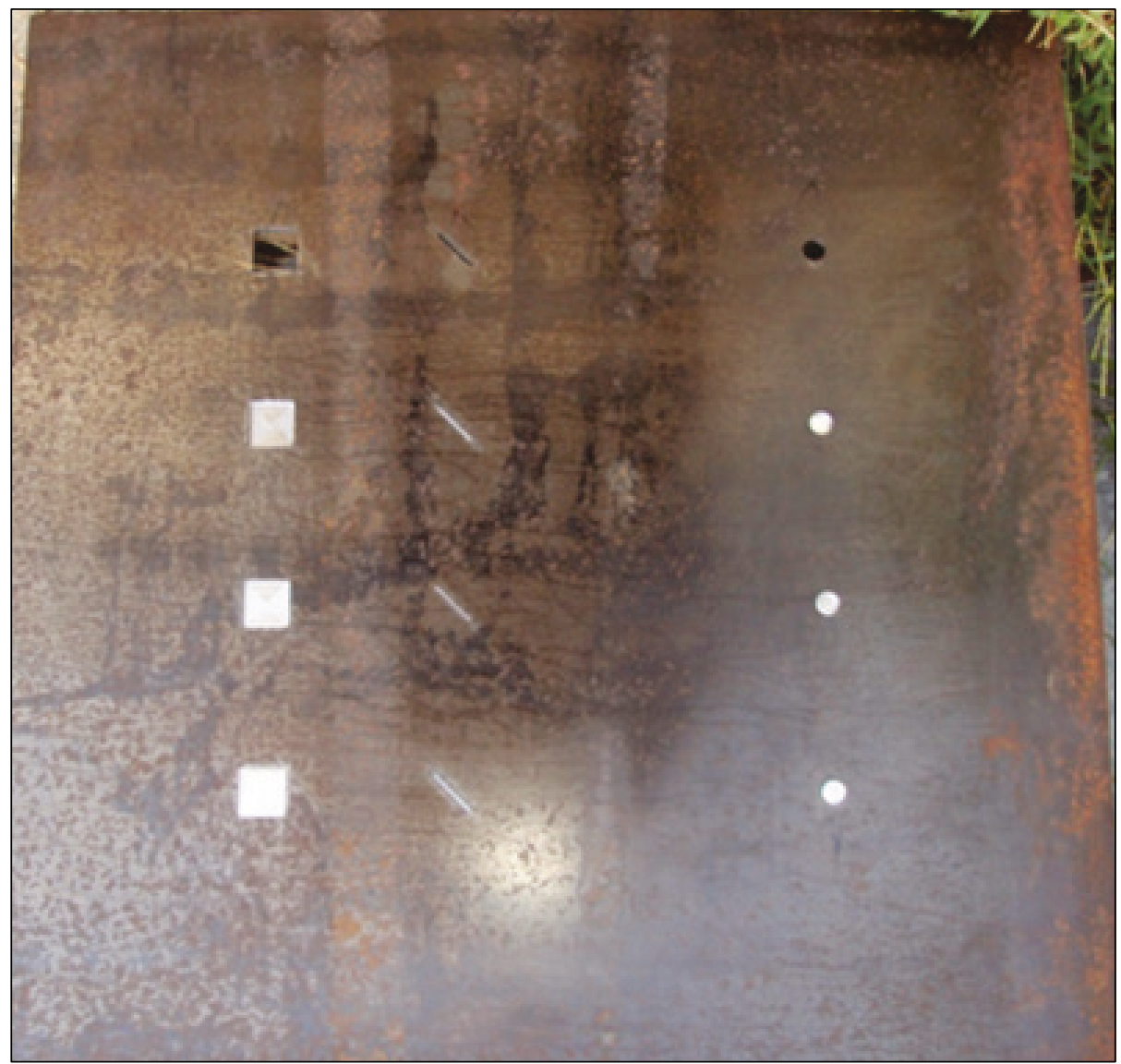

\subsubsection{MFL corrosion sensor test procedure}

1. The steel plate test standard was mounted below the Z-axis of the XYZ Table. The test plate was leveled in the $\mathrm{X}$ - and $\mathrm{Y}$-axis.

2. The selected magnetic flux sensor from Table 5 was mounted to the MFSD as determined by the FEMM software and as shown in Figures 16 and 17.

3. The MFSD was mounted to the Z-axis of the XYZ Table. The Z-axis of the Table was lowered to a position such that the height of the magnets above the steel plate was verified. This height or offset varied between $0.75 \mathrm{in}$. and $0.375 \mathrm{in}$.

4. After homing or zeroing the $\mathrm{X}$ - and $\mathrm{Y}$-axis, a program was executed that moved the sensor over the area of the test plate defined in Figure 20 by the yellow dotted line. The sensor moved along the Y-axis from $\mathrm{Y} 1$ to $\mathrm{Y} 2$ at a constant speed of $\mathrm{xx} \mathrm{mm} / \mathrm{second}$. Both sensor data and position data were collected during the move. Sensor data were collected at approximately $20 \mathrm{~Hz}$, and position data were collected every $1 \mathrm{~mm}$. Once the sensor reached the end-of-move (Y2), data 
collection stopped; the $\mathrm{Y}$-axis returned to $\mathrm{Y} 1$, and the $\mathrm{X}$-axis was incremented by $+1 \mathrm{~mm}$. The process continued until the entire plate was scanned with the sensor arriving at the marker indicated by $\bullet$, labeled "Stop Scan" in Figure 19.

Figure 19. Scan area of steel plate.

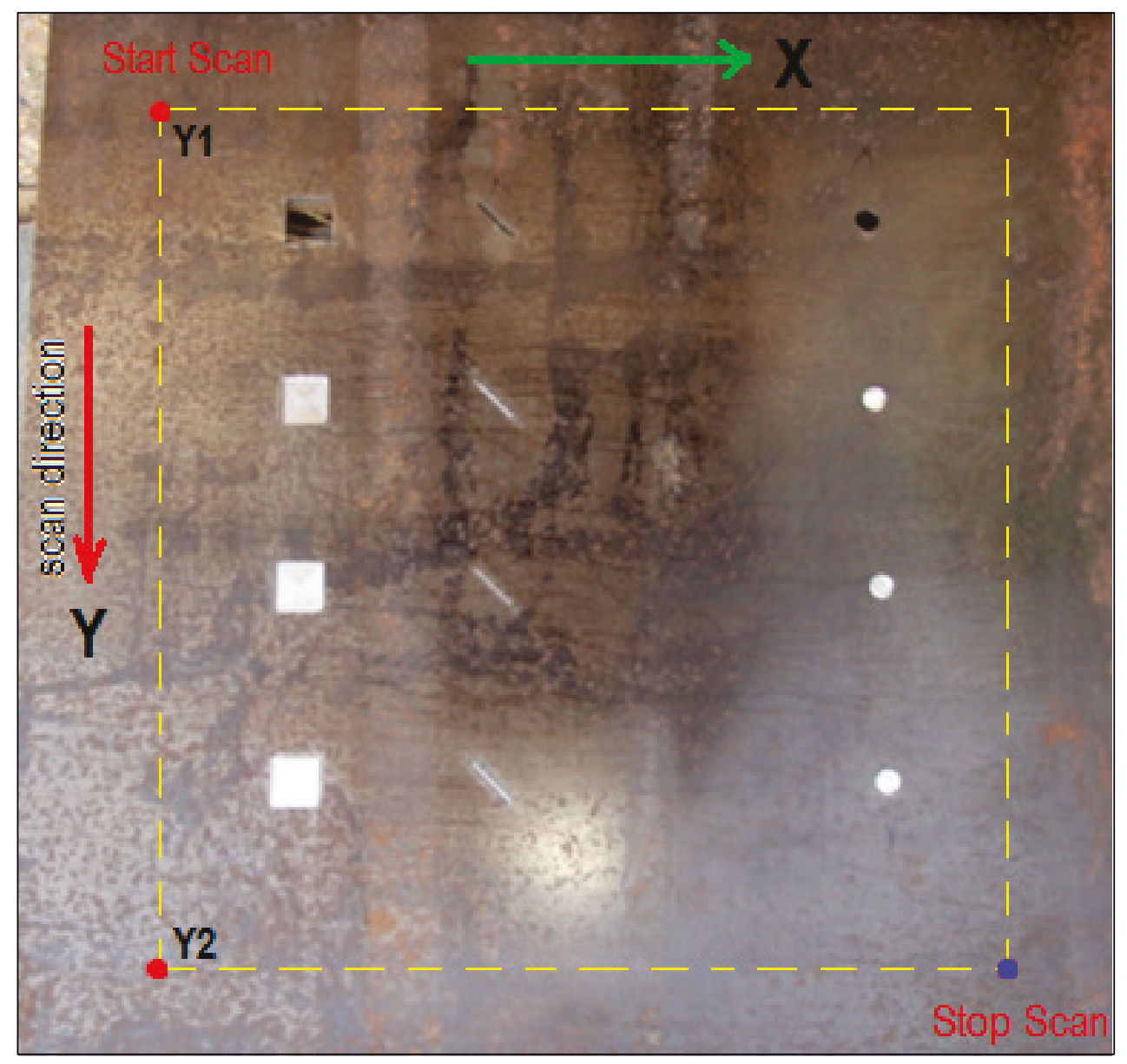

\subsubsection{MFL corrosion sensor data analysis}

As a first step in analyzing the magnetometer data, an interpolation of the point cloud is performed to produce a plane (Figure 20) representative of the actual magnetic flux recorded on the plate.

Additionally, a Gabor wavelet (Hjelmas and Wroldsen 1999) filter was applied to further delineate magnetic leakage fields. The Gabor wavelet defines its impulse response by a sinusoidal wave multiplied by a Gaussian function and can be defined as a complex function as defined in Figure 21. 
Figure 20. Data interpolation (source: Matlab).

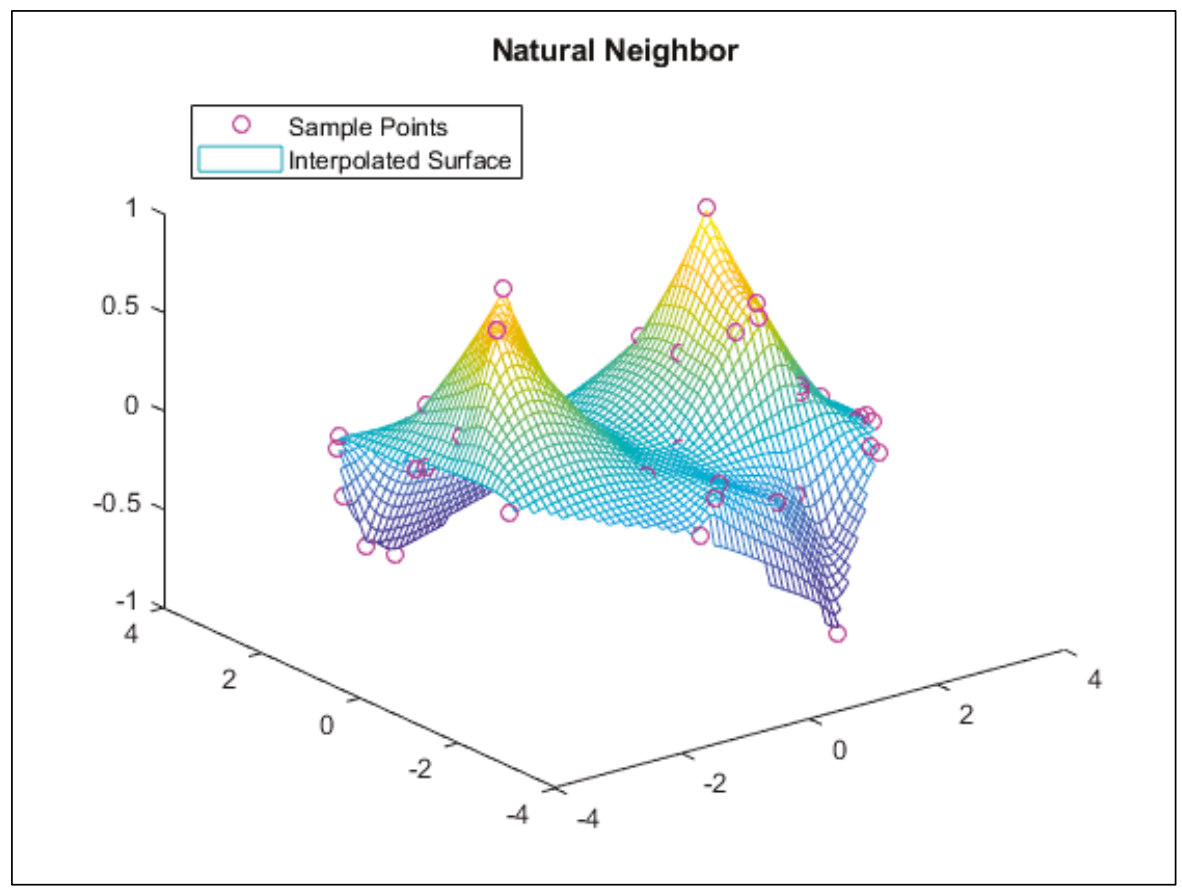

Figure 21. Gabor complex function (Hjelmas and Wroldsen 1999; Murthy 2014).

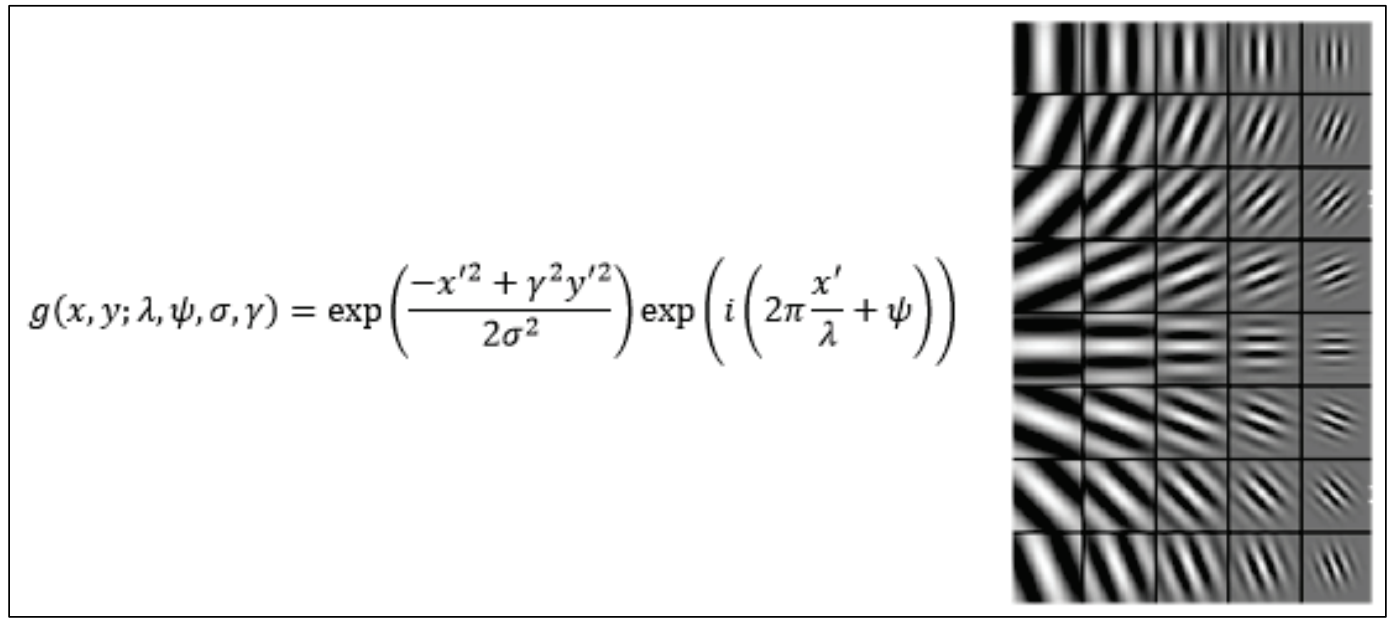

Because the direction of the defect on the steel plate is unknown, the Gabor wavelet filter can be rotated and sized to correctly identify the defect in the metal. All Gabor wavelets are created from a single kernel and can be convolved with the magnetic flux data to classify areas of corrosion, cracking, or structure loss. By rotating the filter, corrosion features such as cracking can be identified in any orientation regardless of the direction to the actual scan. 
By convoluting the Gabor wavelet with the radial component of the magnetometer data, it is possible to select a preliminary set of Gabor parameters that display a high response to the areas of the scan where corrosion is known to be present. By selecting the wavelength and angle of the filter that maximizes the response of known areas of corrosion, it is possible to construct a feature detector to use for classification of corrosion on the plate (Figure 22). Preliminary results using wavelengths of 26 to 32, corresponding to 13 to $16 \mathrm{~mm}$, and angles of 50 deg to $60 \mathrm{deg}$ show very promising results on various scans with multiple sensor heads.

Figure 22. Gabor response to various wavelengths and angles.

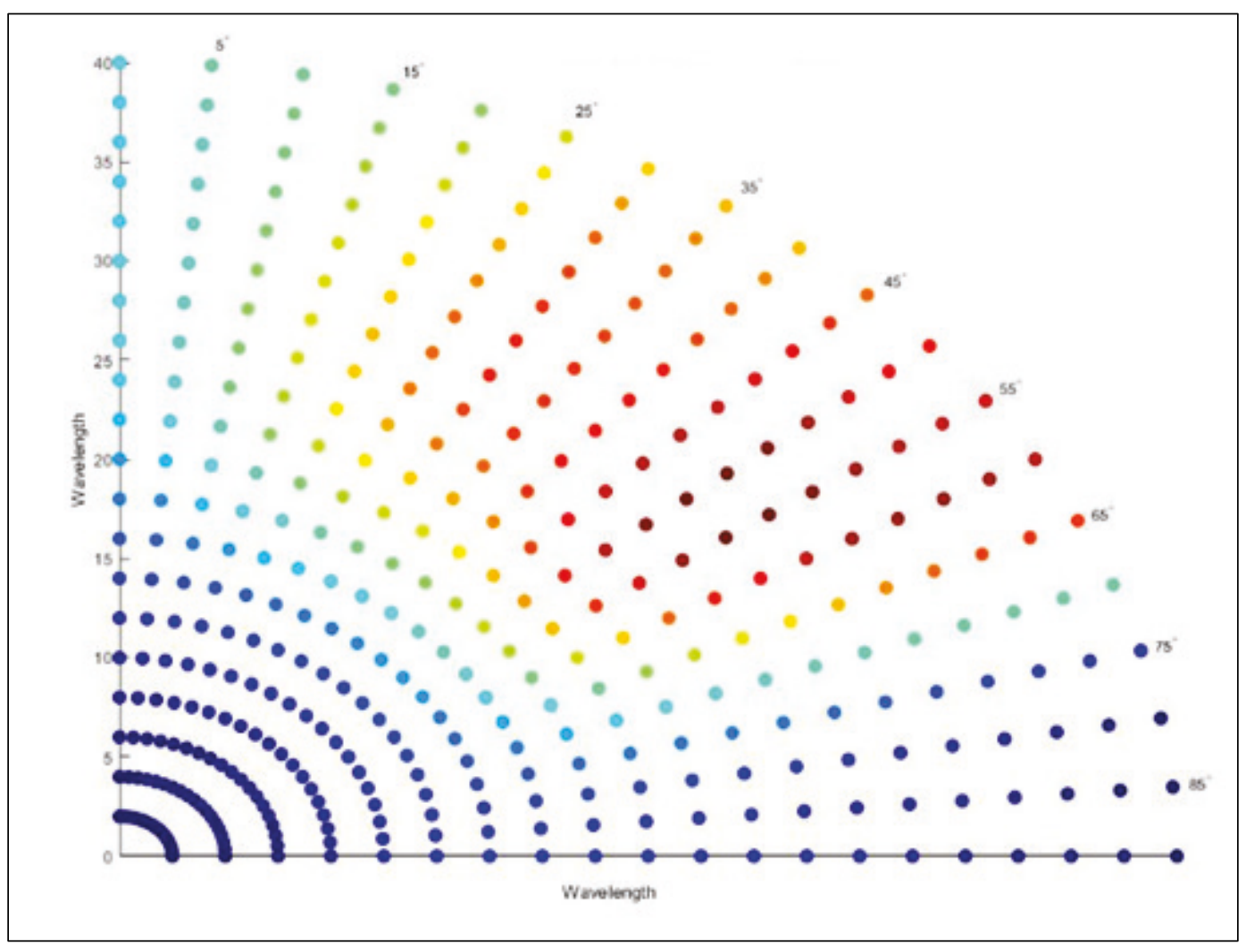

Combination of Gabor wavelet filters with chosen parameters produces signature responses in the data such that simple thresholding techniques can be used to detect corrosion and cracking on ferrous metals. In Figure 23 the wavelet filter output is shown for the raw data collected from the MAG3110 3-axis magnetometer. Using thresholding, it is possible to detect all of the round and square simulated corrosion spots and three of four simulated cracks on the test plate while also showing the extent of the defect. 
Figure 23. Gabor filter response of magnetometer data.

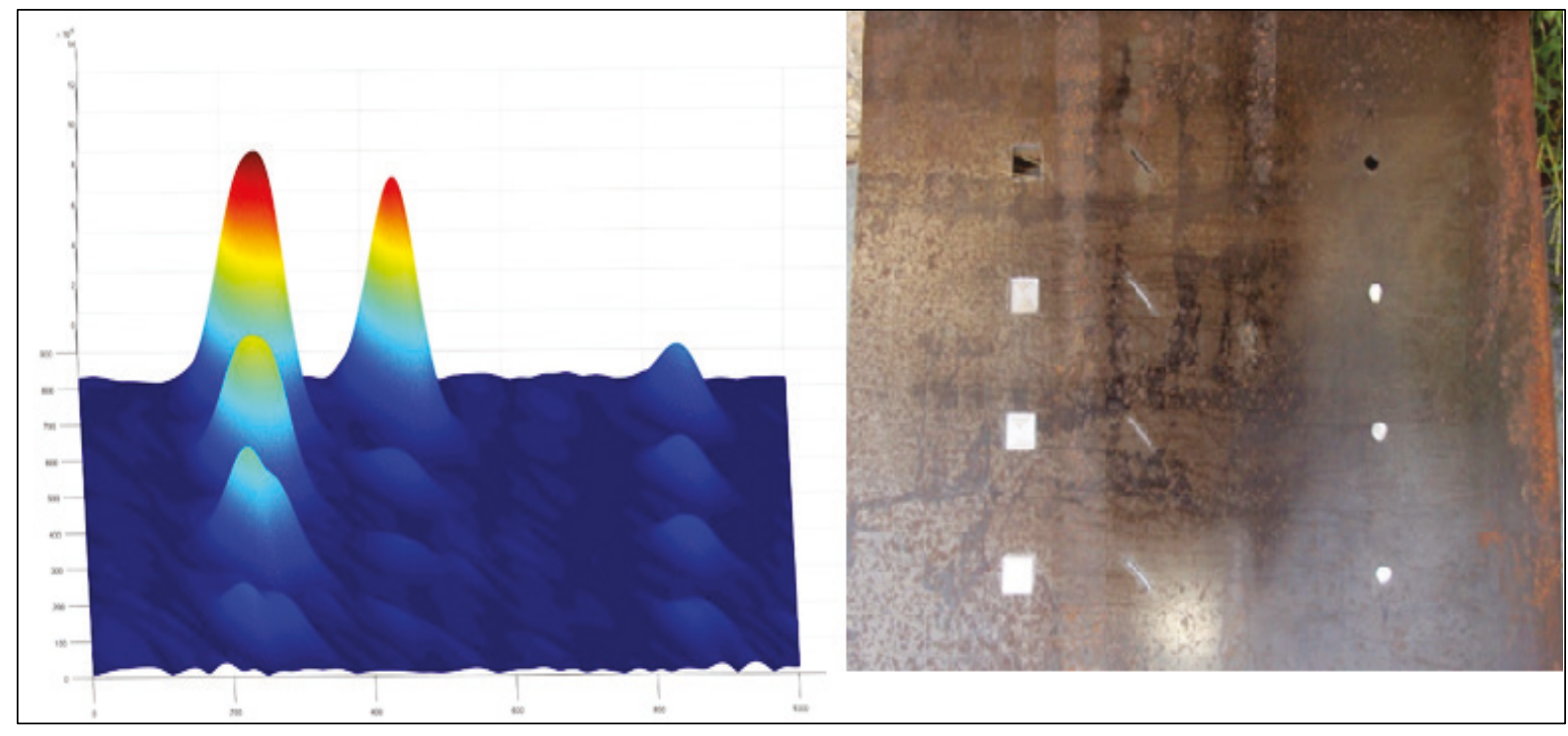

Three-dimensional (3D) sensor data were collected and analyzed for each of the four magnetic flux detector types, and a final selection was made based on sensitivity, repeatability, and functionality. Example test results are shown in Figure 24.

Figure 24. Example sensor test response.

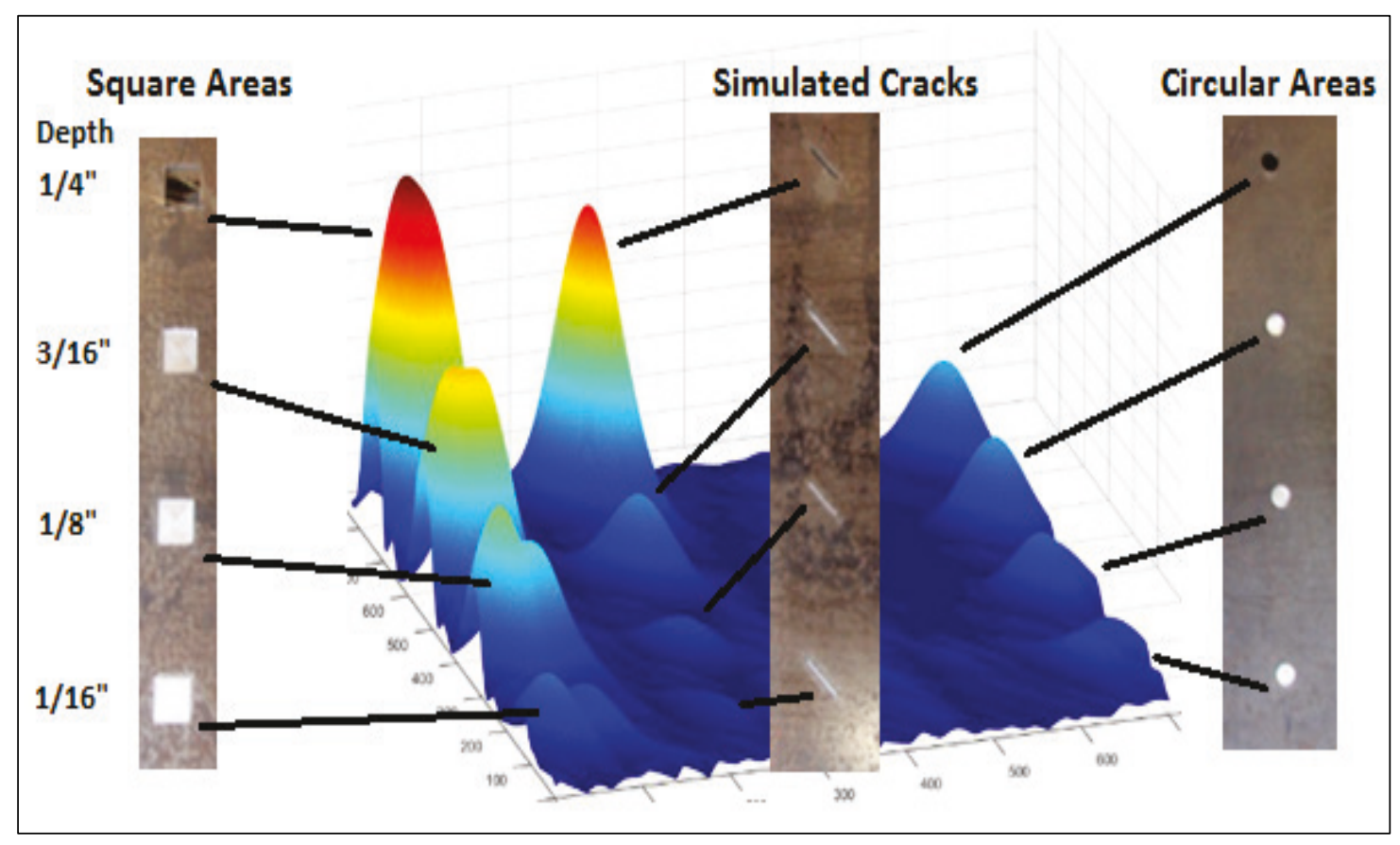




\subsubsection{MFL corrosion sensor data comparison and anomalies}

Raw data produced by the MFL sensor may allow for visual inspection of large imperfections in the plate but will not be sufficient to identify small imperfections (defects). The MFL sensors investigated in this program have three axes of magnetic flux sensitivity, namely axial, radial, and tangential axis (Figure 25), where the horizontal axis represents the width of the defect and the vertical axis represents the intensity of the magnetic induction. Defects in the scanned substrate will produce responses that vary with the axis of measurement.

Figure 25. Three components of magnetic flux sensitivity (Shi et al. 2015).

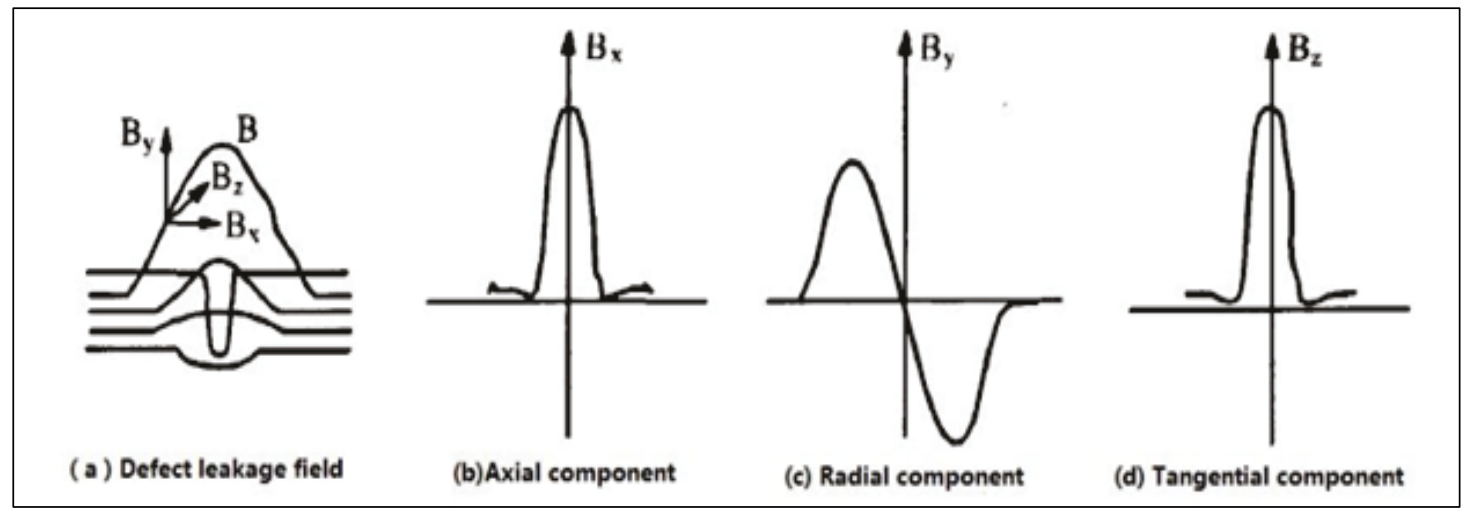

The metal substrate scan generated data from each axis of the 3 -axis magnetic flux sensor. This data represent the intensity of the magnetic induction due to anomalies in the metal substrate such as a pit, crack, or missing material. The data were analyzed for each axis and as a vector resulting from combining the three axes. An example plot of raw sensor output for individual axial components of the test plate is shown in Figure 26, and a vector representation of the three axes is shown in Figure 27. The vector data representation of Figure 27 clearly shows several locations where magnetic induction due to anomalies in the metal substrate is concentrated. These location of anomalous magnetic flux coincide with the square cut zones shown in Figures 20 and 26. 
Figure 26. Example plot of 3D raw magnetometer sensor data for individual axial components of the test plate.

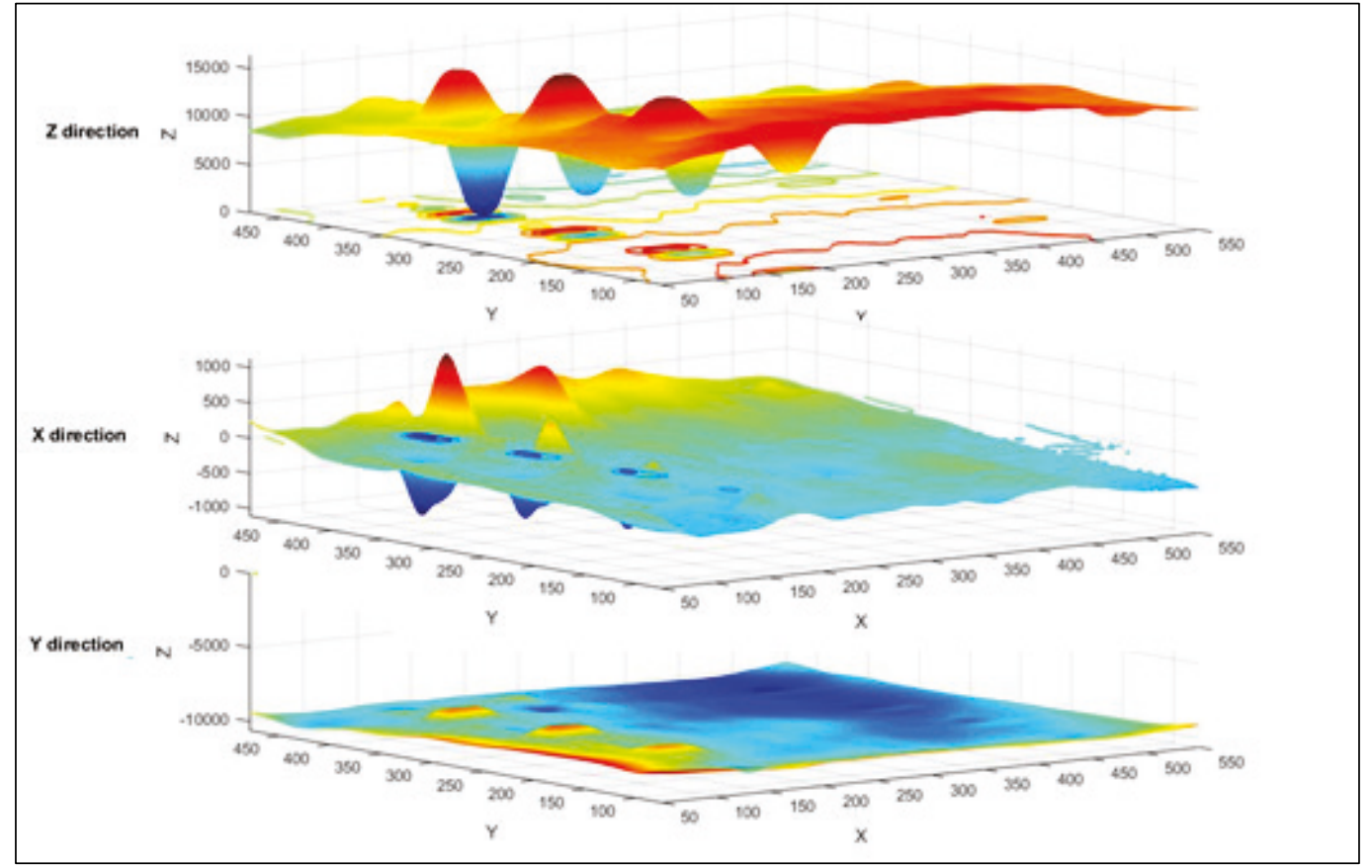

Figure 27. Example plot of vector data showing magnetic induction due to anomalies.

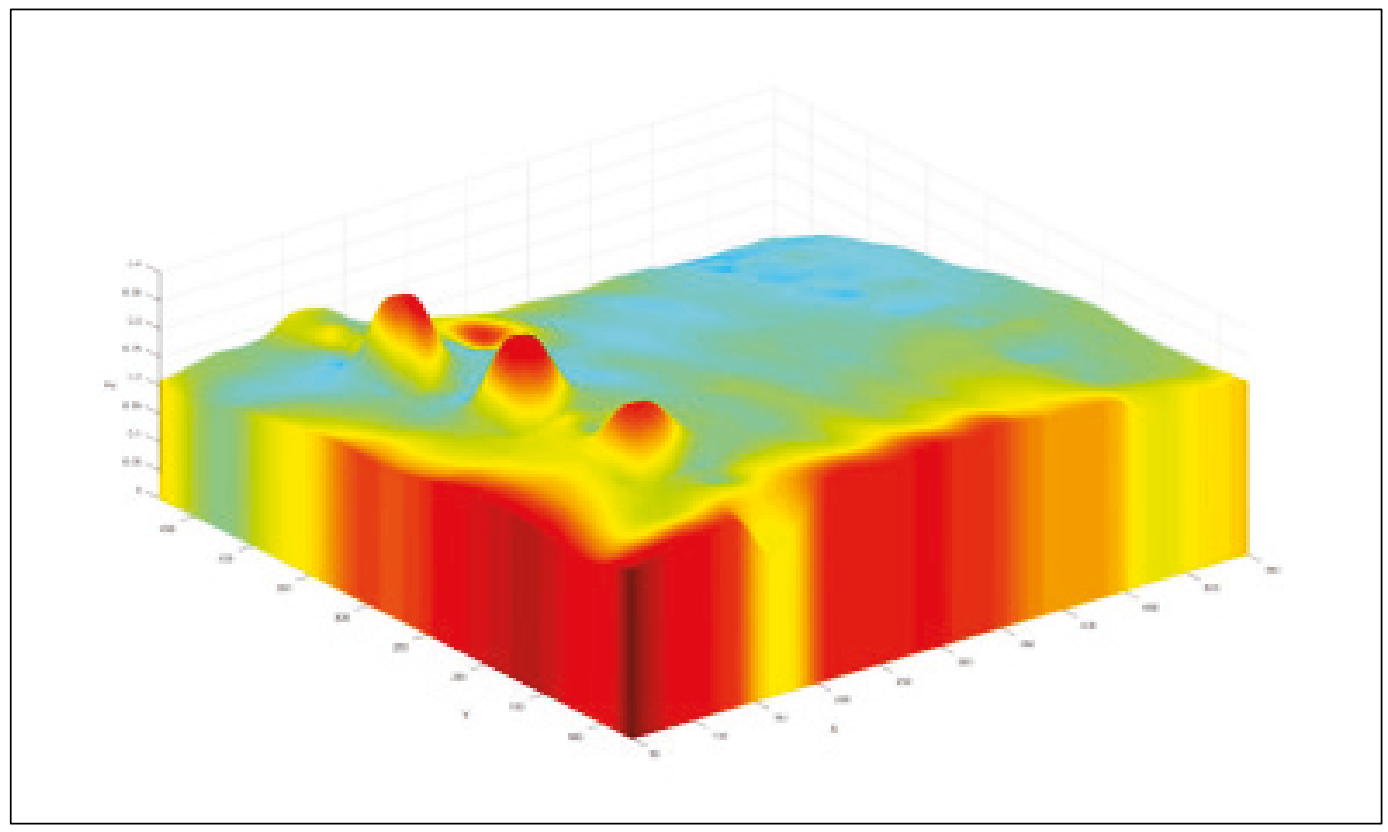

The method of sensor evaluation used here was basically a comparison of magnetic induction responses to known metal substrate defects. Those sensors that produced a repeatable maximum response were selected for further analysis. Several scans were performed using each sensor to measure the sensor's magnetic induction responses to the test plate defect 
and repeatability of measured response. This series of intense test scans and data analyses was applied to the four sensors under critical evaluation: (1) Freescale MAG3110 3-axis magnetometer, (2) NVE AAoo2-2E, 1-axis magnetometer, (3) Memsic MMC5883MA 3-axis magnetic sensor, and (4) Melexis MLS90393 Triaxis magnetometer.

After extensive laboratory test scan data collection and analyses, the Melexis MLX90393 Triaxis magnetometer was finally selected as the sensor of choice for determining plate corrosion. This sensor supports selectable resolutions, wide magnetic operating range, and expandability due to I2C or SPI communication protocol. Other sensors that employ digital communication protocols lacked the option of selecting an address; thus, a multiplexer would have to be used for the design of an array. Figures 28-30 show responses acquired through a scan of the test plate. Scan dimensions of $\mathrm{X}$ and $\mathrm{Z}$ showed fairly similar responses while MLX90393 showed higher fidelity in the Y-orientation.

Figure 28. Freescale Mag3110 magnetometer plate scan.

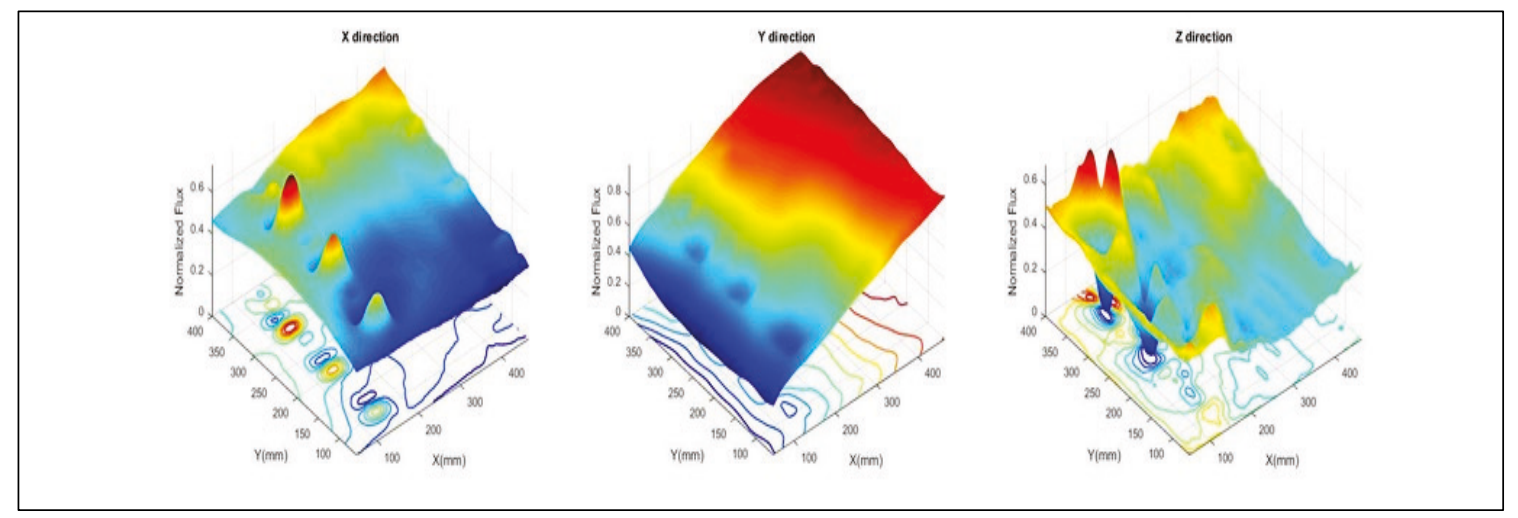

Figure 29. NVE Corp AA002-02E magnetometer plate scan.

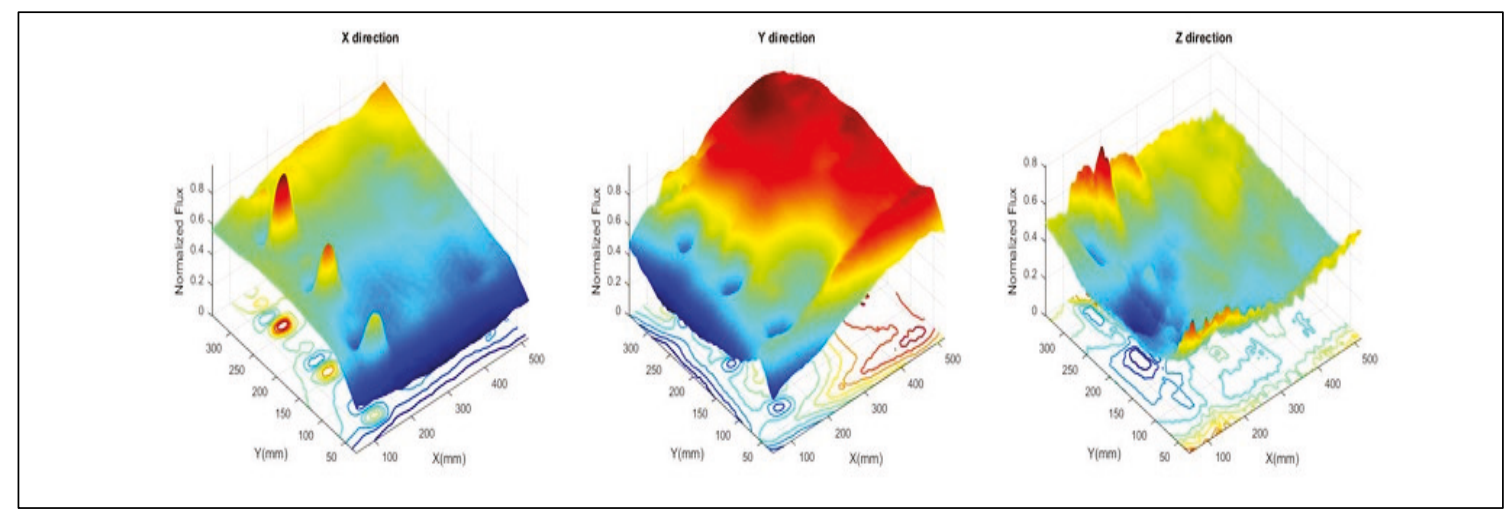


Figure 30. Melexis MLX90393 Triaxis plate scan.

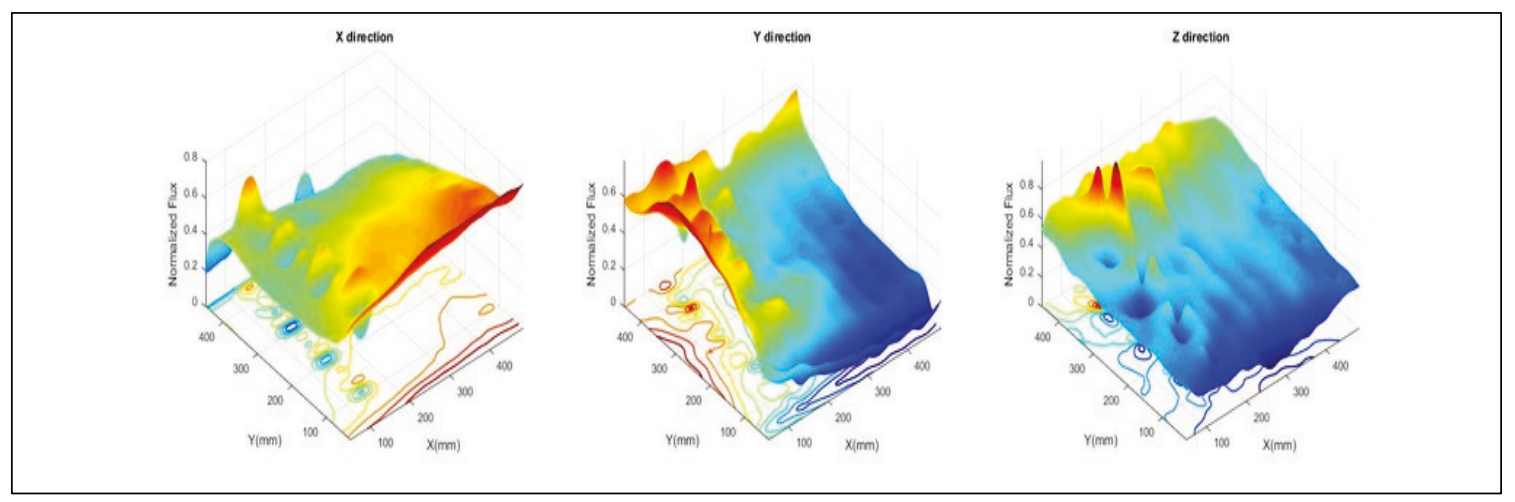

\subsubsection{MFL corrosion sensor package design}

The following discussion pertains to the three primary components of the MFL sensor package: (1) the magnetic flux detector circuit, (2) the permanent magnets, and (3) the flux bridge. The design and configuration of these three components define the capabilities of the MFL sensor package.

A typical miter gate skin plate thickness varies between three-eighths to three-quarter in., and for complete through material, inspection will require a high magnetic saturation. For this reason, the magnetic components (permanent and flux bridge) were scaled up from laboratory tests conducted on one-quarter in. plates. FEMM (Meeker 2014) was used to design the magnetic components (permanent magnets and bridge) based on the miter gate skin plate thickness requirements, the platform clearance requirements, and the flux sensor limitations. Maintaining sufficient platform clearance from the skin plate is necessary to avoid protruding rivets or bolts as the inspection platform traverses the gate surface. This clearance was specified as one-half in. The flux sensor selected for platform integration was the Melexis MLX90393 Triaxis magnetometer. This sensor operates in the range of 1 microTesla to $50 \mathrm{mt}$; therefore, the FEMM simulated magnetic flux field produced by the permanent magnets, flux bridge, skin plate, and modeled defects must remain within the sensor's measurement range to avoid sensor over-saturation.

Given this new design criteria, combinations of permanent magnets and flux bridges were modeled in FEMM. Using the original flat-top flux bridge design (Figure 31) and scaled permanent magnets, it was found that flux leakage occurred from the skin plate to the flux bridge, causing a reduction 
of flux density on the skin plate. This leakage was due to the high levels of magnetic flux in both the bridge and plate and the high resistance of the air gap below each magnet. In an effort to alleviate this flux leakage issue, an arched flux bridge design was investigated (Figure 32).

Figure 31. Original flat flux bridge design.

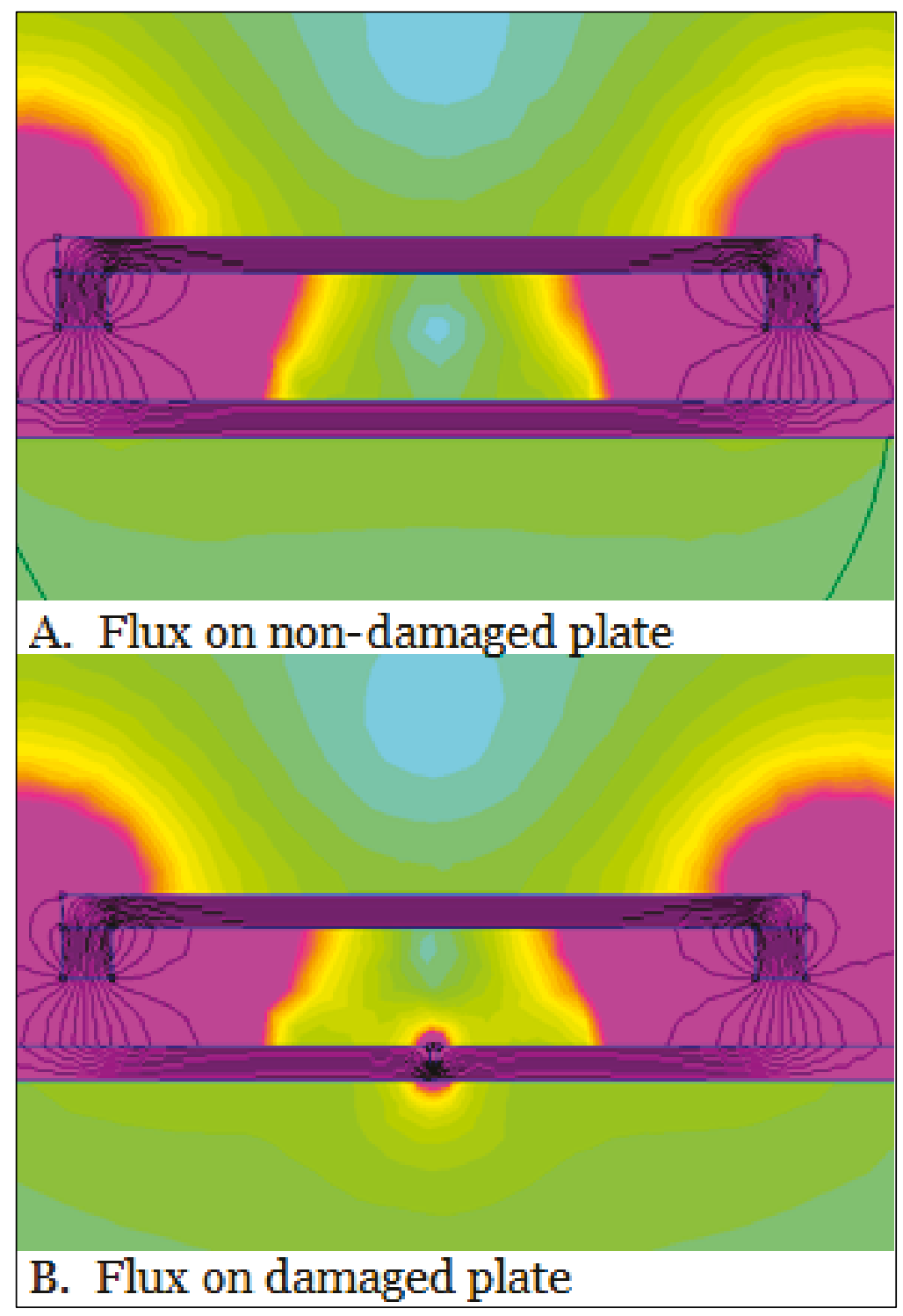


Figure 32. FEMM simulations with arched magnetic flux leakage device.

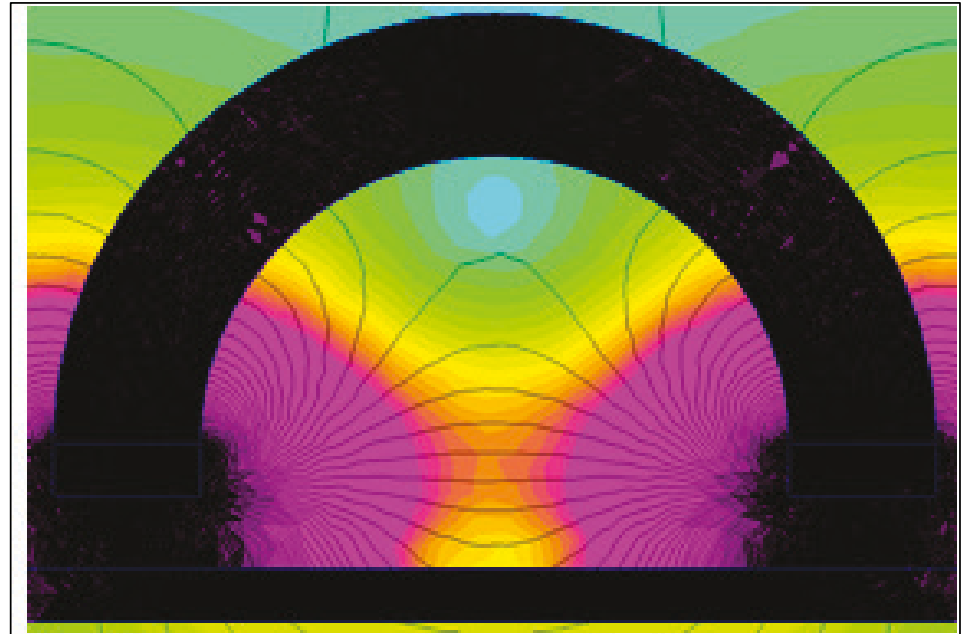

A. Flux on non-damaged plate

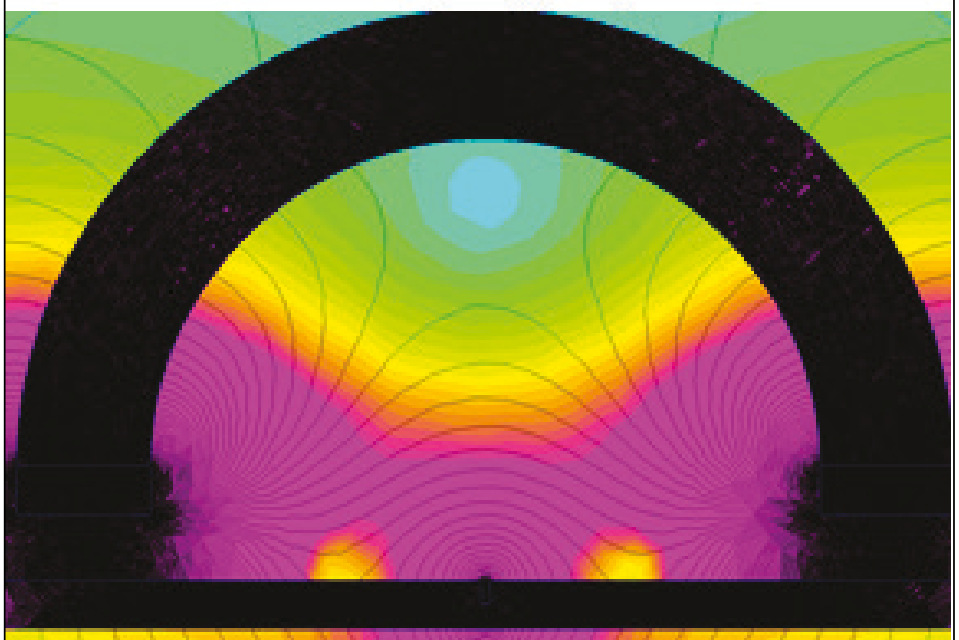

B. Flux on damaged plate

Based on FEMM simulation results, the arched flux bridge proved to be a superior design to the original flat-top bridge design. The arched design reduces the magnetic field under the bridge on an undamaged surface, thus reducing the magnetic pull force from the magnets and increasing the flux density induced to the test skin plate. According to FEMM results, the Melexis MLX90393 Triaxis sensor could be located beneath the arched flux bridge and avoid over-saturation on an undamaged skin plate (Figure 33). 
Figure 33. Melexis MLX90393 Triaxis flux sensors mounted beneath the arched flux bridge.

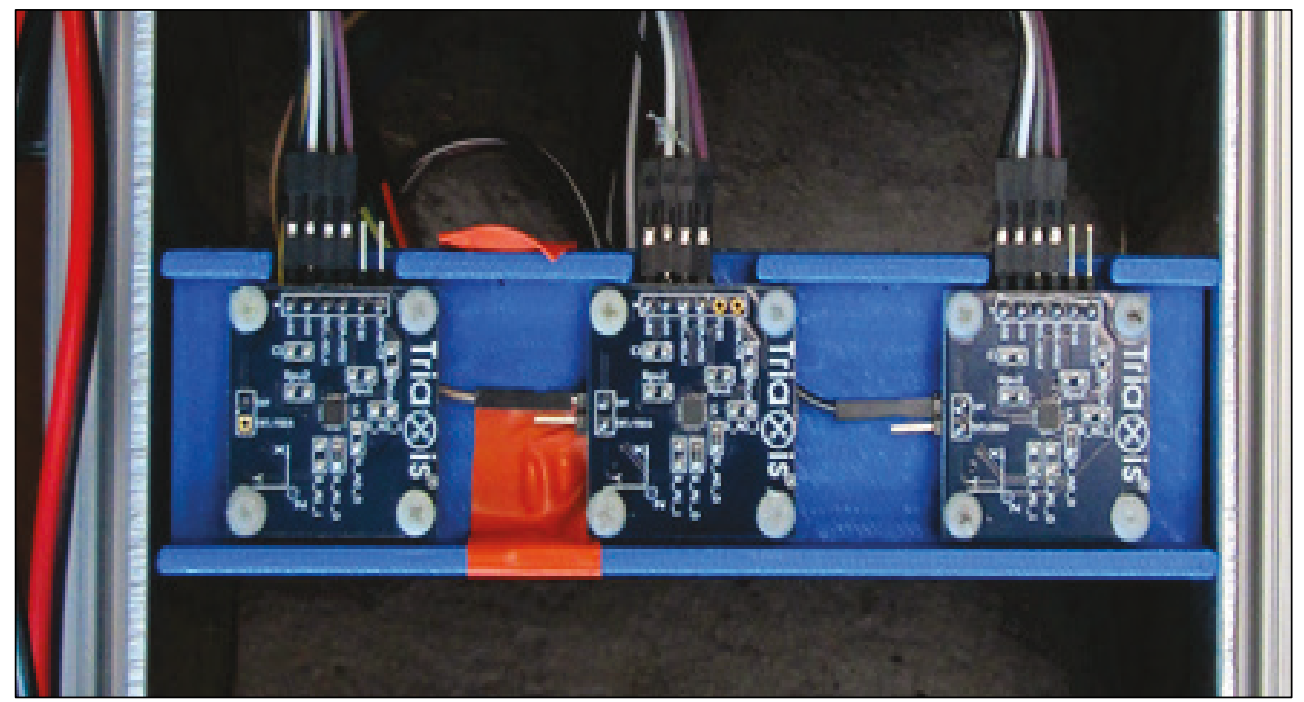

The final design of the flux-bridge resulted in a $1 \mathrm{in}$. thick steel arch with an outer radius of $8 \mathrm{in}$. The resulting flux-bridge weighs approximately $20 \mathrm{lb}$ with three rare earth magnets attached to each side. In Figure 34, the arched flux bridge and permanent magnet product is shown. One negative side effect of this design is the added weight to the inspection platform resulting in the need for larger motors, thus additionally increasing platform weight and power requirements.

Figure 34. Final flux bridge and permanent magnet design.

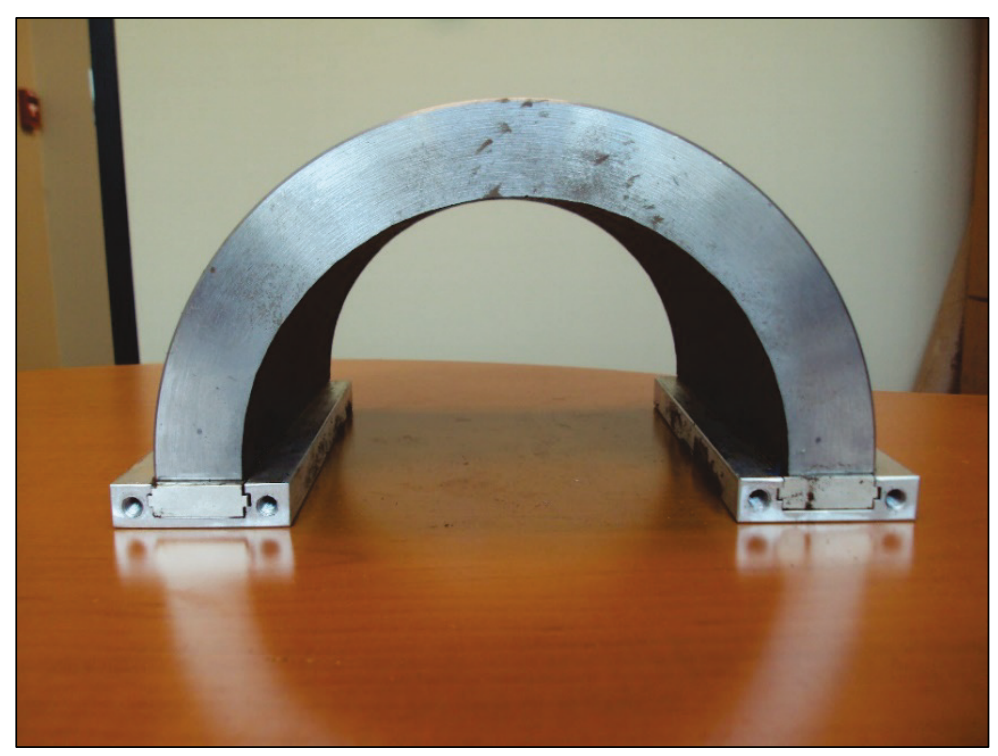




\section{Determining Thickness of Anti-Corrosion Coatings}

\subsection{Existing technologies for miter gate anti-corrosion thickness assessment of non-metallic coatings}

Four different sensor technologies were investigated to ascertain the most appropriate design for determining the thickness of the anti-corrosion coating on the upstream side of a miter gate: (1) Electromagnetic Induction, (2) Ultrasonic Pulse-Echo, (3) Low-Coherence Interferometry, and (4) Magnetic Pull-Off.

\subsubsection{Electromagnetic Induction sensor}

The Electromagnetic Induction (EI) technique measures the change in magnetic flux density at the surface of a magnetic probe as it nears a steel surface (Figure 35). The magnitude of the magnetic flux density at the probe surface is inversely proportional to the square of the distance from the steel substrate. Therefore, by placing the probe directly on the nonconductive coating, the magnitude of the flux density at the probe surface corresponds to the thickness of the anti-corrosion coating. EI testing for coating thickness measurement is one of the most-accepted methodologies in industry today, and many relatively low-cost EI sensors are commercially available.

Figure 35. Physical principle of El.

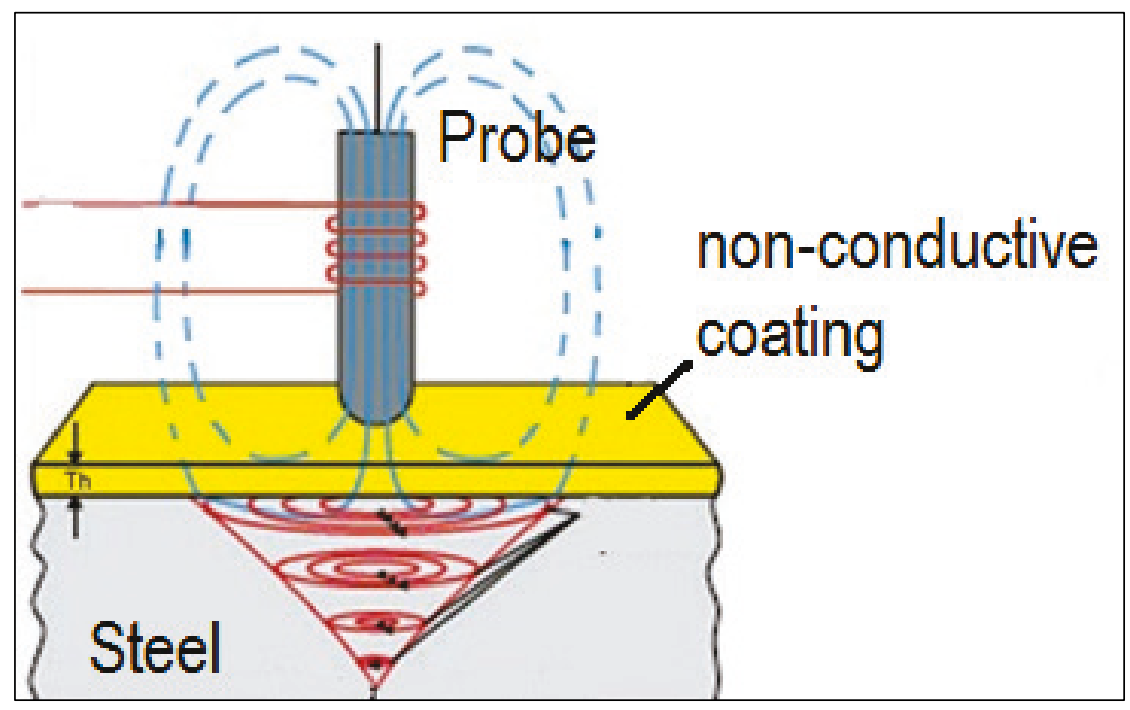




\subsubsection{Ultrasonic Pulse-Echo sensor}

The Ultrasonic Pulse-Echo technique can be used to measure both protective coating and steel substrate layer thickness. An ultrasonic pulse is sent through the test substrate, and the pulse reflects back from each layer interface. The time of flight of the reflected pulse is measured and used to determine the thickness of both layers (Figure 36). This technique requires significant precision to measure the pulse's short time of flight from the thin coating layer $(50-500$ microns $[\mu \mathrm{m}])$ and is relatively new to the commercial market.

Figure 36. Ultrasonic Pulse-Echo for coating thickness measurement.

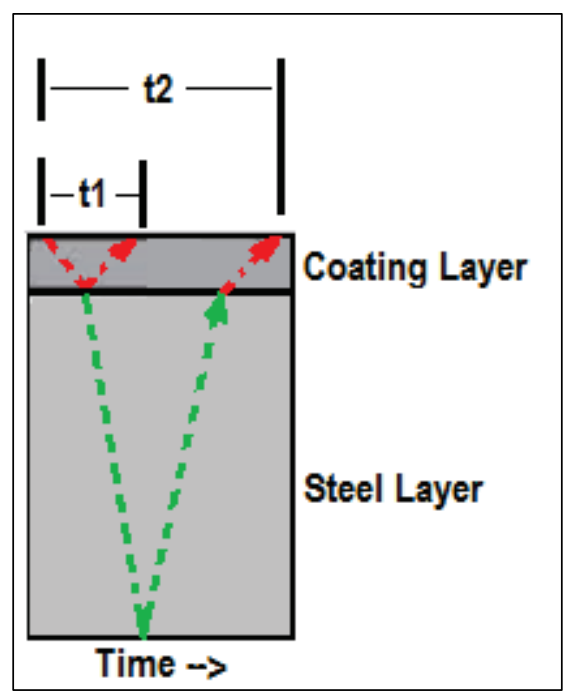

\subsubsection{Low-Coherence Interferometry sensor}

Low-Coherence Interferometry, also known as white light or optical interferometry, uses broadband light for illumination. The profiler splits a single source light into two paths, directing one beam to a sample surface and the other to a reference mirror. Light signals returning from the sample and reference path are recombined, causing a pattern of signal interference that is recorded in the form of an interferogram (Figure 37). The profiler software optically separates and analyzes the interferogram peaks. It uses each material's index of refraction to calculate the layer thickness. If desired, the upper and lower surfaces of each substrate can also be characterized and imaged and their roughness calculated (Novacam Technologies Inc. 2011). The Low Coherence Interferometry sensor requires no surface contact and can measure coating thickness at a 
high frequency while moving over a surface. The sensor has been tested in submerged environments under low turbidity.

Figure 37. Physical principle of Low-Coherence Interferometry (Novacam Technologies Inc. 2011).

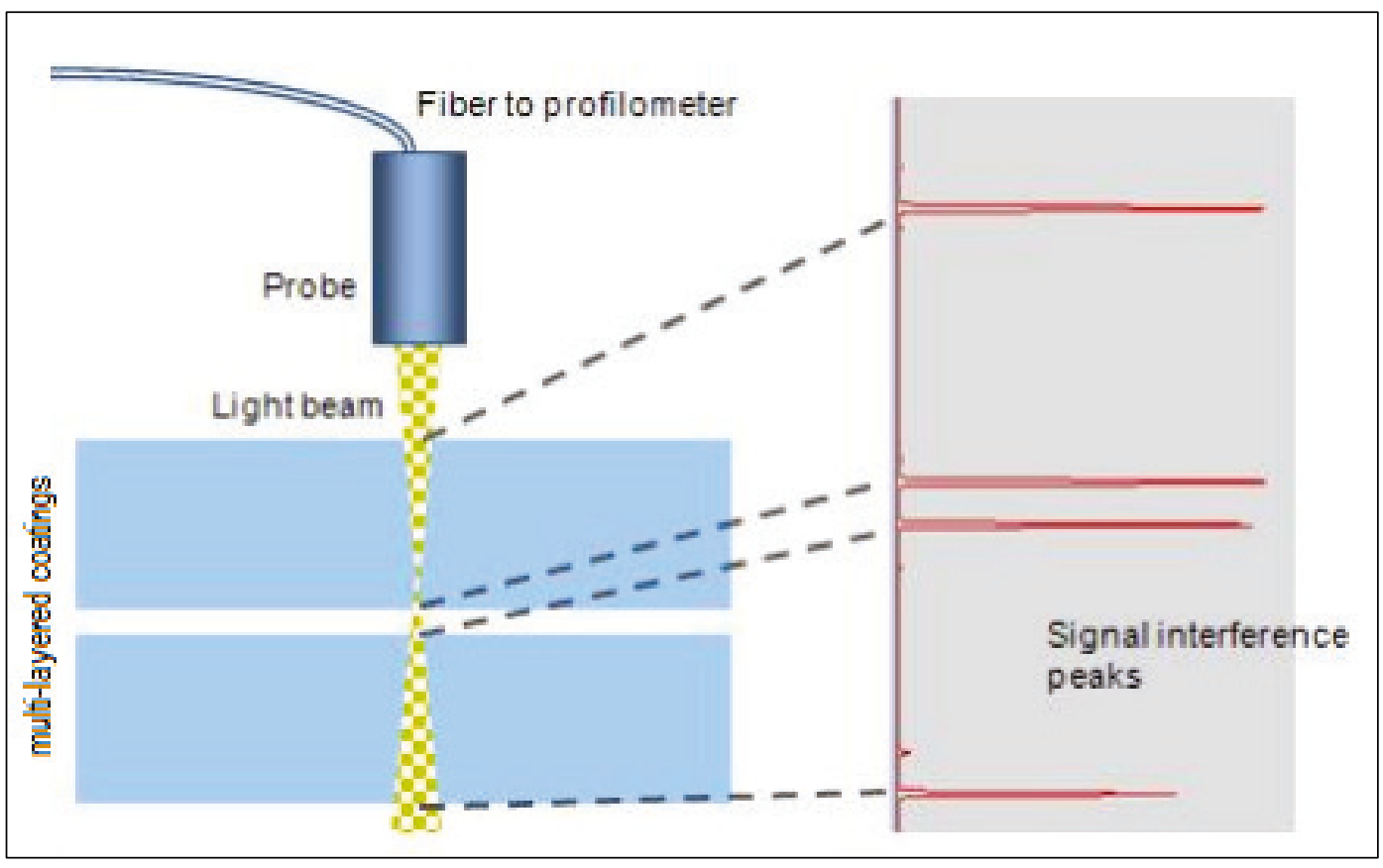

\subsubsection{Magnetic Pull-Off gage}

Magnetic Pull-Off gages use a permanent magnet, a calibrated spring, and a graduated scale to measure the attraction between the magnet and a steel test plate. As the coating thickness separating the two increases, it becomes easier to pull the magnet away. Coating thickness is determined by measuring this pull-off force. Thinner coatings will have stronger magnetic attraction while thicker films will have comparatively less magnetic attraction. Testing with Magnetic Pull-Off gages is sensitive to surface roughness, curvature, substrate thickness, and the makeup of the metal alloy. Magnetic Pull-Off gages are rugged, simple, inexpensive, portable, and usually do not require any calibration adjustment. They are a good, low-cost alternative in situations where quality goals require only a few readings during production. Magnetic Pull-Off gages are typically pencil-type or rollback dial models (Figure 38). Pencil-type models use a magnet that is mounted to a helical spring that works perpendicularly to the coated surface. Most pencil-type Magnetic Pull-Off gages have large magnets and are designed to work in only one or two positions, which partially compensate for gravity. A more accurate version is available, 
which has a tiny, precise magnet to measure on small, hot, or hard-toreach surfaces. A triple indicator ensures accurate measurements when the gage is pointed down, up, or horizontally with a tolerance of $\pm 10 \%$ (Beamish 2015).

Figure 38. Magnetic Pull-Off type gage.

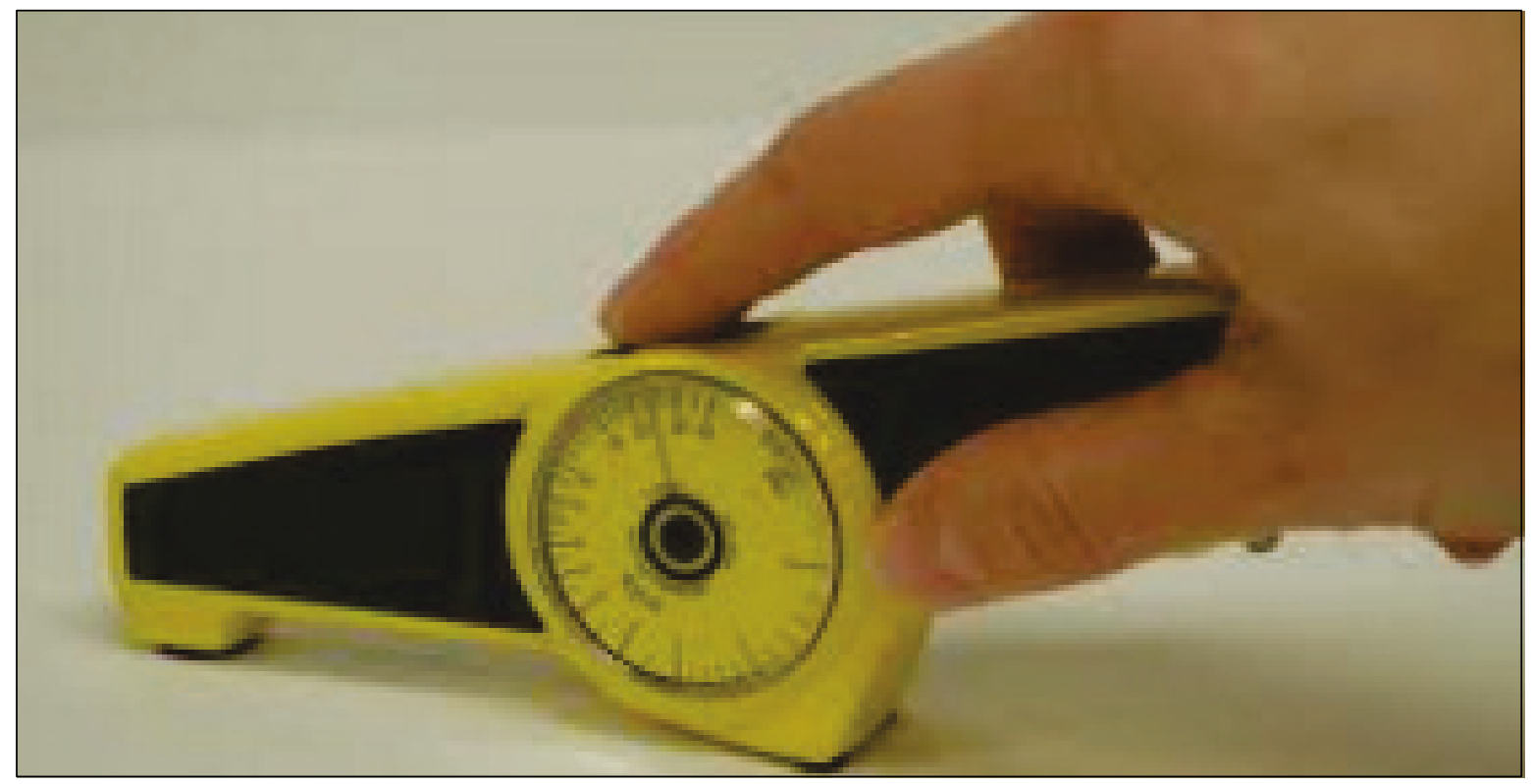

\subsection{Ultrasonic Pulse-Echo sensor design}

Of the four existing technologies for anti-corrosion thickness assessment of non-metallic coatings on metal substrates investigated, only two (Ultrasonic Pulse-Echo sensor and the Low-Coherence Interferometry sensor) do not require direct contact with the substrate. Ultimately, the Ultrasonic Pulse-Echo sensor was considered to be most appropriate for the above- and below-water conditions and the even harsher splash zone where material loss due to corrosion is known to be greatest.

A sensor system was designed to determine the thickness of an anticorrosion coating on a metal substrate. This system includes an array of piezo elements for emitting an ultrasonic signal into the coating and an array of piezo elements capable of receiving the returned signal (Figure 39). The system is mounted on a moving platform capable of operating above and below the water surface. The transmitting and receiving elements must be in close proximity to the structure to operate properly, yet far away enough to avoid protruding objects such as rivets, bolts, etc. A protrusion detection sensor should be developed in the future. 
Figure 39. Overview of the coating thickness measurement system.

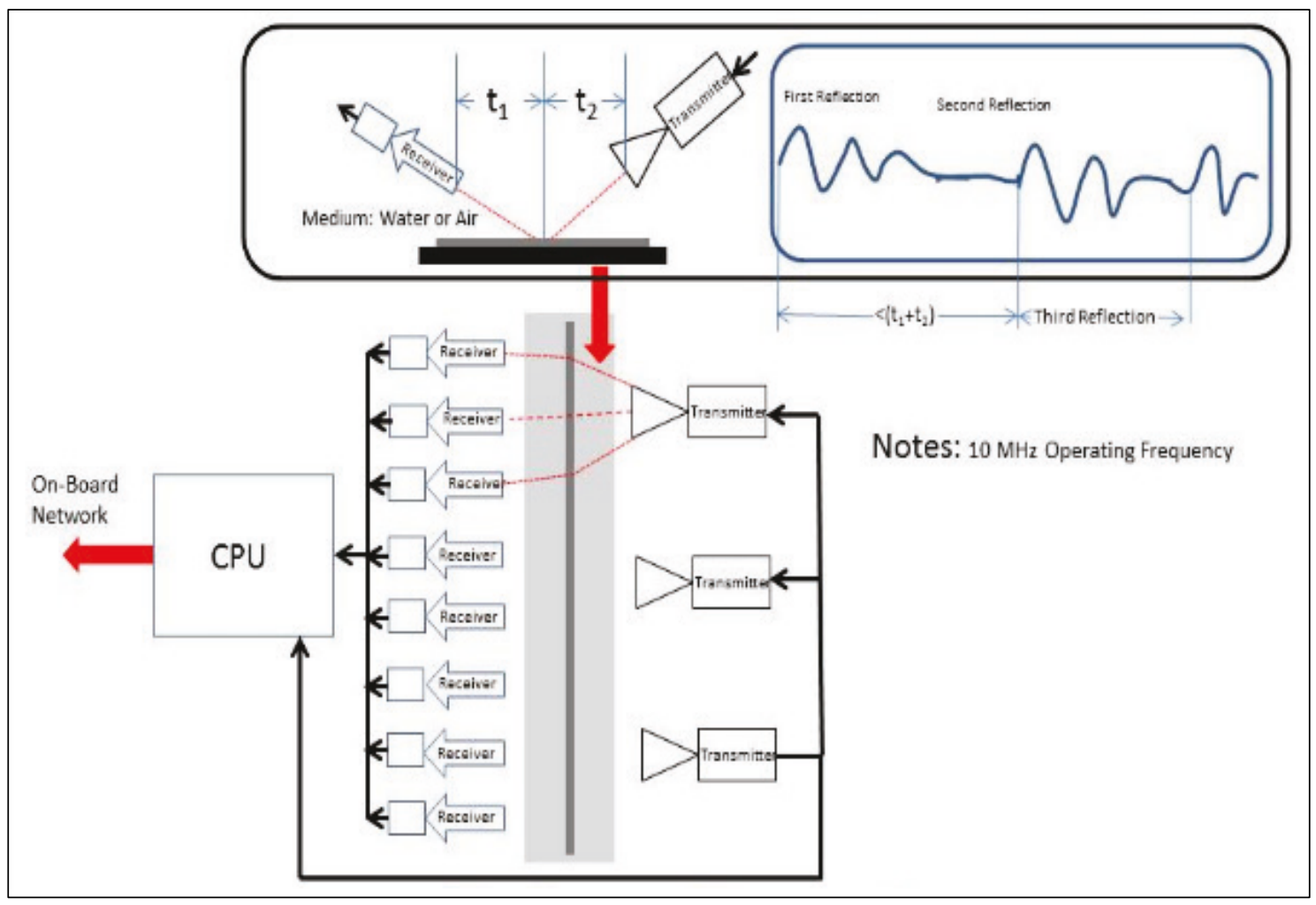

For ultrasonic coating thickness measurement, a high-frequency ultrasonic pulse is generated by the pulse echo system. A portion of the signal reflects off the coating, and a fraction penetrates the coating and is reflected off the coating/steel-structure interface. The thickness measurement is then based upon the time difference between return waveform, as shown in Figure 40. Because the coating is very thin, a very short pulse is required to avoid blanking-out the initial pulse. To assure the separation of the front and back of the coating, a 10 megahertz $(\mathrm{MHz})$ target frequency was chosen for the initial design of the ultrasonic scanning system. Ultimately, it may turn out that a higher frequency (shorter pulse) is required due to variations in the coating thicknesses. 
Figure 40. Received voltage from piezo-film versus time shows echo response.

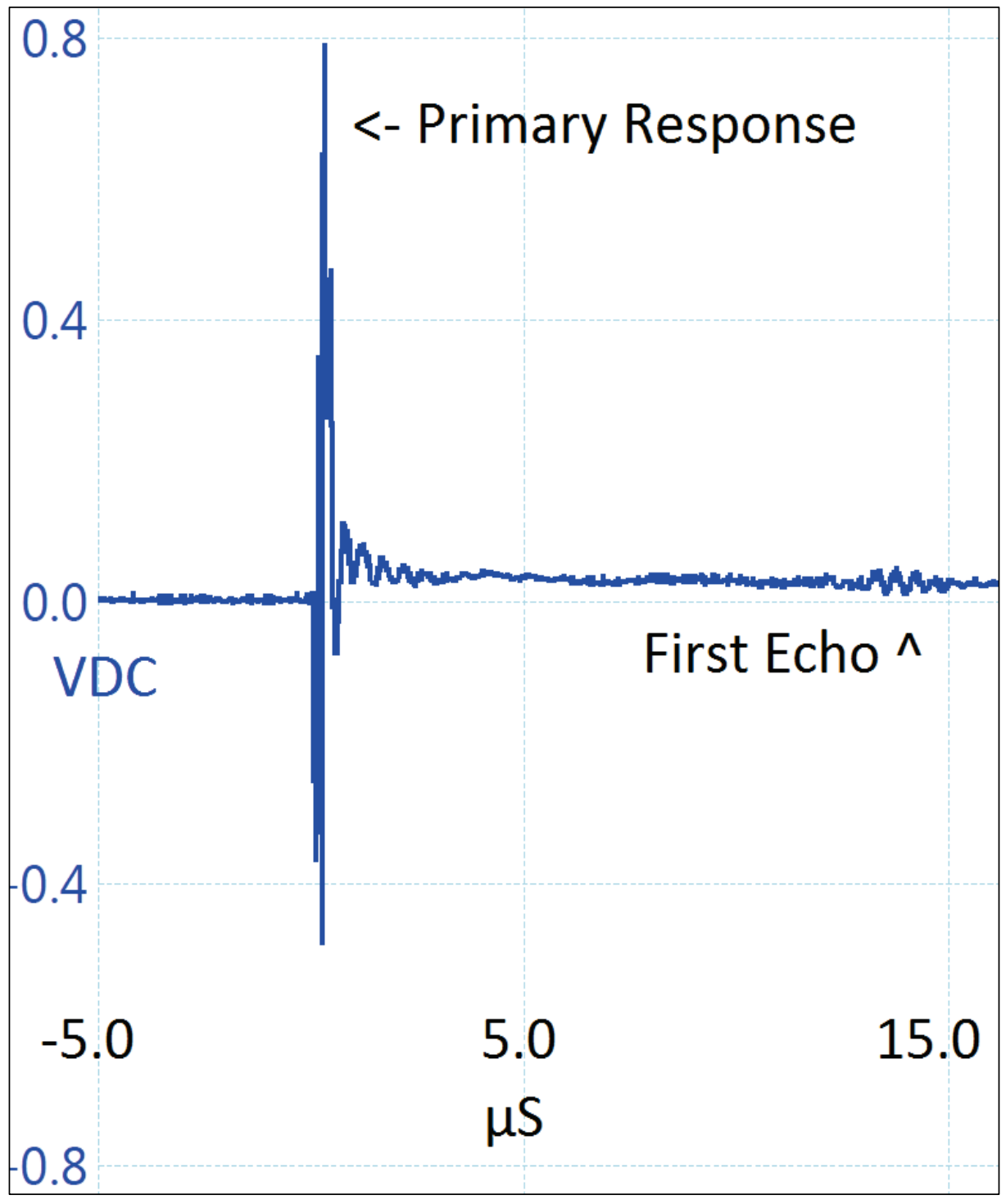




\section{Development of Automated Mobile Sensor Inspection Platform}

As defined in Table 2, the semi-automated inspection platform must have the ability to maneuver over vertical steel walls. The ability to climb steel walls above and below water requires wheels or tracks with embedded magnets. The original drive wheel design employed in this inspection platform was based on the Navy's Multi-Segmented Magnetic Robot, developed specifically for ship hull inspection.

\subsection{Mobile Sensor Inspection Platform design}

\subsubsection{Initial MFL robot platform design}

The mechanical design of the mobile platform (magnetic crawler) has changed significantly over the course of the project based on need requirements. The initial test platform (Figure 41) was designed primarily for laboratory use (dry) and on relatively smooth and near-horizontal surfaces. The payload of this initial design was minimal ( $2 \mathrm{lb})$ since the magnetic flux sensor package was miniaturized. Additionally, the linear inspection area was limited to approximately 2 in., and it was only able to inspect relatively thin steel plate ranging from one-eighth to one-quarter in. The primary purpose of this platform was for testing various magnetic flux IC sensors.

Figure 41. Initial MFL robotic crawler test platform (dimensions: 9 in. wide, $11 \mathrm{in.} \mathrm{long,} \mathrm{and}$ 5 in. tall).

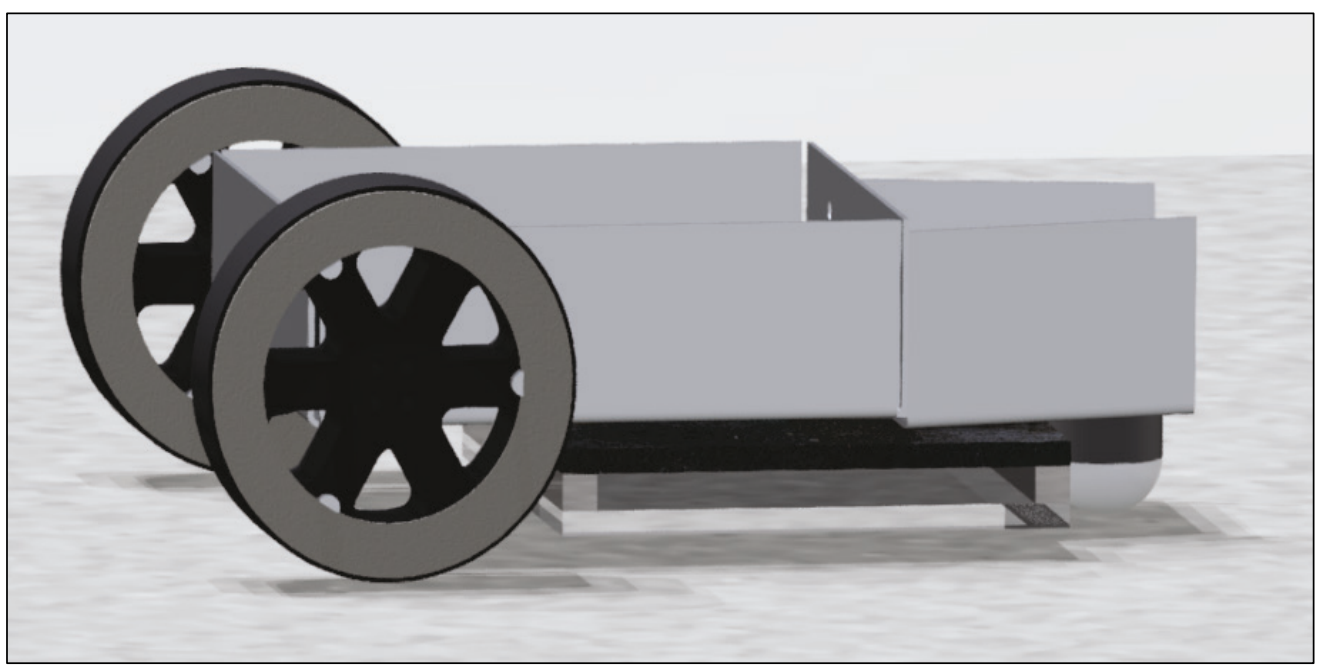




\subsubsection{Second MFL robot platform design}

In the second mobile platform design (Figure 42), an arched and hinged rear appendage was added. This crawler operated on both horizontal and vertical walls. As in the initial design, the payload was minimal ( $\sim 2 \mathrm{lb})$ as it was designed primarily for the purpose of testing various magnetic wheel designs and navigating 90 deg angles and sharp radial turns.

Figure 42. Second MFL test platform.

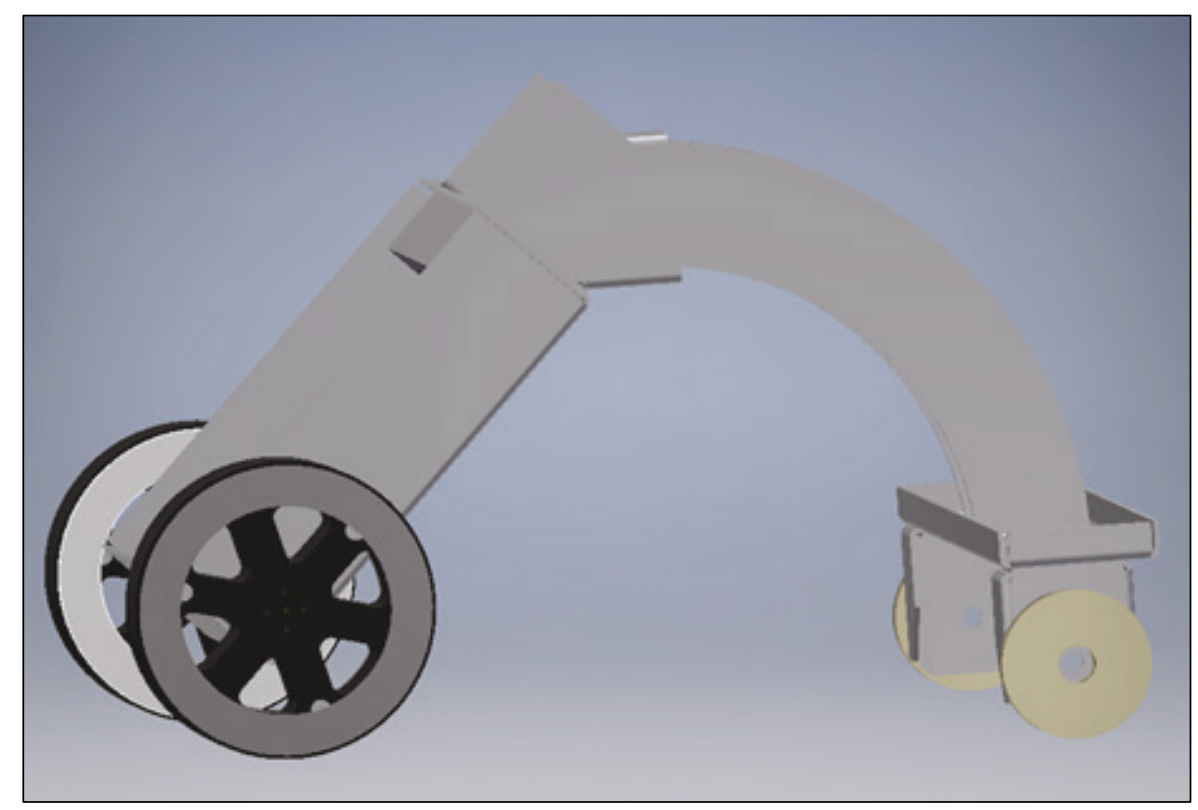

A magnetic crawler prototype of this second MFL test platform was built to test functionality of physical design concepts. With a modular design, it is capable of accepting future attachments and accepting changes to the body of the vehicle. The primary goal was to test the magnetic wheel designs, maneuverability, and control software. The crawler was designed with the ability to transition walls with up to a $90 \mathrm{deg}$ angle via the angled design of the drive section and tail section. Significant ground clearance allows the crawler to move over obstacles without bottoming out. Additionally, the arch of the tail permits the rear axle to be farther away from the drive wheels while still maintaining clearance.

The crawler's on-board electronics control system is detailed in Figure 43. The crawler presently operates on a lithium polymer battery supply and communicates with the operator via $\mathrm{Wi}$-Fi; however, a future submersible design may include a tether for inspection data transmission to the remote operator. 
Figure 43. Electrical component layout for inspection platform.

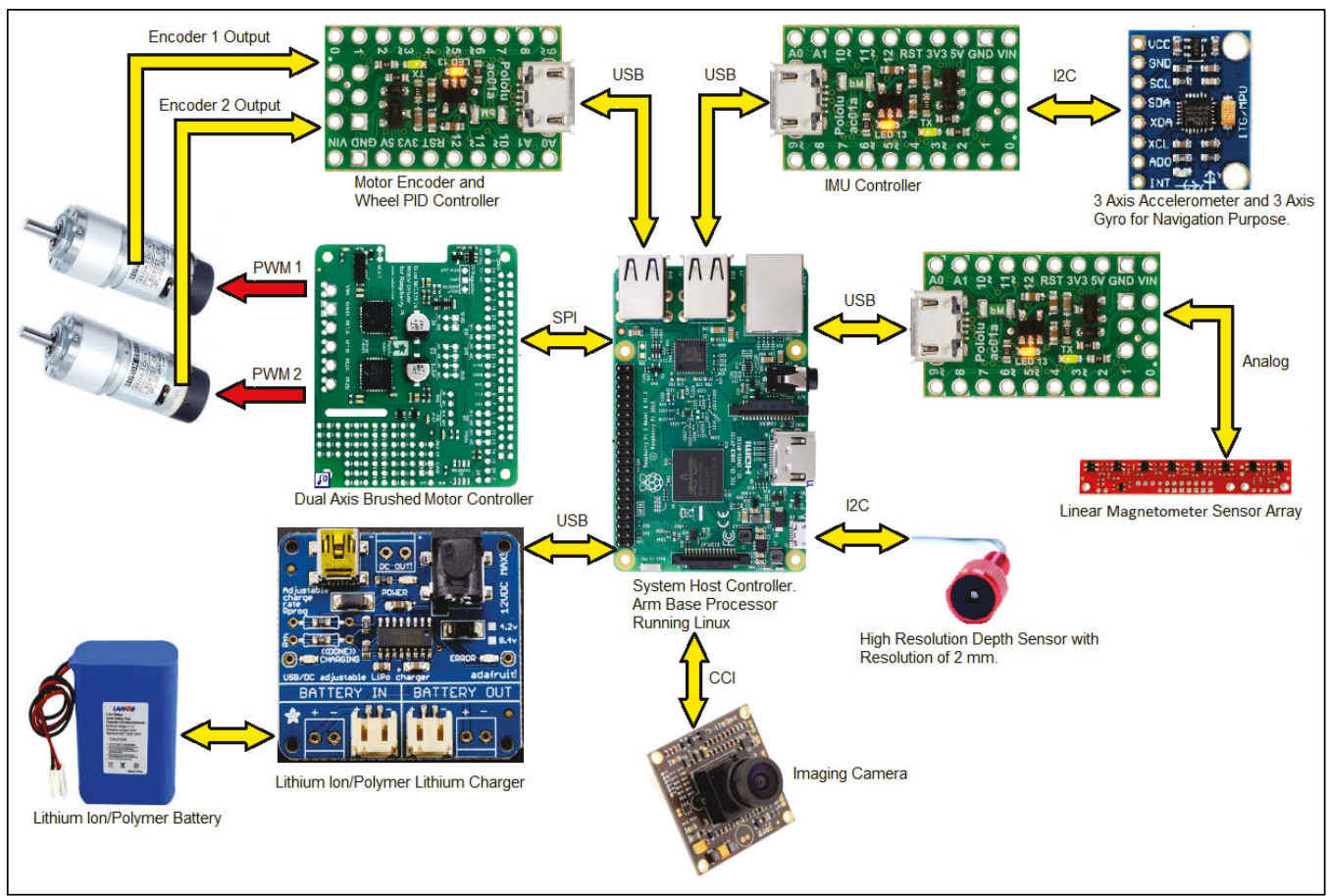

One of the primary objectives of this design is to enable the ability to autonomously follow an inspection path plan. To achieve this goal, several sensors are integrated into the control system, including a 6-axis inertial measurement unit, a depth sensor with $2 \mathrm{~mm}$ resolution, and a camera with on-board image processing capability. A concept drawing of the magnetic crawler inspecting a steel structure is show in Figure 44.

Figure 44. Concept drawing of inspection crawler in action.

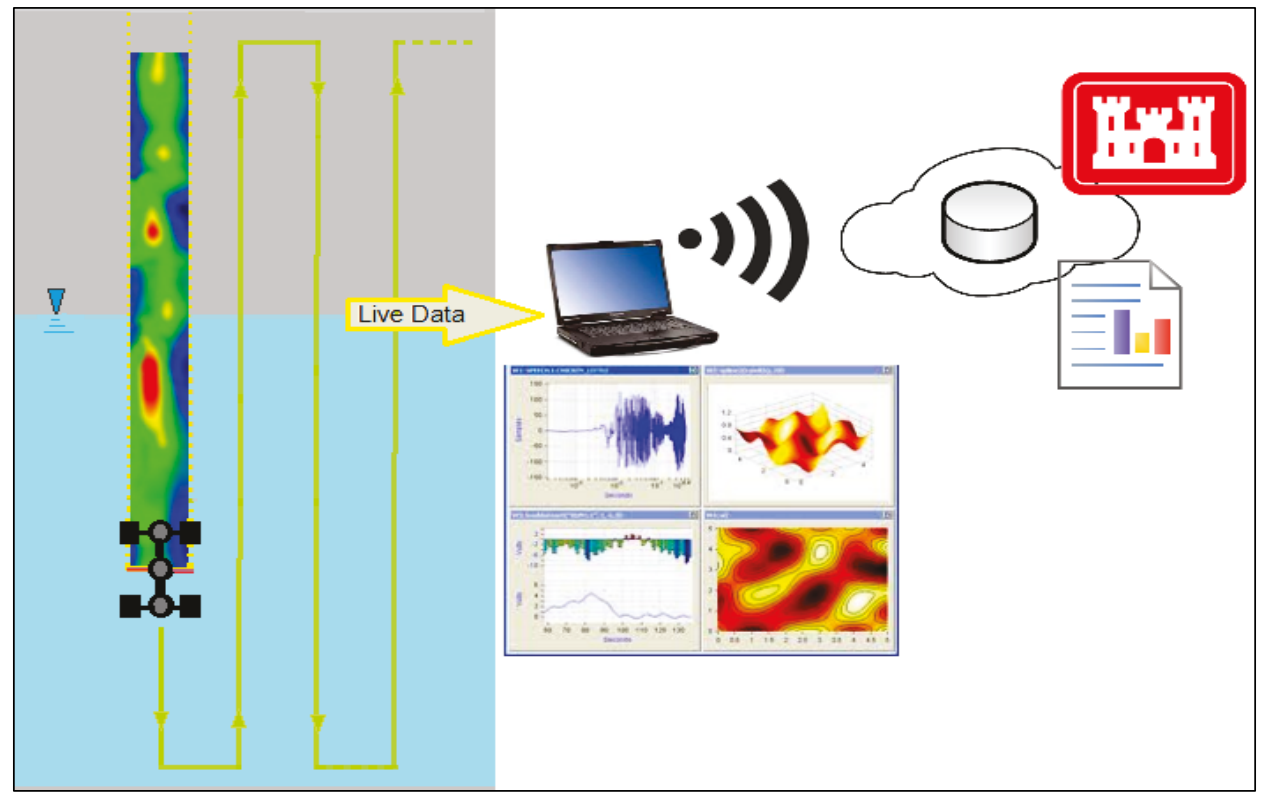


The prototype version of the magnetic crawler was successfully tested on a steel wall as shown in Figure 45. The prototype underwent a design change to include a second drive module to increase the maneuverability of the crawler. This change not only added the ability to climb from vertical walls up to a flat surface but also improved the crawler ability to hold position. The second drive module will also allow the crawler to operate in a bidirectional mode, thus eliminating the need of turning around to perform the next scan.

Figure 45. Magnetic crawler test steel wall platform.

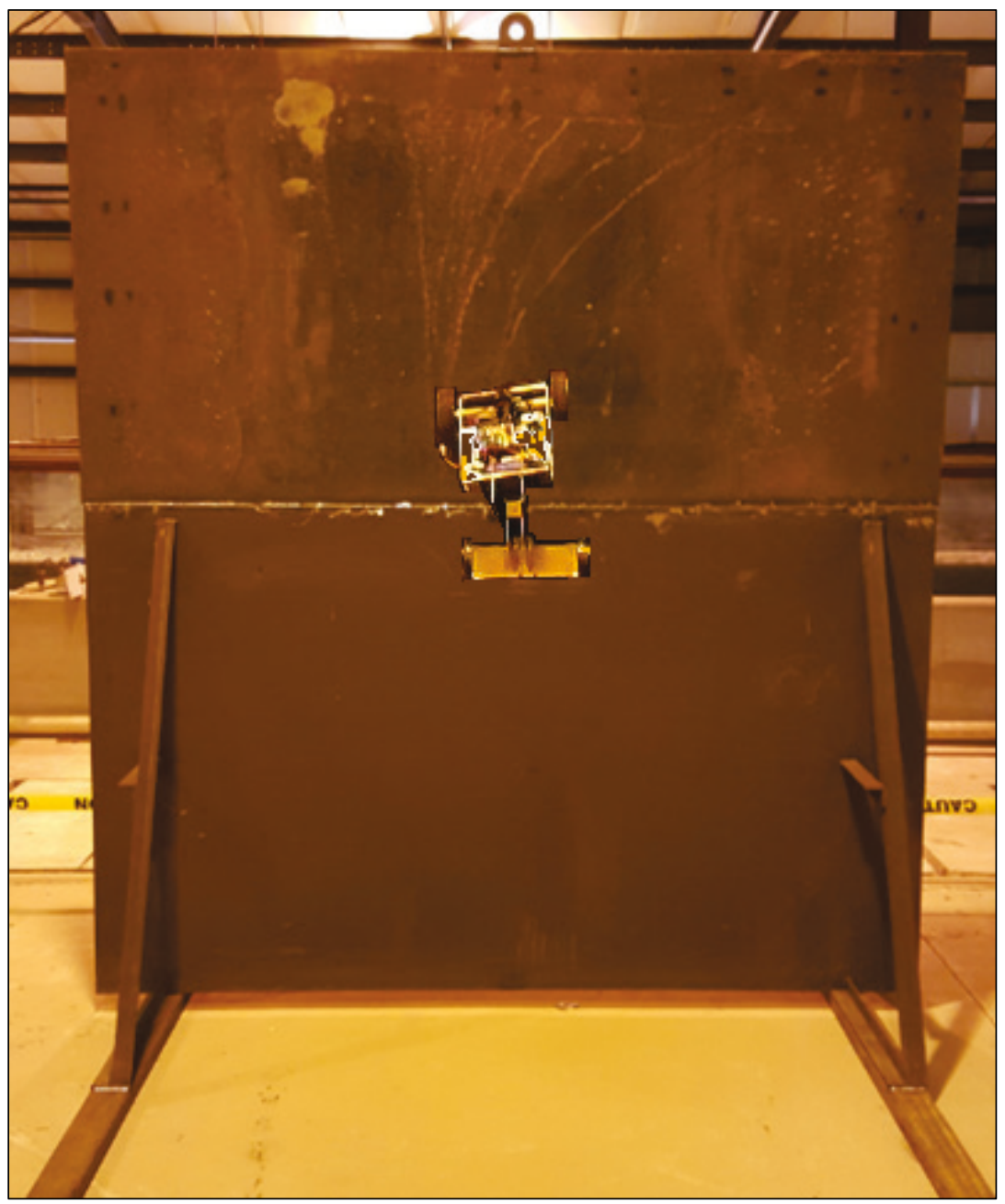

\subsubsection{MFL robot platform design}

The present mobile platform design (Figures 46) incorporates the latest MFL sensor package and the latest magnetic wheel design but is capable of operating only above water. The waterproofed design (Figure 47) is discussed in Section 4.4. Additionally, the payload of this platform 
increased to approximately $50 \mathrm{lb}$, and the linear inspection area of the MFL sensor package increased to approximately 6 in. This mobile platform was designed to operate primarily on inclined and flat surfaces such as the case of the upstream-side of the miter gate. The primary obstacle on the upstream-side of the miter gate is the rivet; therefore, the floor clearance of this design is set at $0.5 \mathrm{in}$. The floor clearance of the mobile platform can be increased while maintaining near $100 \%$ substrate saturation for steel plate thickness of 0.5 in. or less.

Figure 46. Prototype of present MFL magnetic crawler large test platform used to collect data from the laboratory test bed above water. This version is not waterproofed and is not capable of being submerged (dimensions: 18 in. wide, 21 in. long, and 7 in. tall).

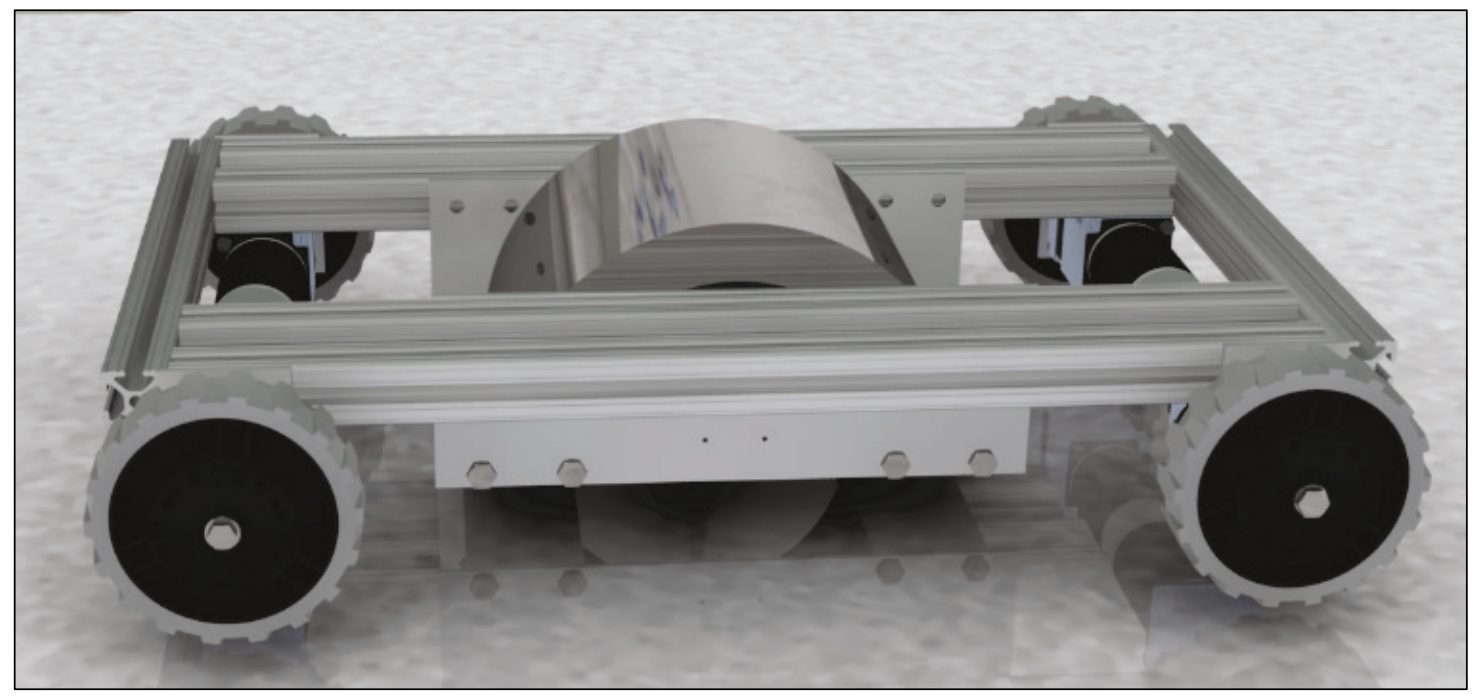

Figure 47. Present MFL magnetic crawler test platform capable of being submerged, showing the waterproof housing around the motors (dimensions: 14 in. wide, 22 in. long, and 8 in. tall).

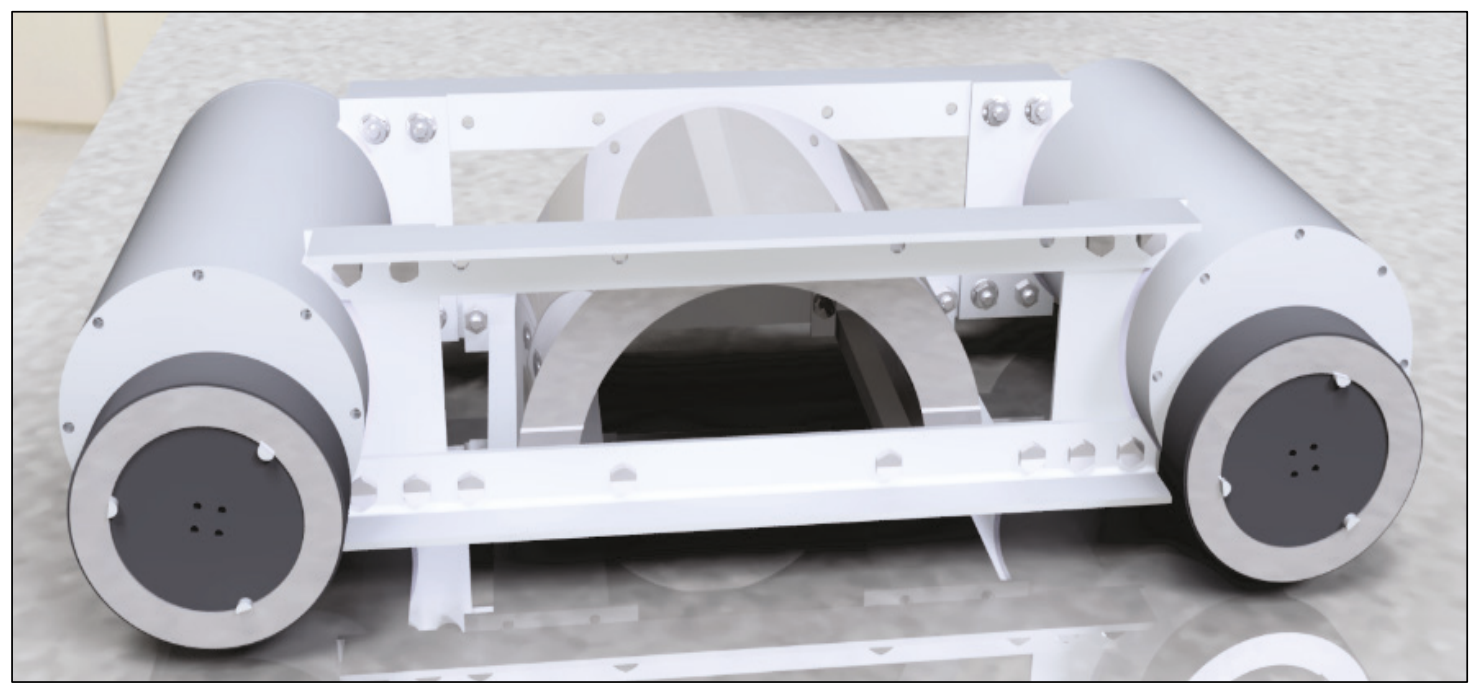


In Figure 48, the prototype platform of the present design is shown navigating the test structure vertically while collecting MFL data.

Figure 48. Prototype of present design climbing vertical wall.

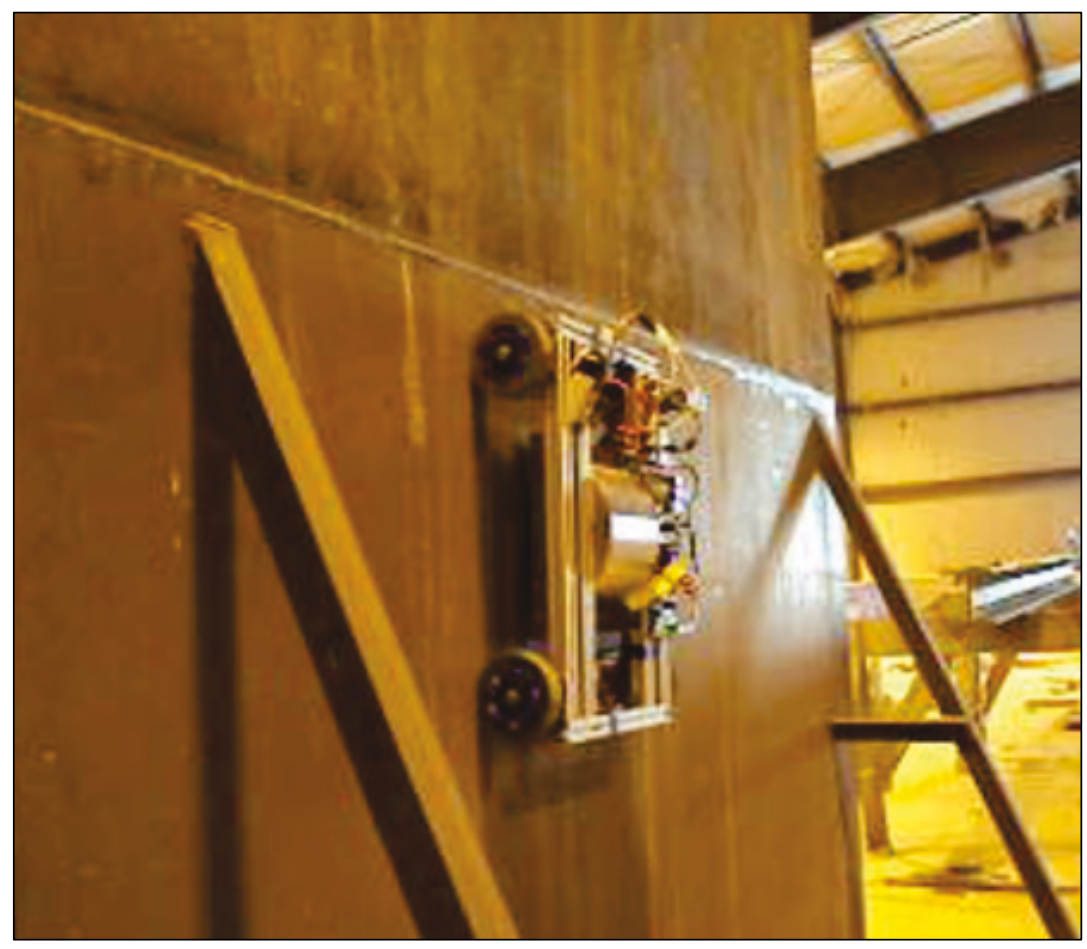

\subsection{Mobile platform wheel design}

The magnetic wheel is made up of three main components: (1) magnets, (2) flux plates, and (3) elastomer. Each of the two drive wheels is capable of holding the full weight of the crawler on a clean vertical wall.

\subsubsection{Initial magnetic wheel design}

Figure 49 shows the initial magnetic wheel design, with one flux plate removed. Magnets used in the wheels were neodymium rare earth magnets of N52 rating. Each magnet was 1 in. long with a one-quarter in. diameter. They are axially magnetized (each end is a pole) and are assembled into the elastomer with all north poles facing the same direction. The flux plates are steel rings attached to each end of the magnets. Not only do they help keep the magnets in place but they combine the magnetic field of all the magnets to increase the pull force of the wheel. Changing the geometries of the flux-plates is a simple way to increase or decrease the pull force of the wheel. The elastomer is a 1 in. thick piece of rubber with a Durometer hardness of $40 \mathrm{~A}$ and is the main 
part of the wheel. It holds all the components in place but is not rigid. It allows for the wheel to flex and gain more surface area on steel plates to improve traction.

Figure 49. Magnetic crawler drive wheel with a flux plate removed.

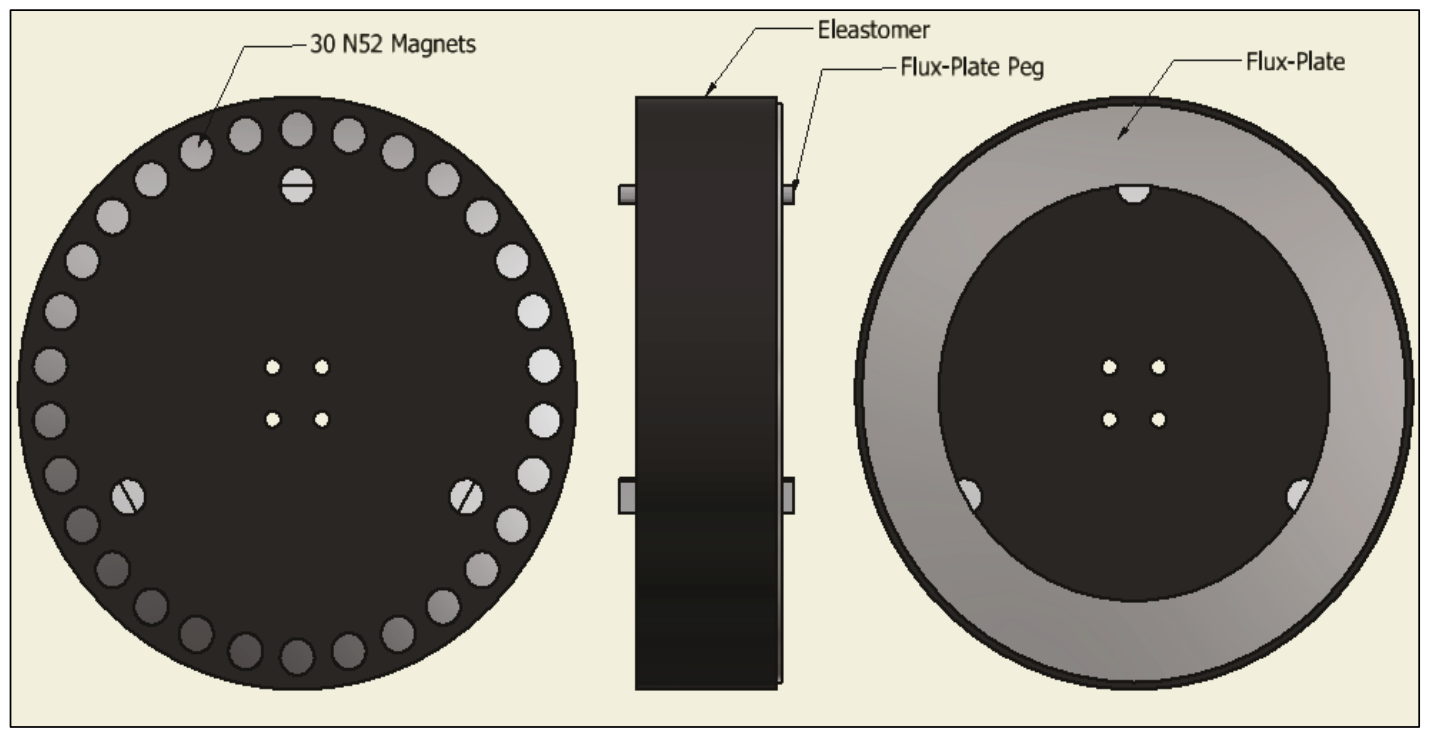

This wheel design proved to be relatively expensive and lacked sufficient robustness. The bulk of the expense of the wheel can be attributed to the cost of the raw materials and custom machining requirements. These wheels also lacked a solid hub and therefore could not handle torque requirements from the larger motors and gearboxes of the new higher payload design.

\subsubsection{Present magnetic wheel design}

The present magnetic wheel design (Figure 50) is a modified version of a commercially available off-the-shelf product. The commercially available components were modified by inserting magnets and reinforcing material inside the wheel as seen in Figure 50. With this modification, sufficient robustness was attained. No conventional machining is required for the wheel to be fitted with magnets, and all parts snap into place with the force of the magnets and without the use of adhesives or fasteners. The structural wheel inserts are $3 \mathrm{D}$ printed using an $\mathrm{ABS}^{1}$ material. Furthermore, the inserts do not require a tight tolerance nor do they require large quantities of material to print. The new wheel design is lower cost, easy to assemble, and available in various input shaft sizes and

${ }^{1} \mathrm{ABS}=$ acrylonitrile butadiene styrene 
durometers. The original magnets and flux plates were re-used in the new wheel design. Figure 51 shows the present Mobile Sensor Inspection Platform fitted with the present magnetic wheel design.

Figure 50. Present magnetic wheel design.

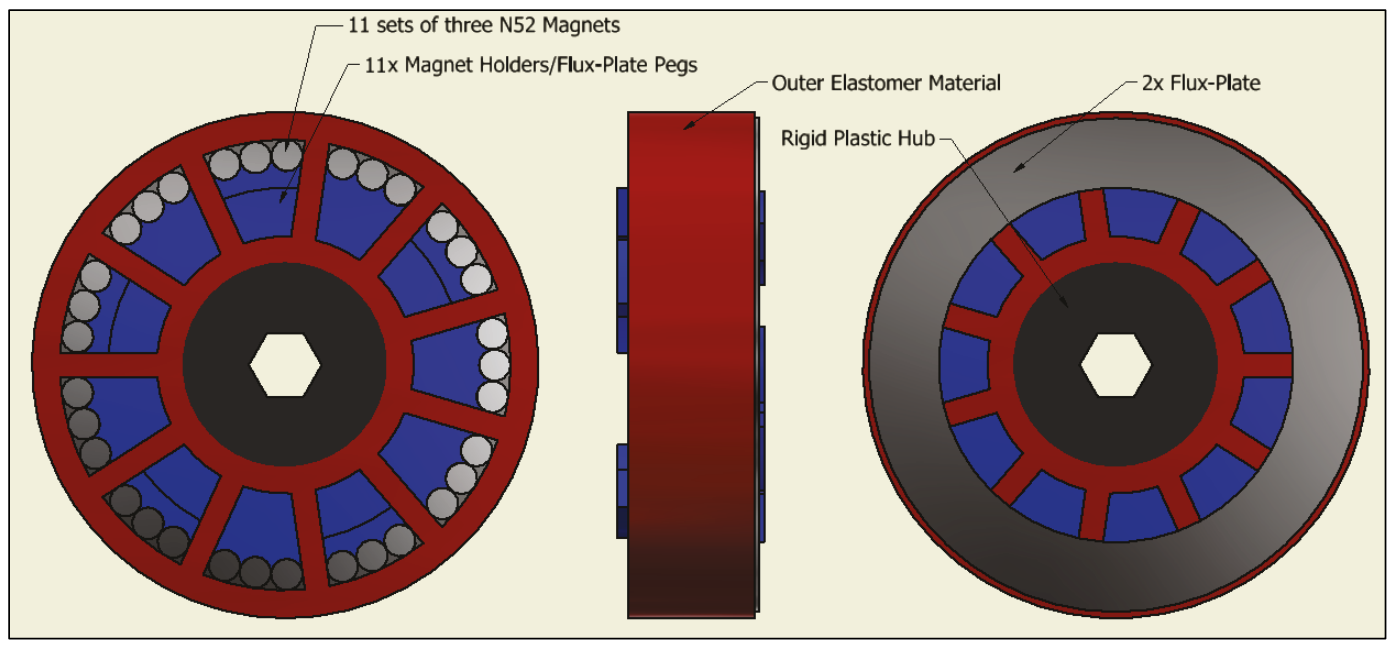

Figure 51. Prototype of present MFL test platform with present magnetic wheel design.

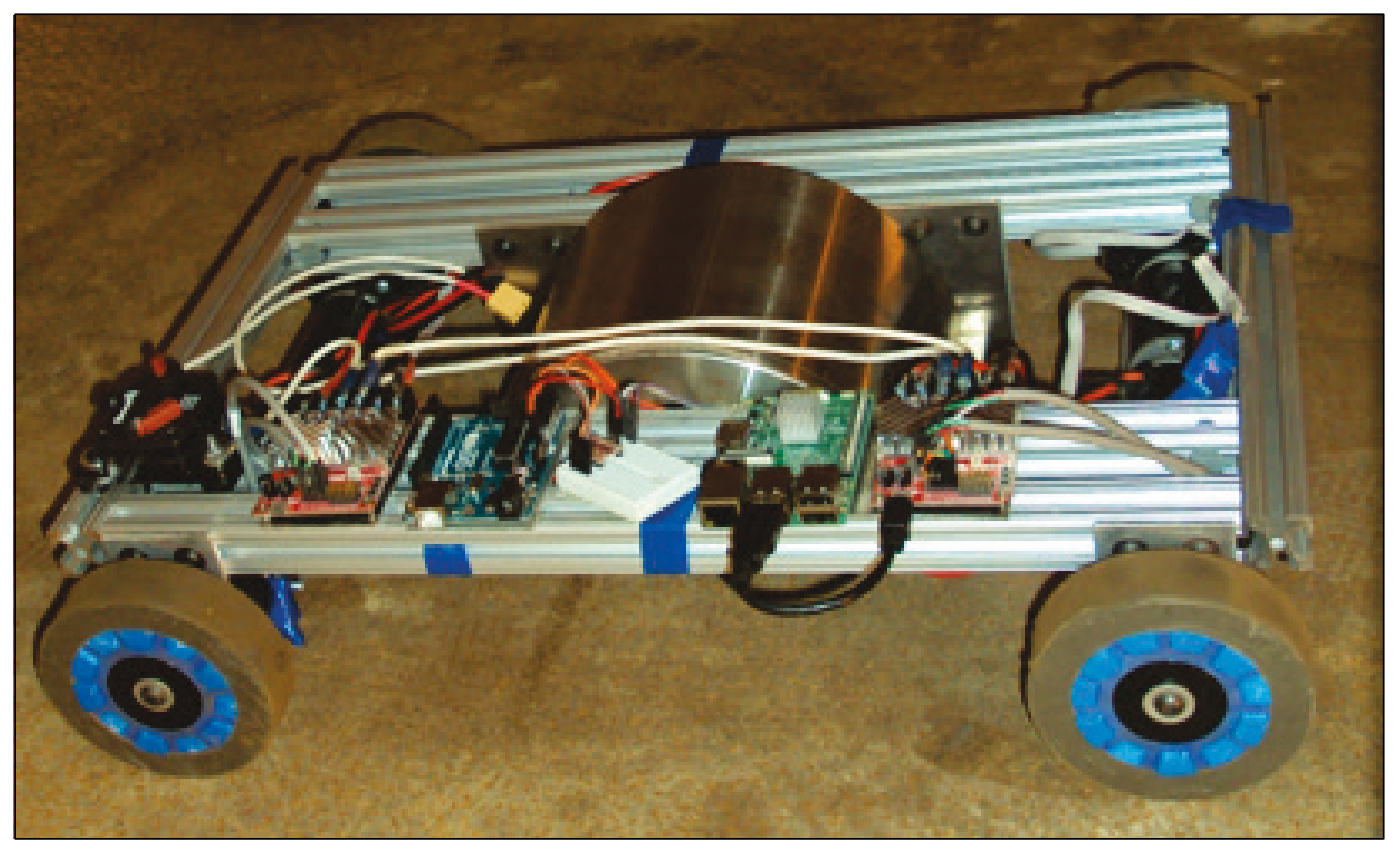

\subsection{Lateral motion of the Mobile Sensor Inspection Platform}

Attempts to reposition the inspection platform on non-vertical surfaces through skid steering has proven to be difficult due to the fact that a magnetometer (compass) cannot be employed Additionally, skid steering does not allow for the horizontal position of the crawler to be measured 
accurately through the wheel encoders due to irregular slippage when turning. Consequently, other methods of horizontal movement were investigated.

\subsubsection{Mecanum wheels}

Non-magnetic Mecanum-type wheels were tested on the prototype crawler platform, Figure 52. With a pull force of over $100 \mathrm{lb}$ from the magnetic flux leakage device, non-magnetic wheels with a coefficient of friction of 0.45 or greater allow for vertical climbing on the test structure. Through laboratory testing, $60 \mathrm{~A}$ rubber on the steel test plates was found to have a coefficient of static friction of nearly 0.55 on a clean dry specimen. The coefficient of friction of Mecanum wheels are reduced due to the rollers on the wheels. These rollers give the wheels their unique characteristic of lateral motion but reduce the friction force by $30 \%$. This reduces the coefficient of friction of the Mecanum wheels down to 0.39 on a clean smooth steel surface. The rollers simply have too great of an adverse effect on the coefficient of friction. When tested on a clean smooth steel surface, the Mecanum wheels experienced slippage.

Figure 52. Prototype of present MFL test platform with non-magnetic Mecanum-type wheels to investigate horizontal moves.

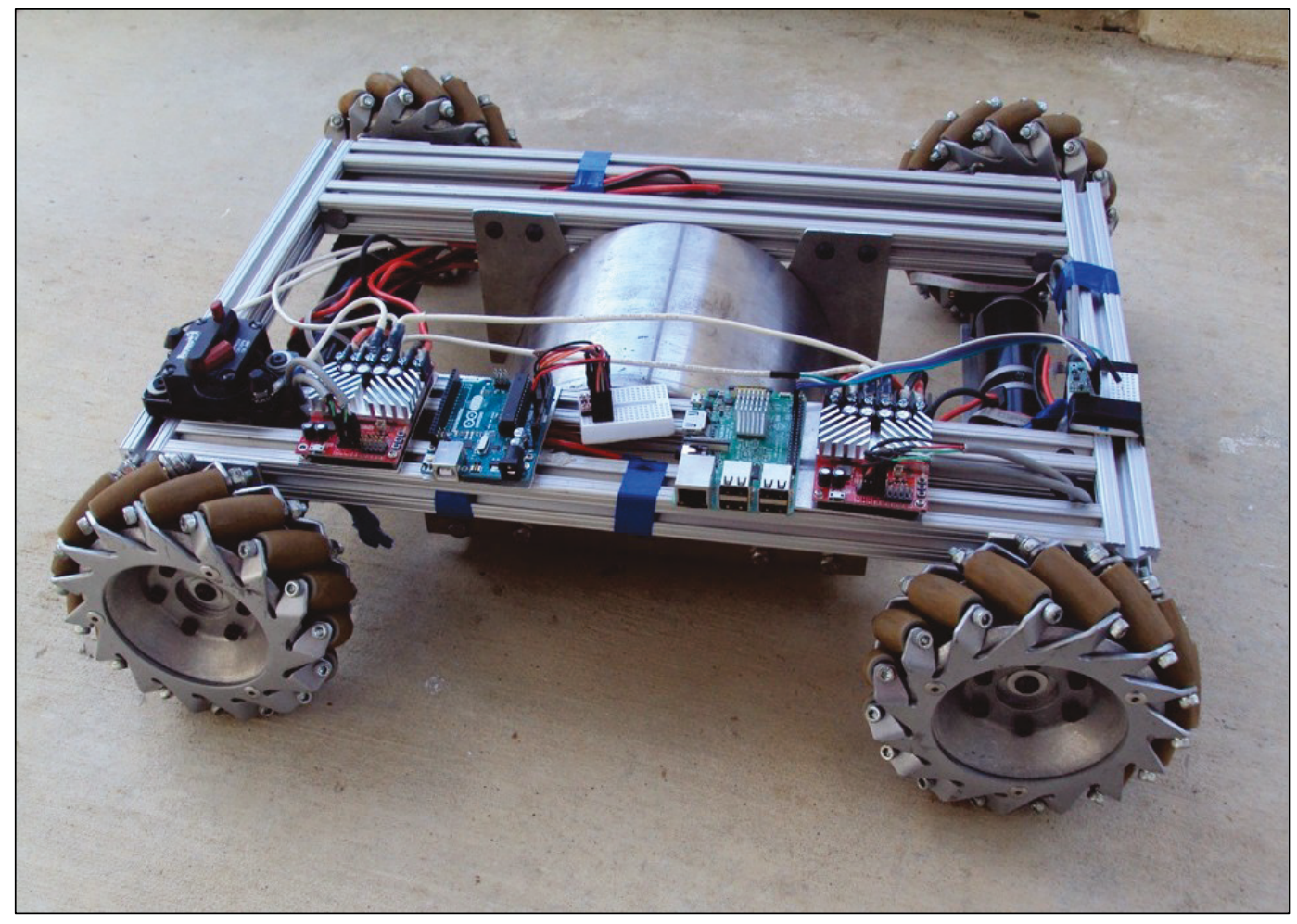




\subsubsection{Expanding wheel concept}

To maximize platform positional accuracy and simplify control software, the platform should be capable of executing lateral moves. Other commercial research-and-development groups have come to the same conclusion, and some are turning to a complete second drive system to move magnetic crawlers laterally. Using the existing drive motors, an expanding wheel design is proposed (Figure 53), that will be placed perpendicular to the magnetic forward moving wheels. These expanding wheels can be forced open to lift the forward moving wheels and allow for lateral movement. With the expected mechanical advantage gained by the expanding wheel design, minimum effort would be required to lift the crawler from the magnetic surface. As little as 62 ounce-inches of torque per wheel is theorized to be adequate to lift the crawler from a steel surface.

Figure 53. Computer-aided drawing of an expanding wheel shown compressed and expanded.

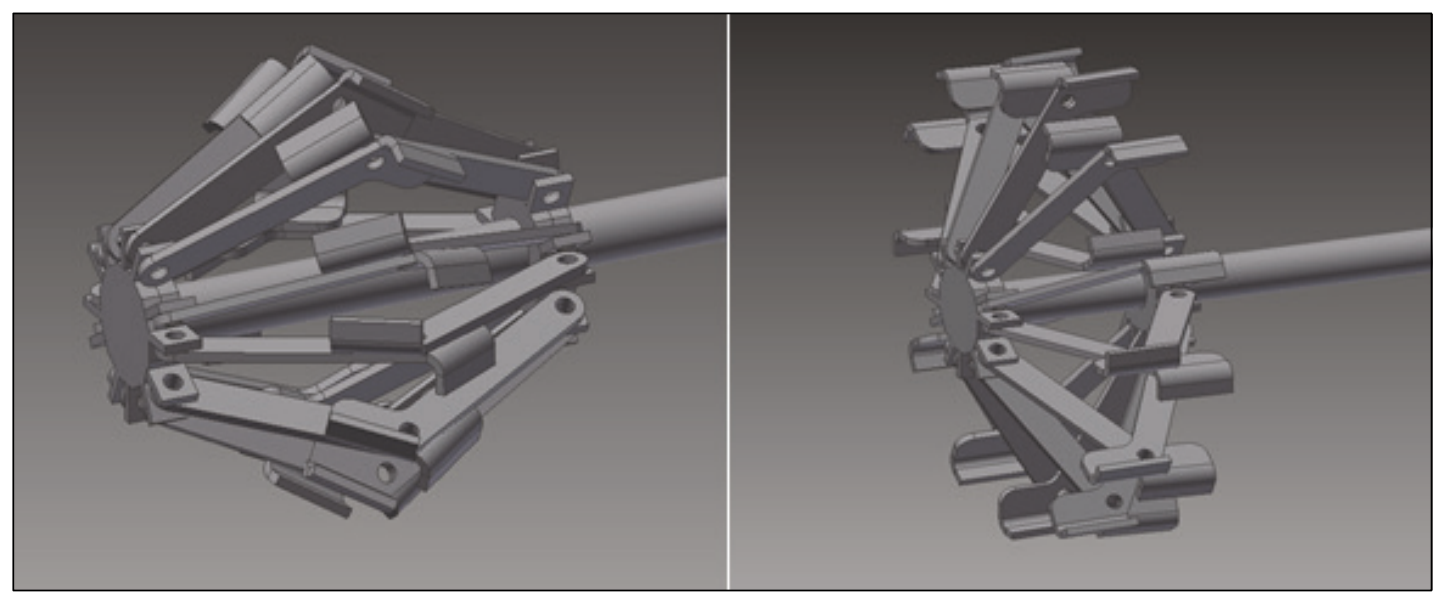

\subsubsection{Mobile Sensor Inspection Platform water sealing}

Water sealing of the Mobile Sensor Inspection Platform has been a major consideration from the start of this project; therefore, water sealing techniques have been studied and tested. In this effort, a sealed underwater camera was developed (Part 6) and tested at operational depths in the range of the magnetic crawler. Lessons learned and techniques employed from this endeavor have been applied to the design of the water sealing of the Mobile Sensor Inspection Platform.

The present waterproof design incorporates a segmented design, separating the crawler into its individual sub-systems with each being encapsulated in a watertight apparatus. Dividing the platform into multiple sub-sections prevents a total loss of hardware should leakage 
occur and allows the sub-sections to be affordably produced. Each section communicates to the next through impermeable disconnects for fast dismantling and repair.

Motors and motor controllers are mounted in the two drive sections located at both ends of the platform. These sections are built from extruded aluminum tubing with one-quarter in. wall thickness. This thick material provides protection from potential impacts with miter gate features and acts as a support member in the frame. Ends of the aluminum tubes are sealed with end caps incorporating two O-rings. The O-rings seal against the extruded aluminum tubes' interior surface. In addition, the end caps house double-lip shaft seals that provide a watertight passage for the gear boxes to connect to the wheels.

Microcontrollers and sensors for navigation, including the camera, are located between the front-motor section and magnetic-flux-bridge. All these units are mounted in one central position to allow easy connection to one another, reducing the number of penetration points on the enclosure thus reducing the likely hood of failure. This section is built from cast polycarbonate allowing the camera to view the steel structure through the enclosure. It is protected from impacts with the structure by both the front motor section and the flux bridge.

The battery compartment is stationed between the magnetic flux bridge and the rear motor enclosure. It houses a charging circuit and a distribution board to provide power to all the other sections. It also is built from cast polycarbonate because of its protected position and low cost of fabrication.

\subsection{Mobile Sensor Inspection Platform control and navigation}

Since river water is often turbid, it is not feasible to rely on a top-side operator to remotely control the submerged mobile platform during the inspection process. Therefore, one important mobile platform operational goal was the ability to semi-autonomously navigate the miter gate during the corrosion inspection process. In essence, this translates to the ability to follow a pre-planned inspection path and the ability to make path corrections as necessary. Path corrections may be due to, for example, wheel slippage or substrate irregularities. The semi-autonomous component here refers to the human operator (supervisor) having the ability to alter or interrupt the inspection plan as needed. 
Navigation of land based autonomous vehicles is typically accomplished using Global Positioning System waypoints and a proportional-integralderivative (PID) controller loop to maintain heading and position. However, navigating underwater and on vertical surfaces requires a different approach. An underwater remotely operated vehicle (ROV) traversing a 3D path often employs acoustic triangulation technologies to maintain 3D positional control; however, in the case of navigating the vertical face of the miter gate, a simplified approach can be employed since only $2 \mathrm{D}$ control is required.

\subsubsection{Simplified navigation control}

One simple vehicle navigation strategy is to use an accelerometer and high-resolution depth gage to control vehicle orientation and position on the miter gate. In Figure 54, an inspection path is illustrated that employs only vertical and horizontal moves. Implementing this simplistic $2 \mathrm{D}$ path plan makes this control strategy achievable.

Figure 54. Simplified 2D path of mobile platform on miter gate.

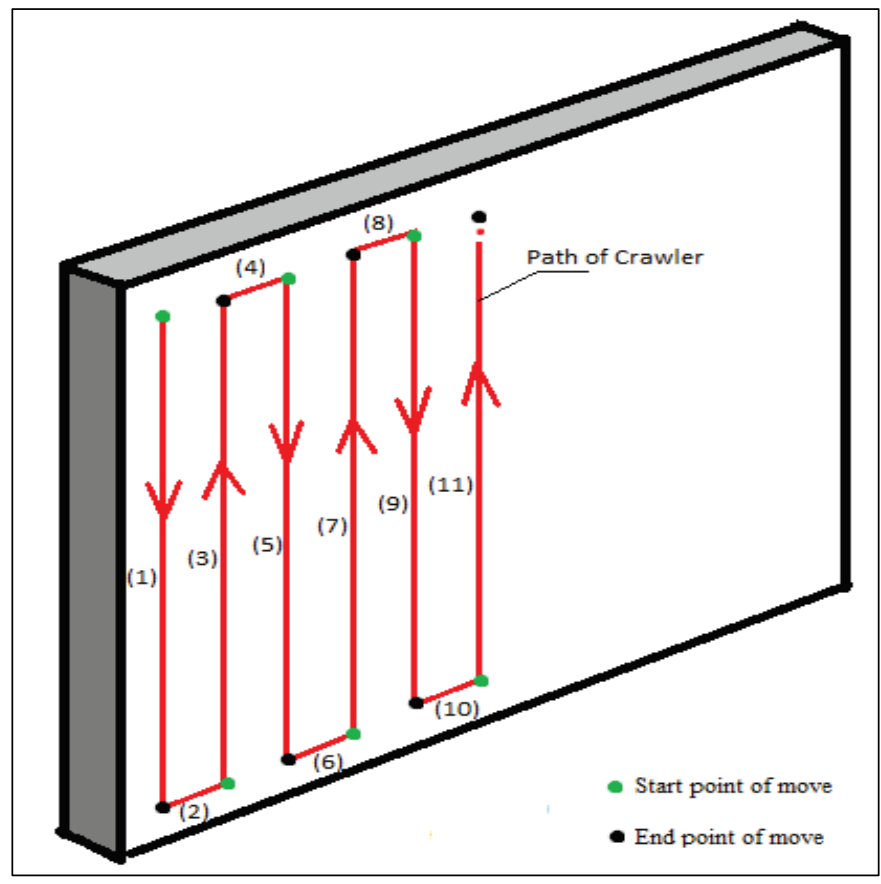

A 1-axis accelerometer was determined to be sufficient for maintaining vertical orientation during path moves, and a high-resolution depth sensor to validate vertical position. Software was developed and successfully tested which employs a PID as the feedback mechanism for vertical 
alignment of the mobile platform as it navigates towards the upper and lower end points of the vertical path.

As illustrated in Figure 54 above, once the mobile platform reaches the upper or lower end position of the move (black circle) a horizontal move is made to the next start position (green circle). This horizontal move eliminates the need for complex skid-like turns that typically lead to platform alignment errors. Furthermore, horizontal moves to start positions can reduce overall inspection time. In Figure 46 (located in Section 4.1.3), the prototype platform is outfitted with non-magnetic Mecanum wheels to test platform horizontal moves. Considering that the pull force of the magnetic flux sensor is approximately $113 \mathrm{lb}$ and the total payload of the platform (in air) is $50 \mathrm{lb}$, horizontal moves on vertical surfaces were tested. Unfortunately, however, the non-magnetic Mecanum wheels were found to have insufficient friction (causing slippage) to maintain proper orientation during the horizontal move. A new wheel design is presently under development that can potentially alleviate the slippage issue during horizontal moves; however, the new wheel (and supporting infrastructure) has not yet been manufactured for testing. The wheel prototype design is discussed above in Section 4.3.2 and identified as the expanding wheel concept. Until the new wheels are manufactured and installed, testing with the Mecanum wheels continues on sloped surfaces.

The mobile platform's path-planning software allows the operator to design a complete multi-step inspection path. Furthermore, a control algorithm was developed to autonomously execute the planned path on the mobile platform. The collection of individual path steps is referred to as a path recipe. Each step of a path recipe includes a set of parameters, as defined in Table 6.

Table 6. Path planning step parameters.

\begin{tabular}{|c|l|}
\hline Parameter & Description \\
\hline 1 & Move Acceleration \\
\hline 2 & Move Deceleration \\
\hline 3 & Move Distance \\
\hline 4 & Move Velocity \\
\hline 5 & $\begin{array}{l}\text { Scan Activation (are we simply moving or moving and } \\
\text { collecting inspection data) }\end{array}$ \\
\hline
\end{tabular}


The path-planning software was designed to allow for future expansion of parameters. For example, if at the end of each crawler move a newly added sensor is to be read and transmitted to the top-side host computer, a new parameter can be added to the path recipe.

\subsubsection{Communication interface}

The communication interface between the operator and the mobile platform was developed using a software protocol known as User Datagram Protocol (UDP). UDP is an alternative communications protocol to Transmission Control Protocol used primarily for establishing lowlatency and loss-tolerating connections between applications. This protocol was selected for two reasons:

1. Because mobile platform status data (battery voltages, motor currents, wheel positions, wheel speeds, etc.) are continuously streamed from the crawler to the remote host software, a low-latency and loss-tolerant protocol is acceptable.

2. UDP protocol allows for broadcasting of the data from the UDP server (mobile platform-side); therefore, it is possible to enable multiple user and/or multiple software application to monitor for mobile platform data. 


\section{Corrosion Sensor Data Collection and Management}

As discussed in Section 2.2.2, the MFL package consists of three Melexis MLX90393 Triaxis sensors, each with three axes of measurement (X, Y, and $\mathrm{Z}$ ). Therefore, nine axes of magnetic flux data are collected as the mobile platform moves from point "A" to point "B." These flux data are collected synchronously with motor encoder position to create a seamless dataset of flux and platform position. Numerous large-scale laboratory tests were conducted to verify system operation and repeatability of corrosion measurements. In Figure 55, sample raw flux sensor output is shown for a three-eighths in. thick steel plate. The scan area was approximately $4 \mathrm{ft} \times 4 \mathrm{ft}$ square. The linear zone, shown in shades of blue in Figure 55, is a weld line along the plate surface. Additionally, several subsurface welds can be observed, as indicated in Figure 55. In Figure 56 the prototype inspection platform is shown during the inspection process.

Figure 55. Raw magnetic flux data from X-axis of sensor array (left) with 3D rendering of structure for comparison (right).

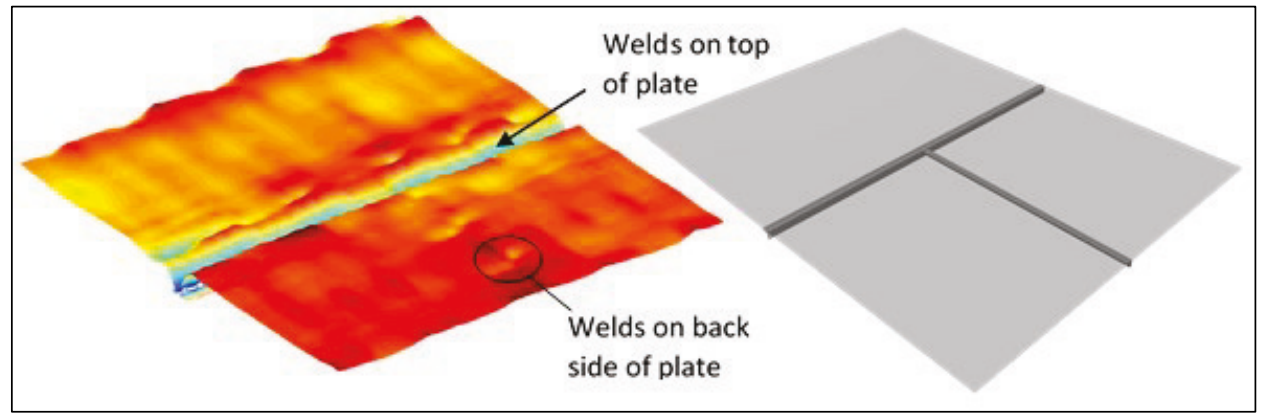

Figure 56. Prototype Mobile Sensor Inspection Platform inspecting steel plate.

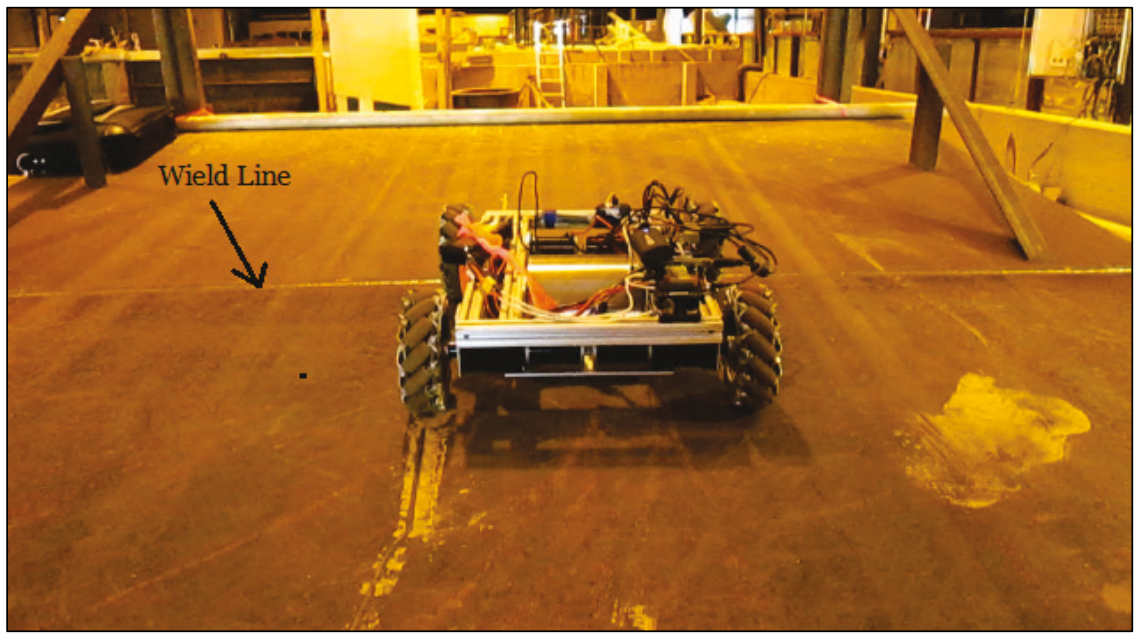




\section{Underwater Imaging System for Corrosion Assessment}

\subsection{Background}

Due to miter gate structural complexities on the downstream side of the gate (Figure 6), automated corrosion assessment using the mobile platform discussed above is not practical. For this reason, a low-cost underwater imaging system was developed specifically for the downstream side of the miter gate. The imaging system is designed to provide three axes of motion control, thus allowing for complete gate inspection. Furthermore, the camera can be driven deep into the recessed cellular structures of the gate for high-resolution surface inspection (Figures 57 and 58).

Figure 57. Imaging system's lateral and vertical move control.

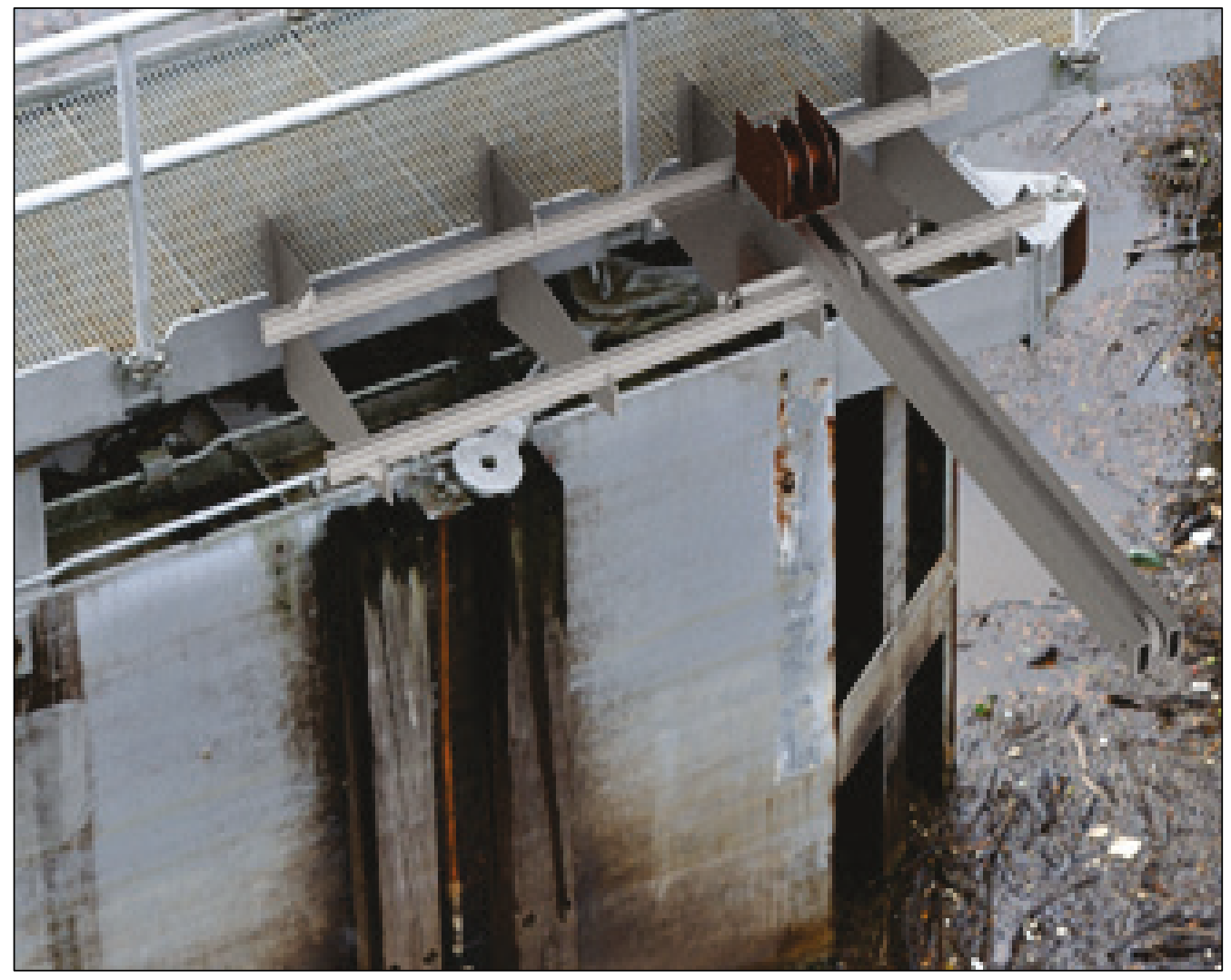


Figure 58. Imaging system's three axes of motion control.

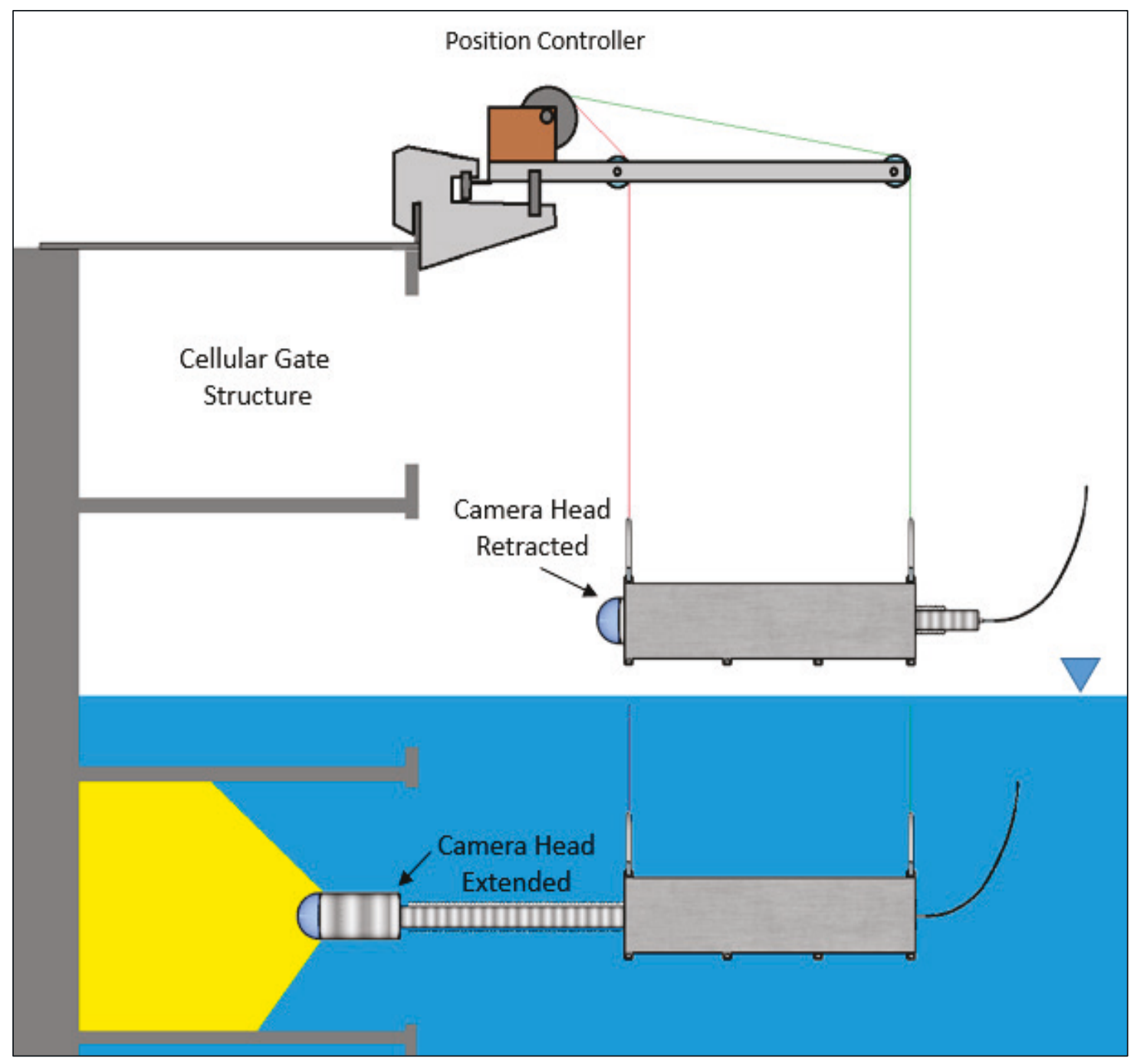

\subsection{Design considerations}

Because turbidity levels and the availability of natural light seriously impact underwater imaging, the camera is designed for near-field imaging. The design camera focal distance is $3-10 \mathrm{in}$. but can be modified to meet requirements. The camera inspection system has the capabilities and features listed in Table 7. In Figure 59, the prototype imaging system is being deployed for test purposes at Columbia Lock and Dam near Columbia, LA. Based on this initial test, several refinements to the system will subsequently be made. 
Table 7. Inspection camera specifications.

\begin{tabular}{|l|l|}
\hline Feature & Description \\
\hline 1 & Single Ethernet for power and data \\
\hline 2 & Power over Ethernet (PoE) via 12-volt direct current \\
\hline 3 & $\begin{array}{l}\text { 24 light-emitting diodes for lowlight and high-turbidity conditions (12 white } \\
\text { light and 12 infrared) }\end{array}$ \\
\hline 4 & Camera tilt of + - 45 deg \\
\hline 5 & 8-megapixel still image capture \\
\hline 6 & Remote viewing and capture of still images \\
\hline 8 & High-definition video capture (1080 lines) \\
\hline 9 & $\begin{array}{l}\text { Remote viewing and recording of live video } \\
\text { low-light conditions, the FD should be minimal. }\end{array}$ \\
\hline 10 & Windows-based control software \\
\hline
\end{tabular}

Figure 59. Test of prototype imaging system.

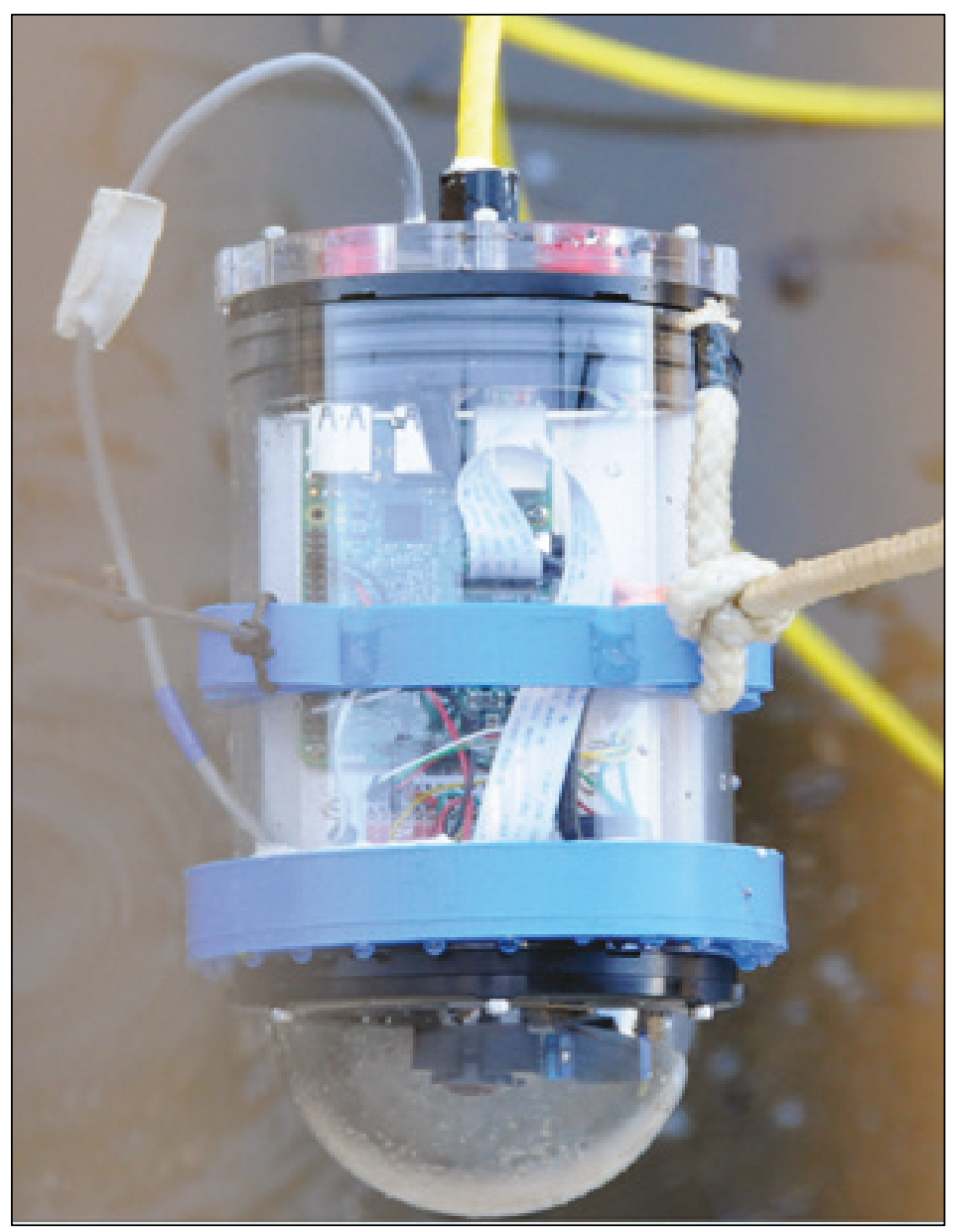




\section{Conclusions and Recommendations}

The performance of the corrosion sensor mounted to a magnetic crawler is presently under investigation. One of the primary concerns is whether the magnetic wheels affect the magnetic flux saturation at the location of the magnetometer(s). The latest results, using a single sensor, indicate that the influence is minimal. However, additional tests are necessary to draw a final conclusion.

A sensor array of Freescale MAG3110 3-axis magnetometer is presently under development. This sensor array, consisting of up to 16 individual sensors with 2 to $10 \mathrm{~mm}$ spacing, will be mounted to the magnetic crawler. The sensor spacing will be optimized and finalized after assembly of the sensor package to the crawler. The primary objective here is to maximize the area of coverage while minimizing the loss in flux leakage resolution.

A coating thickness measurement sensor that operates in water, requires no surface contact and operates while moving is presently under development. This sensor will use the ultrasonic resonance spectroscopy technique for measuring coating thickness where the water separating sensors and metal substrate acts as the couplant. The sensor elements shown in Figure 60 are polyvinylidene fluoride broadband sensors used for high-frequency operations. These will be used as receivers with a pitch to be determined. The top circular sensor in Figure 60 is a high-frequency (10 MHz resonant frequency) PZT-5 element that is the source of the pulsed ultrasonic signal.

Figure 60. Polymer ultrasonic sensor array.

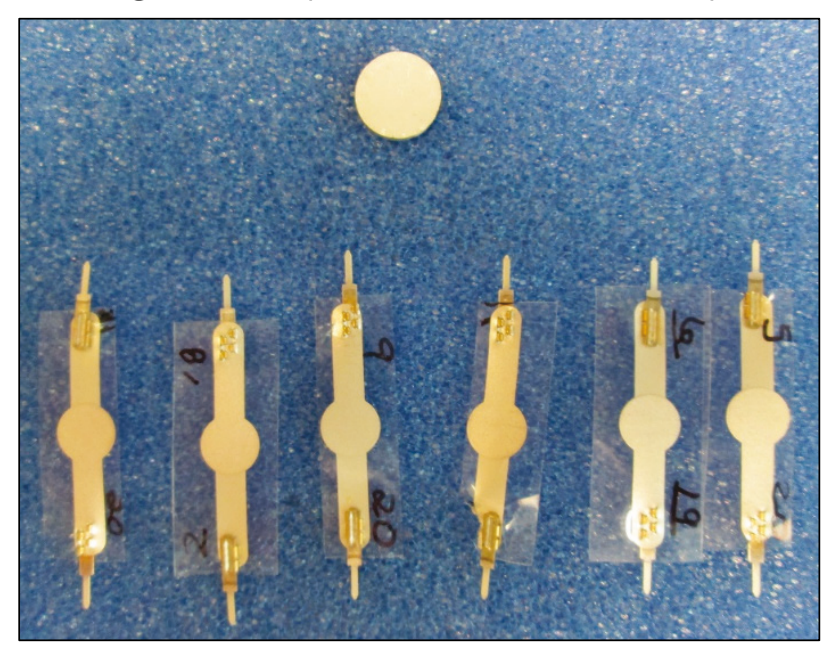


The magnetic crawler platform is presently undergoing significant modifications to the drive system, the magnetic wheels, the electronics package, and the sensor platform. Additionally, the platform is being redesigned for submersion. Submerged tests will be conducted subsequently. As mentioned previously, the magnetic crawler inspection robot is targeted for the relatively smooth side of the miter gate. The inspection solution for the more complex (downstream) side of the miter gate is presently in the design stage. A prototype of this inspection device will be tested in near-future evaluation studies. 


\section{References}

Beamish, D. 2015. Coating thickness measurement. Quality 54(9):24-30. https://erdclibrary.idm.oclc.org/login?url=https://search.proquest.com/docview/1718293152 ?accountid=26153

Canal and Lock. 2017. Accessed 18 December. http://www.madehow.com/Volume-6/Canal-andLock.html

Daniel R. A. 2011. New Materials and Systems in Miter Gates. New Orleans, LA: Permanent International Association of Navigation Congresses (PIANC) Workshop, 13-14 September 2011. Power Point presentation. http://www.anast.ulg.ac.be/doc/PIANC/P3-3\%20DANIEL\%20R\%20\%20New\%20Mat\%20Systems.pdf

Estes, A. C., D. M. Frangopol, and S. D. Foltz. 2004. Updating reliability of steel miter gates on locks and dams using visual inspection results. Engineering Structures 26(3):319-333. https://doi.org/10.1016/i.engstruct.2003.10.007

Greimann, L., J. Stecker, and K. Rens. 1990. Inspection and Rating of Miter Lock Gates. TR- REMR-OM-7. Ames, Iowa: Iowa State University, Engineering Research Institute. Prepared for U.S. Army Corps of Engineers, Washington, DC. https://erdc-library.erdc.dren.mil/xmlui/handle/11681/4442

Hjelmas, E., and J. Wroldsen. 1999. Recognizing Faces from the Ground up: Gabor Wavelets. Translated by Nikos Drakos. Oslo, Norway: University of Oslo, Department of Infomatics; and Gjovik, Norway: Gjovik College, Department of Electrical Engineering and Science. http://www.ansatt.hig.no/erikh/papers/scia99/scia99.html

Huang, Songling, and Shen Wang. New Technologies in Electromagnetic NonDestructive Testing. Springer: Singapore. Springer Series in Measurement Science and Technology. https://doi.org/10.1007/978-981-10-0578-7

Laughton, M. A., and D. J. Warne, eds. 2003. Electrical Engineer's Reference Book. Sixteenth edition. ISBN 978-0-7506-4637-6. Burlington, MA: Elsevier Science. https://www.sciencedirect.com/science/book/9780750646376

Mathon J., and Umerski A. 2001. Theory of tunneling magnetoresistance. Physics of Low Dimensional Systems. Edited by J. L. Morán-López. Boston, MA: Springer. https://doi.org/10.1007/0-306-47111-6_34

Meeker, D. 2014. Finite Element Method Magnetics. Waltham, MA: QinetiQ North America. http://www.femm.info/wiki/HomePage

Merrick Group. 2015. What is Eddy Current Testing? Accessed 18 December 2017. http://www.merrickgroupinc.com/2015/08/what-is-eddy-current-testing

Murthy K. 2014. Gabor Filters: A Practical Overview. Accessed 18 December 2017. https://cututs.wordpress.com/2014/04/27/gabor-filters-a-practical-overview 
Nickel, J. 1995. Magnetoresistance: An Overview. Palo Alto, CA: Hewlett Packard, Computer Peripherals Laboatory. https://en.wikipedia.org/wiki/Magnetoresistance\#Anisotropic_magnetoresistance_.28AMR.29

Novacam Technologies Inc. 2011. Multi-Layer Thickness Measurement with LowCoherence Interferometry: Application Note for Industry. Accessed 18 December 2017. http://www.novacam.com/pdf/ApplicationNote_Novacam_multilayer_film_thickness_rev_1$\underline{0 . p d f}$

Paun, M. A., J. M. Sallese, and M. Kayal. 2013. Hall Effect sensor design, integration, and behavior analysis. Journal of Sensor and Actuator Networks 2(1):85-97. DOI: 10.3390/jsan2010085. http//www.mdpi.com/journal/isan

Shi, Yan, Chao Zhang, Rui Li, Moalin Cai, and Guanwei Jia. 2015. Theory and application of magnetic flux leakage pipeline detection. Sensors 15(12):31,036-31,055. https://www.researchgate.net/publication/287107715_Theory_and_Application_of_Magnetic Flux_Leakage_Pipeline_Detection

U.S. Army Corps of Engineers (USACE). 1994. Lock Gates and Operating Equipment. EM 1110-2-2703. Washington, DC: U.S. Army Corps of Engineers.

Valchev, V., and A. Van den Bossche. 2005. Inductors and Transformers for Power Electronics. Boca Raton: CRC Press. https://www.taylorfrancis.com/books/9781420027280Canal and Lock

White, R. L. 1992. Giant Magnetoresistance: A Primer. Stanford, CA: Stanford University, Department of Material Science and Engineering. DOI: 10.1109/20.179533. http://ieeexplore.ieee.org/document/179533

Wikipedia. 2017. Hall Effect. Wikipedia. Accessed 18 December. https://en.wikipedia.org/wiki/Hall_effect. 


\section{Appendix: Safe Underwater Corrosion Condition Assessment of Structures}

U.S. Bureau of Reclamation (USBR) partners: Jessica Torrey, Bobbi Jo Merten, Matthew Klein

U.S. Army Corps of Engineers (USACE) partners: Jim Evans, Dr. James Tallent, Dr. Anton Netchaev

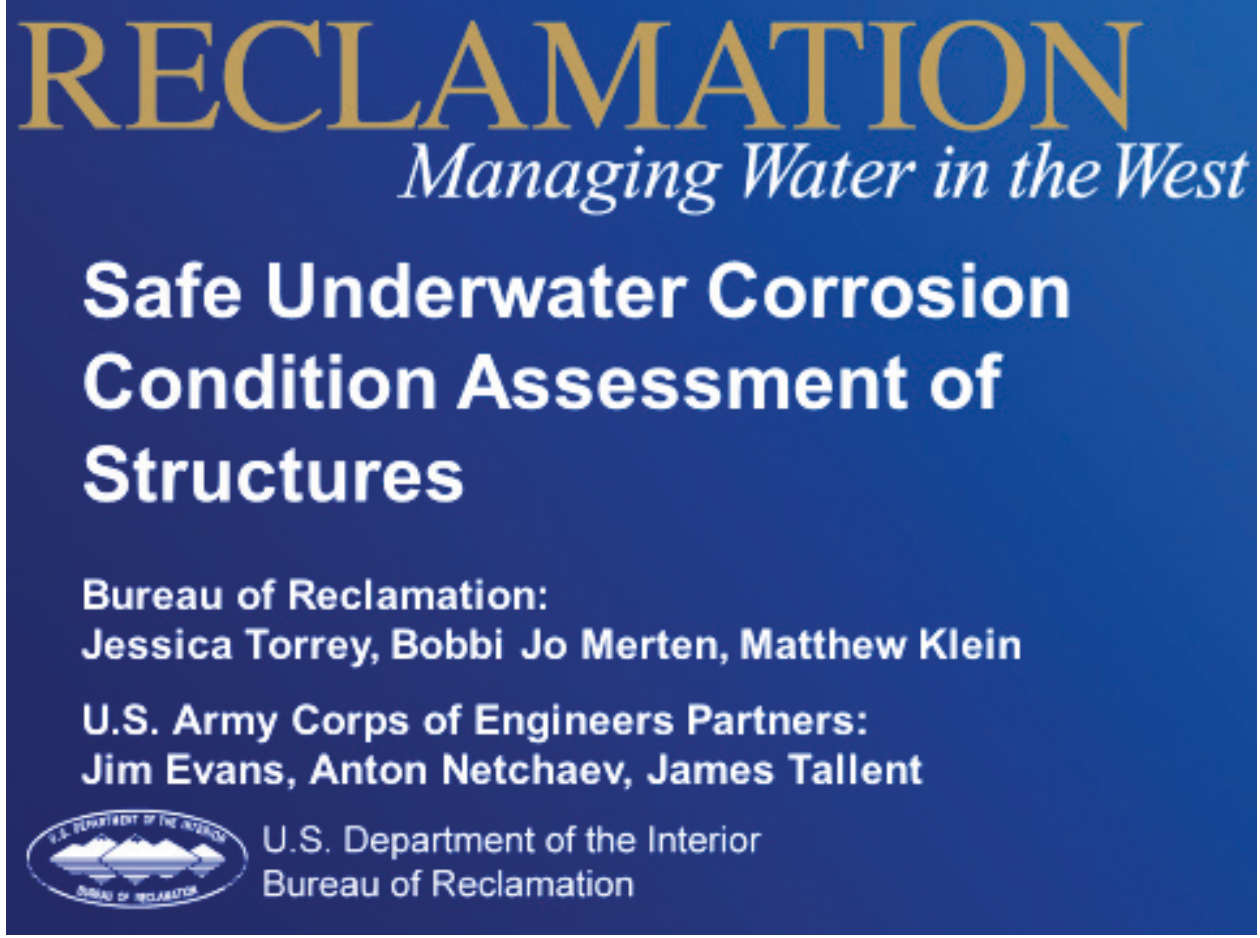




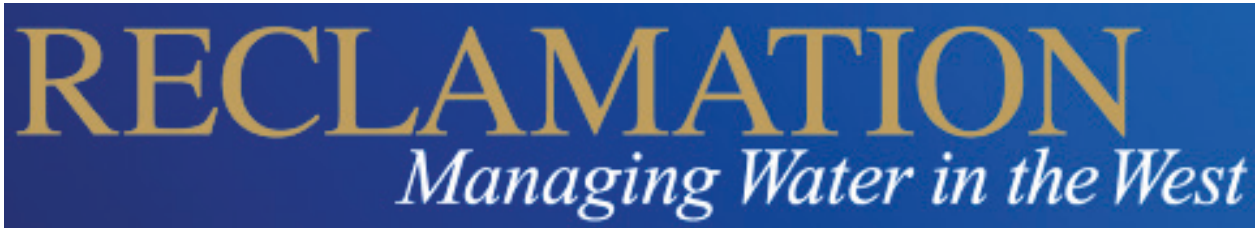

Safe Underwater Corrosion Condition Assessment of Structures

Bureau of Reclamation:

Jessica Torrey, Bobbi Jo Merten, Matthew Klein

U.S. Army Corps of Engineers Partners:

Jim Evans, Anton Netchaev, James Tallent

U.S. Department of the Interior

Bureau of Reclamation

\section{Reclamation Project}

- Project planned for FY16 - 18

- FY16 Milestones

- Establish collaboration with USACE

- Complete reviews of existing technologies

- State-of-the-art and capabilities

- Options for implementation, remotely-operated vehicle (ROV) readiness 


\section{Existing Technologies}

- 3D scanning and corrosion detection

- Coating thickness gauge

- Ultrasonic thickness testing (section loss)

- Electrochemical impedance spectroscopy (EIS) coating assessment

\section{RECLAMATION}

\section{D Scanning}

- Damages identified in 3D model by feature extraction

- Underwater cameras and sensors available

- Sonar, LIDAR, photogrammetry

- Already onboard some ROVs

- No barriers to implementation

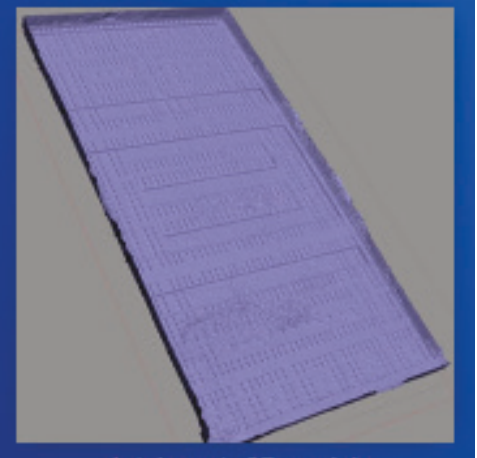

Intake gate 3D model 


\section{Coating Thickness Gauge}

- Indication of coating's effectiveness

- Underwater gauges available

- Onboard data storage

- Depth rating at least $1000 \mathrm{ft}$

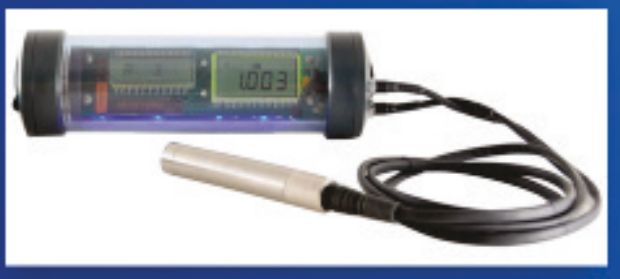

Undenwater film thickness gauge from Elcometer

- Minimal barriers to ROV implementation

- Keep probe perpendicular to surface

\section{RECLAMATION}

\section{Ultrasonic Thickness Testing}

- Measures thickness (section loss) and internal defects in a structure

- Underwater gauges available

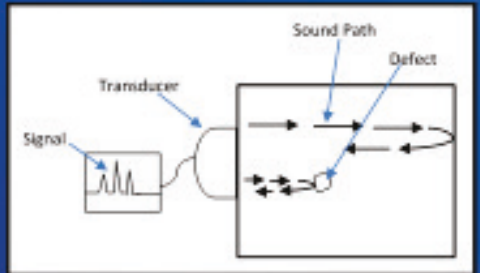

- Display screens are not available, but internal memory and wireless communication possible

- Depth rating at least $800 \mathrm{ft}$

- Minimal barriers to ROV implementation

- Keep probe perpendicular to surface 


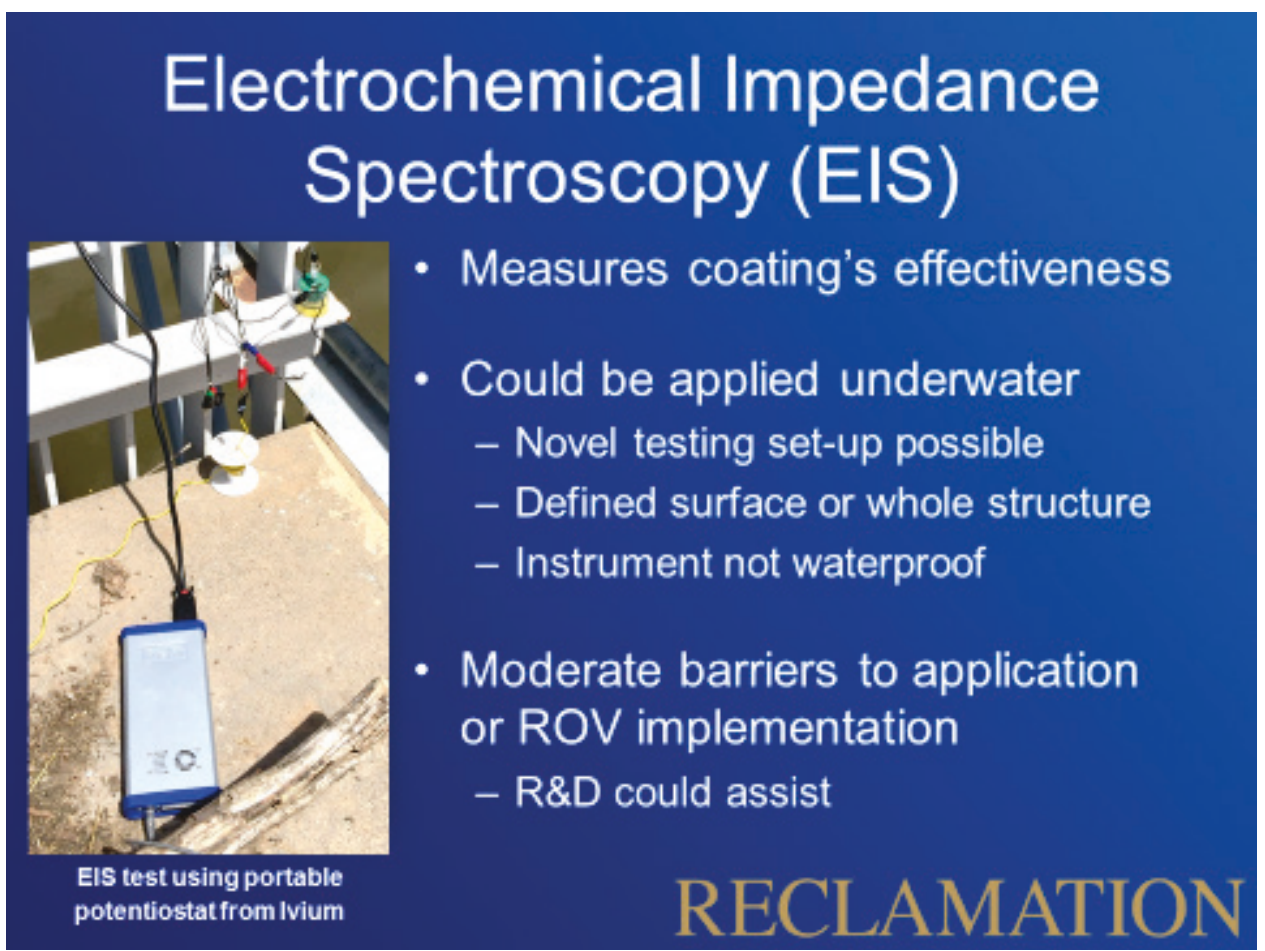

\section{Next Steps}

- Discuss potential implementation opportunities for existing technologies

- USACE or Reclamation modifications?

- How can Reclamation help to further USACE efforts?

- Prototype evaluations

- Field demonstrations

- Dissemination of results 


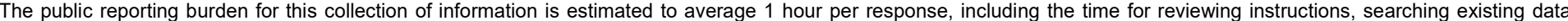

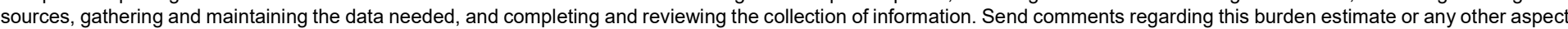

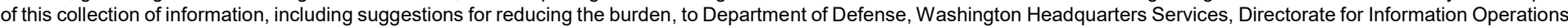

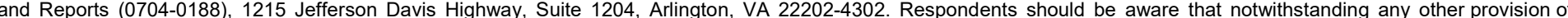
law, no person shall be subject to any penalty for failing to comply with a collection of information if it does not display a currently valid OMB control number.

PLEASE DO NOT RETURN YOUR FORM TO THE ABOVE ADDRESS.

\begin{tabular}{l|l|l}
\hline $\begin{array}{l}\text { 1. REPORT DATE } \\
\text { April } 2019\end{array}$ & $\begin{array}{l}\text { 2. REPORT TYPE } \\
\text { Final Report }\end{array}$ & 3. DATES COVERED (From - To)
\end{tabular}

\section{TITLE AND SUBTITLE}

Determining Miter Gate Plate Corrosion, and Thickness of anti-Corrosion Coatings; and

Development of a Mobile Sensor Inspection Platform 5a. CONTRACT NUMBER

5b. GRANT NUMBER

5c. PROGRAM ELEMENT NUMBER

5d. PROJECT NUMBER

5e. TASK NUMBER

5f. WORK UNIT NUMBER

H1HF62

\section{PERFORMING ORGANIZATION REPORT NUMBER}

Information Technology Laboratory

U.S. Army Engineer Research and Development Center

3909 Halls Ferry Road

Vicksburg, Mississippi 39180-6199

9. SPONSORING/MONITORING AGENCY NAME(S) AND ADDRESS(ES)

U.S. Army Corps of Engineers

ERDC/ITL TR-19-2

Washington, DC 20314-1000

\section{SPONSOR/MONITOR'S ACRONYM(S) USACE}

\section{SPONSOR/MONITOR'S} REPORT NUMBER(S)

\section{DISTRIBUTION/AVAILABILITY STATEMENT}

Approved for public release; distribution is unlimited.

\section{SUPPLEMENTARY NOTES}

\section{ABSTRACT}

Navigation structures such as miter gates and sluice gates are primarily made out of steel, which makes them highly susceptible to corrosion, pitting, and fatigue cracks after many years in service. To mitigate the corrosion issue, protective anti-corrosion epoxy coating are applied to the steel surface before the structure goes into operation and following scheduled inspections if coating loss is detected. The inspection process is typically a costly and potentially dangerous endeavor due to the need to inspect submerged areas of the structure where structural and environ-mental conditions may be at their worst. Divers are often used when dewatering is too costly or no possible. This study was generated by the need to find a better solution to the navigational structure corrosion/coatings inspection process. Primary objectives of this endeavor are to improve inspection area coverage, reduce inspection subjectiveness, reduce time, reduce cost, and reduce risk to human life. To achieve these objectives, a sensor system was developed to collect corrosion data and anticorrosion coating thickness data; the system was then integrated onto a semi-automated platform capable of traversing targeted inspection areas above and below the water surface. This platform is referred to as the Mobile Sensor Inspection Platform.

\section{SUBJECT TERMS}

Corrosion and anti-corrosives, Corrosion-Detectors, Corrosion-Inspection, Epoxy coating, Hydraulic gates, Hydraulic structuresMaintenance and repair, Sluice gates, Steel--Corrosion

\begin{tabular}{|l|c|c|l|}
\hline \multicolumn{1}{l|}{ 16. SECURITY CLASSIFICATION OF: } & 17. LIMITATION OF \\
aBSTRACT \\
a. REPORT & b. ABSTRACT & c. THIS PAGE & \\
Unclassified & Unclassified & Unclassified & SAR \\
& & &
\end{tabular}

18. NUMBER OF PAGES

77 19a. NAME OF RESPONSIBLE PERSON

James A. Evans

19b. TELEPHONE NUMBER (Include area code) 601-634-2535 